\title{
ENHANCED DURABILITY OF DESULFURIZATION SORBENTS FOR
} FLUIDZED-BED APPLICATIONS

Topleal Report

By

R. P. Gupta

S. K. Gangwal

June 1991

Work Performed Under Contrect NO. AC21-88MC25006

For

U.S. Department of Energy

Morgantown Energy Technology Center

Morgantown, West Virginia

By

Research Triangle Insthute

Research Trlangle Park, North Carolina 


\section{DISCLAIMER}

This report was prepared as an account of work spionsored by an agency of the United States Government. Neither the United States Government nor any agency thereof, nor any of their employees, makes any warranty, express or implied, or assumes any legal liability or responsibility for the ascuracy, completeness, or usefulness of any information, apparatus, product, or process disclosed, or represents that its use would not infringe privately owned rights. Reference herein to any specific commercial product, process, or service by trade name, trademark, manufacturer, or otherwise does not necessarily constitute or imply its endorsement, recommendation, or favoring by the United States Government or any agency thereof. The views and opinions of authors ex. pressed herein do not necessarily state or reflect/those of the United States Government or any agency thereof.

This report has been reproduced directly from the best available copy.

Available to DOE and DOE contractors from the Offic: of Scientific and Technical Information, P.O. Box 62, Oak Ridge, TN 37831; prices available from $(\epsilon 15) 576.8401$, FTS 626-8401.

Available to the public from the National Technical Information Service, U.S. Department of Commerce, 5285 Port Royal Rd., Springfield, VA 22161. 


\title{
Enhanced Durability of Desulfurization Sorbents for Fluidized-Bed Applications
}

\author{
Topical Report
}

R.P. Gupta

S.K. Gangwal

Work Performed Under Contract No.: DE-AC21-88MC25006

For

U.S. Department of Energy Office of Fossil Energy

Morgantown Energy Technology Center

P.O. Box 880

Morgantown, West Virginia 26507-0880

\author{
By \\ Research Triangle Institute \\ P.O. Box 12194 \\ Research Triangle Park, North Carolina 27709
}

Juı. : 1991 


\begin{abstract}
Advanced integrated gasification combined cycle (IGCC) power systems require the development of high-temperature desulfurization sorbents capable of removing hydrogen sulfide from coal gasifier gas down to very low levels. The objective of this investigation was to identify and demonstrate methods for enhancing the long-term chemical reactivity and mechanical strength of zinc ferrite, a leading regenerable sorbent, for fluidized-bed applications. Fluidized sorbent beds offer significant potential advantages in IGCC systems because of their ability to control the highly exothermic regeneration involved. However, fluidized beds require a durable, attrition-resistant sorbent in the 100-300 $\mu \mathrm{m}$ size range.

A bench-scale high-temperature, high-pressure (HTHP) fluidized-bed reactor (7.6-cm I.D.) system capable of operating up to 24 atm and $800^{\circ} \mathrm{C}$ was designed, built, and tested. A total of 175 sulfidation-regeneration cycles were carried out using $\mathrm{KRW}$-type coal gas with various zinc ferrite formulations. A number of sorbent manufacturing techniques including spray drying, impregnation, crushing and screening, and granulation were investigated. While fluidizable sorbents prepared by crushing durable pellets and screening had acceptable sulfur capacity, they underwent excessive attrition during multicycle testing. The sorbent formulations prepared by a proprietary granulation technique were found to have excellent attrition resistance and acceptable chemical reactivity during multicycie testing. However, zinc ferrite was found to be limited to $550^{\circ} \mathrm{C}$, beyond which excessive sorbent weakening due to chemical transformations, e.g., iron oxide reduction, was observed.
\end{abstract}




\section{ACKNOWLEDGMENTS}

This research was sponsored by the Morgantown Energy Technology Center (METC) of the U.S. Department of Energy (DOE) under Contract No. DE-AC21-88MC25006. Valuable guidance and suggestions provided by Mr. Suresh C. Jain of METC as Contracting Officer's Representative (COR) are sincerely acknowledged. Dr. Douglas P. Harrison of Louisiana State University provided significant technical input to the project. He was a principal contributor to the modeling of the bench-scale reactor described in Chapter 6. United Catalysts, Inc. (UCI) prepared and supplied several spray-dried sorbent formulations free of charge. Also, General Electric Company (GE) provided free of cost a generous amount of the T-2465M sorbent pellets prepared by UCI for GE. Technical assistance from Mike McMichael, Gary Folsom, Teresa Paar, Scott Harkins, Mark Woods, Don Janiak, Dan Ward, Chris Fuller and Jan Shirley is acknowledged. 


\section{TABLE OF CONTENTS}

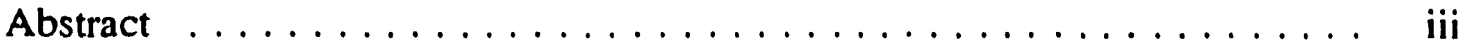

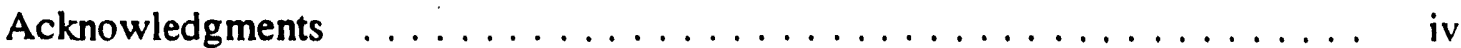

Tables .............................. vii

Figures $\ldots \ldots \ldots \ldots \ldots \ldots \ldots \ldots \ldots \ldots \ldots \ldots \ldots \ldots \ldots \ldots \ldots \ldots$ viii

Executive Summary $\ldots \ldots \ldots \ldots \ldots \ldots \ldots \ldots \ldots \ldots \ldots$

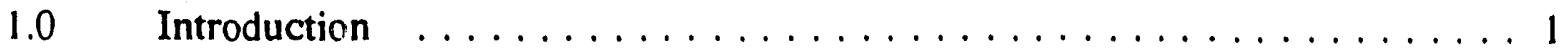

1.1 Zinc Ferrite Process $\ldots \ldots \ldots \ldots \ldots \ldots \ldots \ldots \ldots \ldots \ldots$

1.1.1 Fixed-Bed Reactor System . . . . . . . . . . . . . . 3

1.1 .2 Moving-Bed Reactor System . . . . . . . . . . . . . . 4

1.1.3 Fluidized-Bed Reactor System . . . . . . . . . . . 4

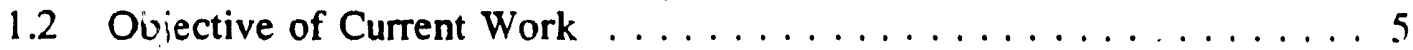

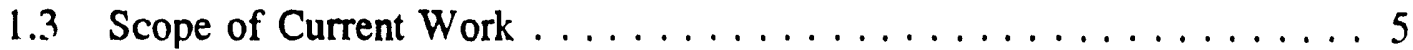

$2.0 \quad$ Bench-Scale Sorbent Test Facility $\ldots \ldots \ldots \ldots \ldots \ldots \ldots \ldots \ldots \ldots \ldots$

2.1 Description of Bench Unit . . . . . . . . . . . . . . 6

2.1.1 Gas Delivery System .................. 6

2.1 .2 Reactor Assembly . . . . . . . . . . . . . . . 6

2.1.3 Data Acquisition and Process Control . . . . . . . . . . . 10

2.1 .4 Gas Analysis System ................... 3

2.1.5 Reactor Offgas Venting System .............. 15

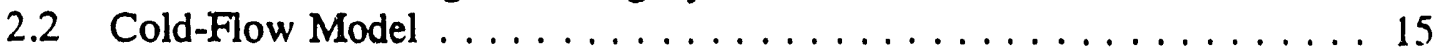

2.3 Test Procedure and Conditions ................. 15

3.0 Sorbent Preparation and Characterization $\ldots \ldots \ldots \ldots \ldots \ldots$

3.1 Sorbent Selection . . . . . . . . . . . . . . . . . . 18

3.2 Sorbent Preparation for Fluidized-Bed Applications . . . . . . . . 18

3.2 .1 Spray Drying . . . . . . . . . . . . . . . . . . 19

3.2.2 Crushing and Screening the Extrudates . . . . . . . . . . 19

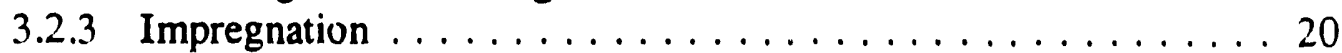

3.2 .4 Granulation ....................... 21

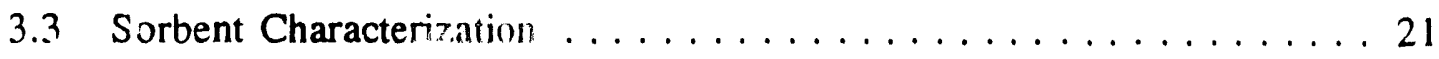

3.3 .1 Thermogravimetric Analysis . . . . . . . . . . . 21

3.3.2 Particle Size Analysis . . . . . . . . . . . . . . . . . 24

3.3 .3 Pore Size Distribution . . . . . . . . . . . . . . . . . 24

3.3 .4 BET Surface Area . . . . . . . . . . . . . . . 24

3.3 .5 Attrition Resistance ................... 25

3.3.6 Determination of Zinc and Iron Contents . . . . . . . . 27 
$4.0 \quad$ Results and Discussion . . . . . . . . . . . . . . . . . . . . . . . 29

4.1 Run No. 1 - 10-Cycle Testing of T-2465MC Sorbent . . . . . . . . 31

4.2 Run No. 2 - 10-Cycle Testing of T-2465MC Sorbent . . . . . . . . 33

4.3 Run No. 3 - 10-Cycle Testing of T-2465MC Sorbent (Rounded) . . . . 36

4.4 Run No. 4 - 5-Cycle Testing of AMAX E-44A Sorbent . . . . . . . . 36

4.5 Run No. 5 - 100-Cycle Testing of T-2465MC Sorbent . . . . . . . . . 39

4.6 Run No. 6 - 10-Cycle Testing of L-7 Sorbent . . . . . . . . . . . 52

4.7 Run No. 7 - 10-Cycle Testing of $\mathrm{T}-2465 \mathrm{MC}$ at $550^{\circ} \mathrm{C} \ldots \ldots \ldots 2$

4.8 Run No. 8 - 10-Cycle Testing of Norton Sorbent . . . . . . . . . . . 54

4.9 Run No. 9 - 10-Cycle Testing of $L-21$ Sorbent . . . . . . . . . . 57

4.10 Run No. 10 - 10-Cycle Testing of $L-16$ Sorbent $\ldots \ldots \ldots 7$

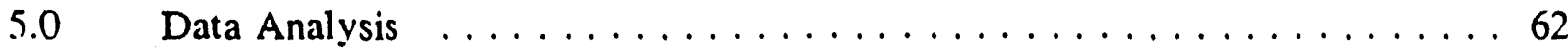

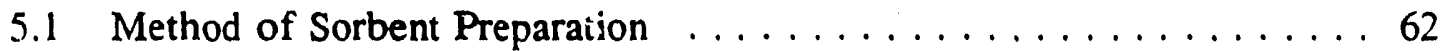

5.2 Sulfidation Temperature $\ldots \ldots \ldots \ldots \ldots \ldots \ldots \ldots \ldots \ldots$

5.3 Binder Content . . . . . . . . . . . . . . . . . . 67

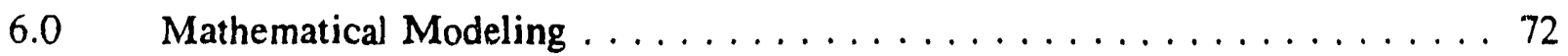

6.1 Background . . . . . . . . . . . . . . . . . . 72

6.2 The Kunii-Levenspiel Model . . . . . . . . . . . . . . . . 72

6.2 .1 Homogeneous Reaction Model . . . . . . . . . . . . . 75

6.2 .2 Unreacted Core Model . . . . . . . . . . . . . . . 78

6.3 Determination of Rate Controlling Step . . . . . . . . . . . 83

6.4 Alternative Models . . . . . . . . . . . . . . . . . . . . . . . 84

6.5 Nomenclature . . . . . . . . . . . . . . . . . . . . . . . 85

$7.0 \quad$ Conclusions and Recommendations $\ldots \ldots \ldots \ldots 7$

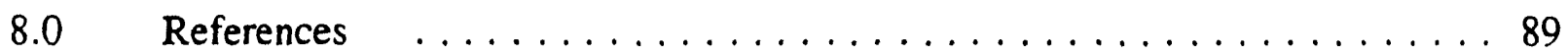




\section{LIST OF TABLES}

Number

Page

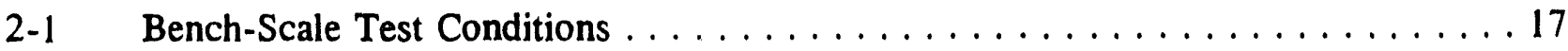

3-1 Sorbent Preparation by 32-Hour Fluidization in the 5.08-cm I.D.

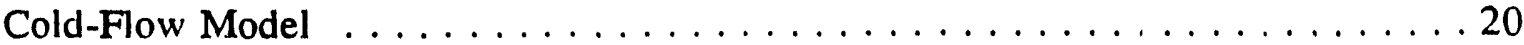

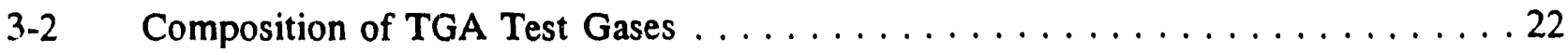

4-1 Sorbent Formulations and Operating Conditions Used for

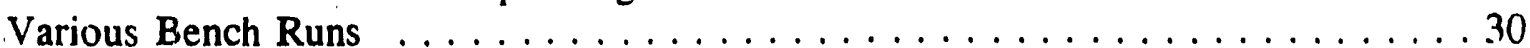

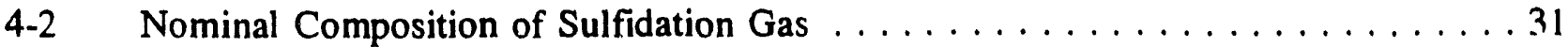

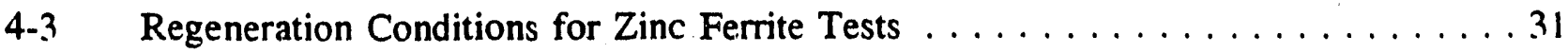

4-4 Physical Properties of T-2465MC Sorbent Pellets $\ldots \ldots \ldots \ldots \ldots \ldots \ldots \ldots$

4-5 Summmary of Bench-Scale Run (\#1) for T-2465MC Zinc

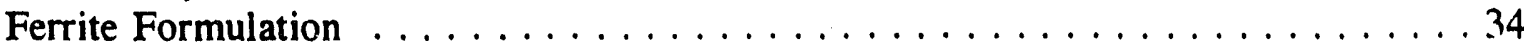

4-6 Summary of Bench-Scale Run (\#2) for T-2465MC Zinc

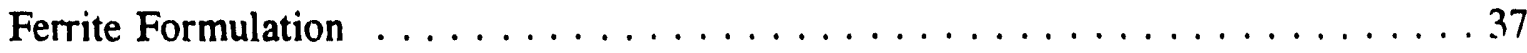

4-7 Summary of Bench-Scale Run (\#3) for T-2465MC (Rounded) Zinc

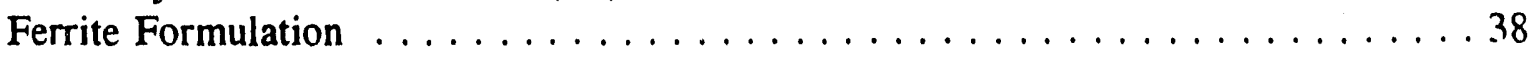

4-8 Physical and Chemical Properties of E-44A Sorbent . . . . . . . . . . . . . . 39

4-9 Summary of Bench-Scale Run (\#4) for AMAX E-44A Zinc

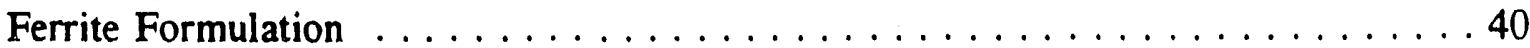

4-10 Summary of Bench-Scale Run (\#5) for T-2465MC Zinc

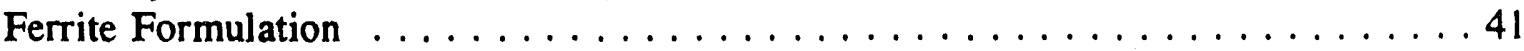

4-11 Particle Size Distribution and Attrition Resistance

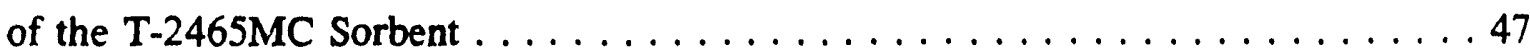

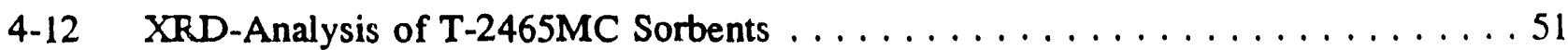

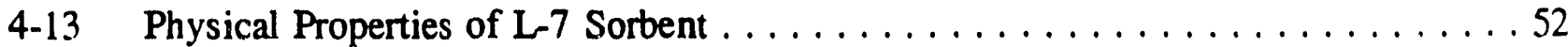

4-14 Summary of Bench-Scale Run (\#6) for L-7 Zinc Ferrite Formulation . . . . . . . . 53

4-15 Summary of Bench-Scale Run (\#7) for T-2465MC Zinc

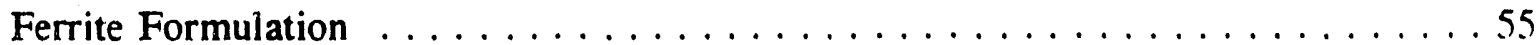

4-16 Summary of Bench-Scale Run (\#8) for Norton Zinc Ferrite Formulation . . . . . . 56

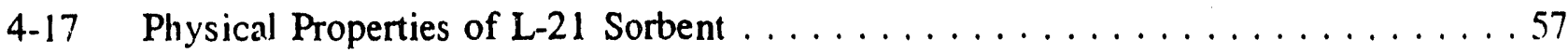

4-18 Summary of Bench-Scale Run (\#9) for L-21 Zinc Ferrite Formulation . . . . . . . 58

4-19 Summary of Bench-Scale Run (\#10) for L-16 Zinc Ferrite Formulation . . . . . . . 60

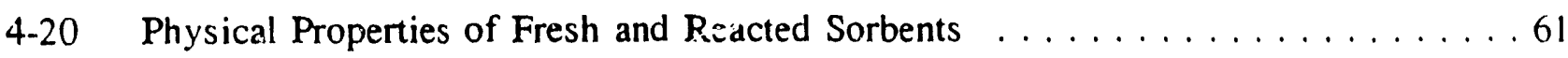

6-1 Parameter Values Used in Various Cases . . . . . . . . . . . . . . . . . . . . 79 


\section{LIST OF FIGURES}

Number

$\underline{\text { Page }}$

2-1 Bench-scale fluid-bed sorbent test facility $\ldots \ldots \ldots \ldots \ldots \ldots \ldots$

$2-2$ Sulfidation gas preheater $\ldots \ldots \ldots \ldots \ldots \ldots \ldots \ldots \ldots \ldots \ldots \ldots$

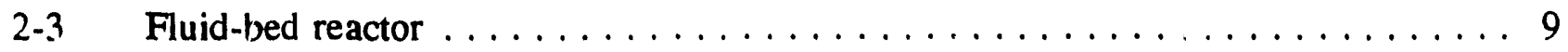

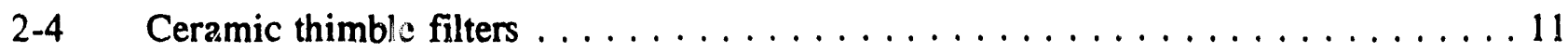

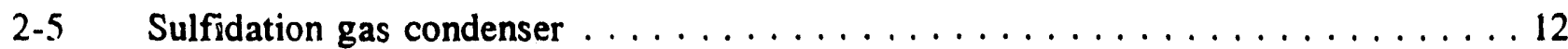

2-6 Schematic of GC sampling system for bench unit $\ldots \ldots \ldots \ldots \ldots \ldots \ldots$

2-7 High-pressure fluid-bed cold see-through reactor model $\ldots \ldots \ldots \ldots$

3-1 RTI atmospheric pressure TGR system $\ldots \ldots \ldots \ldots \ldots \ldots \ldots \ldots \ldots$

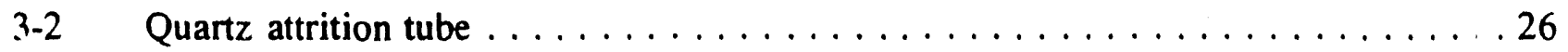

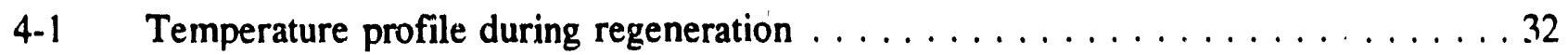

4-2 Effect of sorbent amount on $\mathrm{H}_{2} \mathrm{~S}$ breakthrough profile $\ldots \ldots \ldots \ldots \ldots \ldots$

4-3 Sorbent mean particle size in a fluidized-bed reactor $\ldots \ldots \ldots \ldots \ldots$

4-4 Sorbent loss in a fluidized-bed reactor $\ldots \ldots \ldots \ldots \ldots \ldots \ldots$

$4-5$ Sorbent capacity in a fluidized-bed reactor $\ldots \ldots \ldots \ldots \ldots \ldots$

5-1 Sulfur capacities of T-2465MC, Norton, L-21 and

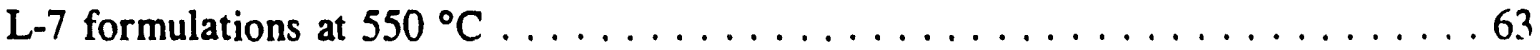

5-2 Attrition resistances of various zinc ferrite formulations in fresh and reacted states $\ldots \ldots \ldots \ldots \ldots \ldots$

5-3 Sorbent loss in the reactor due to elutriation for various

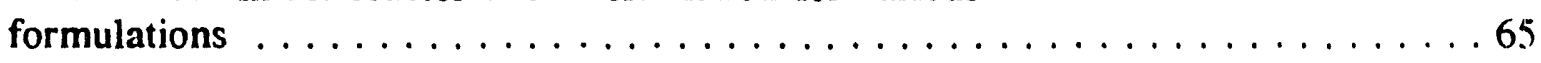

$5-4$ Sulfur capacities of $\mathrm{L}-16$ and $\mathrm{T}-2465 \mathrm{MC}$ at $625^{\circ} \mathrm{C} \ldots \ldots \ldots \ldots$

5-5 Attrition resistances of T-2465MC and other sorbents at $550^{\circ} \mathrm{C}$

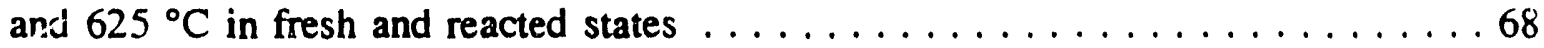

5-6 Sulfur capacities of $\mathrm{L}-7$ and $\mathrm{L}-16$ formulations at $550^{\circ} \mathrm{C}$ and $625^{\circ} \mathrm{C} \ldots \ldots 9$

$5-7$ Sulfur capacities of $\mathrm{T}-2465 \mathrm{MC}$ at $625^{\circ} \mathrm{C}$ and $550^{\circ} \mathrm{C} \ldots \ldots \ldots \ldots$

6-1 Batch fluidized-bed reactor $\ldots \ldots \ldots \ldots \ldots \ldots \ldots \ldots$

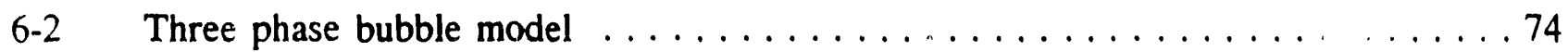

$6-3$ Comparison of model and experiment $\ldots \ldots \ldots \ldots \ldots \ldots$

6-4 Comparison of experimental data with predictions of

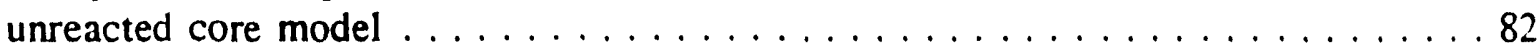




\section{EXECUTIVE SUMMARY}

\section{BACKGROUND}

The Morgantown Energy Technology Center (METC) of the U.S. Department of Energy (DOE) is actively pursuing the development of reliable and cost-effective processes to clean coal gasifier gases for application to integrated gasification combined cycle (IGCC) and gasifier/molten carbonate fuel cell (MCFC) power plants. A major portion of the DOE/METC in-house and sponsored research on gas cleanup has been directed toward high temperature desulfurization using mixed-metal oxide sorbents, specifically zinc ferrite and zinc titanate. Zinc ferrite $\left(\mathrm{ZnFe}_{2} \mathrm{O}_{4}\right)$ is formed by heating an equimolar mixture of zinc oxide $(\mathrm{ZnO})$ and iron oxide $\left(\mathrm{Fe}_{2} \mathrm{O}_{3}\right)$ and its theoretical capacity for sulfur adsorption is close to 40 weight percent. It can remove hydrogen sulfide $\left(\mathrm{H}_{2} \mathrm{~S}\right)$ from coal gasifier gas to less than $10 \mathrm{ppmv}$ and can be easily regenerated with air and/or steam for multicycle operation.

Early testing of zinc ferrite was conducted in fixed-bed reactor systems using cylindrical extrudates and spherical pellets. However, the need for valves operating at high-temperature, high-pressure (HTHP) conditions and the highly exothermic regeneration imposed severe restrictions on the fixed-bed system. Hence, moving-bed and fluidized-bed reactor systems are being developed with DOE/METC sponsorship.

Provided that suitable sorbents can be developed, fluidized-bed reactors offer several potential advantages over fixed-bed reactors. These advantages include better gas-solid contact, preveniion of solids segregation, ability to continuously add and remove sorbent, better control of the highly exothermic regeneratiou reaction, use of small particles leading to minimization of diffusional resistances and faster overall kinetics, and a steady-state operation. However, highly durable (attrition-resistant) sorbents capable of withstanding stresses induced by rapid temperature swings, chemical transformations, and fluidization and transport are required before fluidized beds can be successfully employed.

\section{OBJECTIVE}

The objective of the base period of this project was to identify and demonstrate methods for enhancing the long-term chemical reactivity and mechanical strength of zinc-ferrite sorbents to be used in a high-pressure fluid-bed reactor for desulfurization of hot coal gasifier gases.

\section{MILESTONES}

The major milestones of this project included:

- Development of methods for manufacturing sorbents with attrition resistance (in fresh, sulfided, and regenerated states) comparable to commercial fluid catalytic cracking (FCC) catalysts along with high capacity and efficiency for hydrogen sulfide removal over numerous cycles. 
- Design and construction of a versatile HTHP bench-scale fluidized-bed reactor facility capable of operation at pressures from 1 to 35 atm and temperatures from 400 to $800^{\circ} \mathrm{C}$ with an on-line gas analysis system.

- Operation of the bench-scale unit over iumerous sulfidation/regeneration cycles to obtain detailed data so that an unbiased ranking of the promising sorbents may be obtained.

- Generation of a database on sorbent properties and performance to be used in the future for the design and scaleup of commercial hot gas desulfurization systems.

\section{SIGNIFICANT ACCOMPLISHMENTS AND CONCLUSIONS}

- A HTHP batch bench-scale fluidized-bed reactor system was designed, built, and commissioned. It was used to conduct numerous multicycle tests with zinc ferrite. A total of 175 sulfidation-regeneration cycles were carried out in this system.

- A number of techniques including spray drying, impregnation, crushing/screening of pellets, and granulation were investigated to prepare mechanically durable sorbents. The snray-drying technique proved to be unsuccessful for manufacture of fluidizable sorbent particles.

- Sorbent formulations prepared by impregnating up to 20 weight percent zinc ferrite on alumina had very low sulfur capacity and appeared to be commercially unattractive.

- A fluidizahle sorbent prepared by crushing of durable sorbent pellets (prepared by UCI for GE's moving-ved reactor) and screening had acceptable levels of chemical reactivity, but on multicycle testing it underwent excessive sorbent loss due to attrition/carryover amounting to approximately 40 percent of the reactor inventory.

- The most significant accomplishment of this program was the identification of a granulation technique to manufacture chemically reactive and attrition resistant sorbent formulations. A number of sorbent formulations prepared using this technique showed good attrition resistance $(>90 \%)$ and acceptable sulfur capacity during multicycle testing. Higher reactivities may be needed at $550^{\circ} \mathrm{C}$ for successful operation.

- Commercial applicability of the granulation technique was demonstrated. Approximately $80 \mathrm{~kg}$ of the best sorbent were prepared and delivered to METC.

- It was shown that attrition of the sorbent in the reactor is primarily due to chemical transformations rather than mechanical forces. The possible chemical transformation 
responsible for chemical attrition was the reduction of zinc ferrite, specifically the reduction of $\mathrm{Fe}_{2} \mathrm{O}_{3}$ precent in it.

- The applicability of zinc ferrite as a hot gas desulfurization sorbent k'as found to be limited to about $550{ }^{\circ} \mathrm{C}$. Excessive sorbent weakening was observed due to "chemical" attrition at $625^{\circ} \mathrm{C}$. The sorbent reactivity at $625^{\circ} \mathrm{C}$ was, however, significantly higher.

- It was demonstrated that sulfided sorbent can be completely regenerated using :. mixture of 2 to 3 percent $\mathrm{O}_{2}$ in $\mathrm{N}_{2}$. Sulfate formation during regeneration can be prevented by operating the reactor at about $760{ }^{\circ} \mathrm{C}$ at $1.5 \mathrm{MPa}$. More research is needed to determine the effect of higher pressures or higher oxygen concentration in the regenerator gas on sulfate formation.

- The sulfidation reaction was found to be controlled by intrinsic reaction and pore diffusion steps. The external mass transfer resistance was found to be negligible. Both homogeneous reaction and unreacted shrinking core kinetics in conjunction with the Kunii-Levenspiel bubbling-bed model overpredicted the breakthrough time.

\section{RECOMMENDATIONS}

- Since zinc ferrite is limited to $550^{\circ} \mathrm{C}$, methods should be investigated to prepare more reactive zinc ferrite for use up to $650^{\circ} \mathrm{C}$.

- The possible use of other sorbents, especially zinc titanate, should be investigated for higher desulfurization temperatures and/or with highly reducing gases such as Texaco oxygen-blown gasifier gas. This will be studied under an option to this contract.

- In addition to bentonite, use of other clays such as forsterite, vermiculite, kaolinite, etc., as potential binders should be investigated.

- After having developed a durable sorbent, to aid in design and optimization of a scaled-up version of the bench-scale unit, advanced mathematical medels should be developed to predict the system behavior. Developing such models will require some fundamental studies on fledization and kinetics of sulficiation and regeneration of that specific sorbent.

- The effect of other contaminants on the performance of zinc ferrite present in coal gas such as alkali, $\mathrm{HCl}$, and $\mathrm{NH}_{3}$ should be studied.

- A continuous sulfider-regenerator system with sorbent circulation between them should be designed, built, and tested. Such a system would serve as a bench-scale prototype of a commercial fluidized-bed hot gas desulfurization system. 


\subsection{INTRODUCTION}

Integrated gasification combined cycle (IGCC) and gasifier/molten carbonate fuel cell (MCFC) power systems employing hot gas cleanup are two of the most promising advanced technologies for producing electric power from coal. The; ir key features include modular shopfabricated construction and hot gas cleanup systems operating at conditions to match the hightemperature high-pressure (HTHP) conditions of the coal gasifier and power generator. These systems eliminate requirements for expensive heat recovery equipment and liquid waste treatment systems and avoid thermal efficiency losses associated with cooling and scrubbing the gas (Williams and Bedick, 1988).

Currently, about half of the electric power in the United States is produced from coal (Energy Statistics, 1988). Use of coal for power generation is generally corcidired to have a greater environmental impact than other fuel feedstocks, such as oil and natural gas, primarily due to the high contaminant levels present in coal. Erivironmental regulations necessitate close control of emissions of sulfur oxides, particulate matter, nitrogen oxides, chlorides, tars, alkali compounds, and trace elements. Advanced IGCC systems using hot gas cleanup are being developed to reduce contaminants to very low levels so that roat is as environmentally acceptable as natural gas or oil.

Sulfur has received more attention than any other coal contaminant. During conversion of coal into electricity, sulfur in coal is primarily converted into sulfur dioxide, which is believed to be a precursor to "acid rain." In addition, sulfur compounds cause material problems such as boiler tube fouling and turbine blade corrosion. New Source Performance Standards (NSPSs) mandate at least a 90-percent sulfur removal for stationary power plants. However, IGCC systems are being looked upon as clean power plants of the future with a promise of achieving $99+$ percent sulfur removal. MCFC systems require far more stringent sulfur removal to prevent electrode poisoning. The fuel gas should contain no greater than $1 \mathrm{ppmv}$ of sulfur to ensure fuel ceil operability.

Hydrogen sulfide is the principal sulfur component in raw coal gasifier gas. Historically, $\mathrm{H}_{2} \mathrm{~S}$ has been removed from the coal gas by wet chemical processes, e.g., absorption in a solvent. Because wet $\mathrm{H}_{2} \mathrm{~S}$ removal processes operate at low temperatures $\left(100\right.$ to $150^{\circ} \mathrm{C}$ ), cooling of hot gas becomes necessary, which in turn results in a loss of thermal efficiency and higher capital cost (Jalan, 1985).

Recent developments in hot gas desulfurization technologies have focused on solid metal oxide sorbents which remove reduced sulfur species $\left(\mathrm{H}_{2} \mathrm{~S}, \mathrm{COS}\right.$, etc.) from the coal gas. The sulfided sorbents are reused after regeneration with air. These sulfidation-regeneration steps comprise a cycle and numerous cycles are carried out until the sorbent deactivates to an unacceptable level of reactivity.

Early work on hot gas desulfurization utilized pure metal oxide sorbents, i.e., zinc oxide and iron oxide. A generic hot gas desulfurization reaction carı be written as: 


$$
\mathrm{MeO}(s)+\mathrm{H}_{2} \mathrm{~S}(\mathrm{~g})-\mathrm{MeS}(\mathrm{s})+\mathrm{H}_{2} \mathrm{O}(\mathrm{g})
$$

where Me is any metal. Westrioreland et al. (1977) screened a number of single metal oxide sorbents to determine both thermodynamic and kinetic limits of desulfurization reactions. Iron oxide has a high capacity for sulfur and possesses high reactivity, but could only remove up to 90 percent sii. under practical conditions. Ishikawajimi-Harima Heavy Industries (IHI) in Japan is developing a hot gas desulfurization process using iron oxide sorbent (Sugitani et al., 1987 ) and their reported sulfur removals are up to 90 percent at $450^{\circ} \mathrm{C}$.

Zinc oxide exhibits a very favorable thermodynamic equilibrium with $\mathrm{H}_{2} \mathrm{~S}$ because it is theoretically capable of removing $99+$ percent sulfur from the coal gas. However, the kinetics of $\mathrm{H}_{2} \mathrm{~S}$ reaction with $\mathrm{ZnO}$, studied by Westmoreland et al. (1977), was found to be slower than iron oxide. Furthermore, higher temperature and/or severely reducing coal gas promotes zinc vaporization.

\subsection{ZINC FERRITE PROCESS}

Researchers at Morgantown Energy Technology Center (METC) of the United States Department of Energy (DOE) envisioned that a sorbent formed from the combination of iron and zinc oxides would retain the rapid reaction rate of iron oxide and the high theoretical capacity of the individual oxides, and the product gas concentrations would be governed by very favorable thermodynam: $c s$ of zinc-oxide. This led to the development of the zinc ferrite $\left(\mathrm{ZnFe}_{2} \mathrm{O}_{4}\right)$ sorbent prepared by calcining an equimolar mixture of $\mathrm{ZnO}$ and $\mathrm{Fe}_{2} \mathrm{O}_{3}$ (Grindley and Steinfeld, 1981).

Zinc ferrite, $\mathrm{ZnFe}_{2} \mathrm{C}_{4}\left(\mathrm{ZnO} \cdot \mathrm{Fe}_{2} \mathrm{O}_{3}\right)$, is claimed to combine the high desulfurization efficiency of zinc oxide $(\mathrm{ZnO})$ with the high sulfur capacity and reactivity of iron oxide $\left(\mathrm{Fe}_{2} \mathrm{O}_{3}\right)$. It is easily regenerated using air/diluent mixtures and has consistently demonstrated $\mathrm{H}_{2} \mathrm{~S}$ removal down to less than 10 ppmv over multiple cycles (Gangwal et al., 1988; Grindley and Goldsmith, 1987).

The chemistry of zinc ferrite is very similar to that of iron and zinc oxides. Under the reactor operating conditions, $\mathrm{H}_{2}$ and $\mathrm{CO}$ react with zinc ferrite and cause it to split into constituent oxides, and $\mathrm{Fe}_{2} \mathrm{O}_{3}$ then reduces to $\mathrm{Fe}_{3} \mathrm{O}_{4}$ according to the following reaction:

$$
\mathrm{ZnFe}_{2} \mathrm{O}_{4}+\frac{1}{3} \mathrm{H}_{2}(\mathrm{CO}) \rightarrow\left(\mathrm{ZnO}+\frac{2}{3} \mathrm{Fe}_{3} \mathrm{O}_{4}\right)+\frac{1}{3} \mathrm{H}_{2} \mathrm{O}\left(\mathrm{CO}_{2}\right)
$$

Assuming that reduction conditions are controlled so that $\mathrm{Fe}_{3} \mathrm{O}_{4}$ is a stable form of iron, then the sulfidation reaction would be

$$
\left(\mathrm{ZnO}+\frac{2}{3} \mathrm{Fe}_{3} \mathrm{O}_{4}\right)+3 \mathrm{H}_{2} \mathrm{~S}+\frac{2}{3} \mathrm{H}_{2} \rightarrow(\mathrm{ZnS}+2 \mathrm{FeS})+\frac{11}{3} \mathrm{H}_{2} \mathrm{O} .
$$

Sulfided sorbent regeneration is carried out with a diluent and air mixture. The primary regeneration reaction is a direct oxidation of zinc and iron sulfides 


$$
(\mathrm{ZnS}+2 \mathrm{FeS})+5 \mathrm{O}_{2}-\mathrm{ZnFe}_{2} \mathrm{O}_{4}+3 \mathrm{SO}_{2}
$$

reaction

Steam, if present as diluent, reacts slowly with the sulfided rroduct according to the

$$
(\mathrm{ZnS}+2 \mathrm{FeS})+\frac{11}{3} \mathrm{H}_{2} \mathrm{O} \rightarrow\left(\mathrm{ZnO}+\frac{2}{3} \mathrm{Fe}_{3} \mathrm{O}_{4}\right)+3 \mathrm{II}_{2} \mathrm{~S}+\frac{2}{3} \mathrm{H}_{2} .
$$

In the presence of oxygen and steam, $\mathrm{Fe}_{3} \mathrm{O}_{4}$ and $\mathrm{ZnO}$ further oxidize to $\mathrm{ZnFe}_{2} \mathrm{O}_{4}$ in a normal rege،seration.

Zinc sulfate can piesumably be formed by one or both of the following reactions, at sufficiently low temperature and/or high oxygen concentration

$$
\begin{gathered}
\mathrm{ZnS}+2 \mathrm{O}_{2} \rightarrow \mathrm{ZnSO}_{4} \\
\mathrm{ZnO}+\mathrm{SO}_{2}+\frac{1}{2} \mathrm{O}_{2} \rightarrow \mathrm{ZnSO}_{4} .
\end{gathered}
$$

Since each reacting species is present under normal regeneration conditions, all regeneration reactions may occur simultaneously.

The theoretical maximum sulfur loading for zinc ferrite is close to $40 \mathrm{~g} \mathrm{~S} / 100 \mathrm{~g}$ sorbent. But typically about 40 to 50 percent of the theoretical capacity is achieved before sulfur breakthrough occurs.

\subsubsection{Fixed-Bed Reactor System}

Earlier testing of zinc ferrite was conducted in fixed-bed reactor systems. Most of the successful zinc ferrite formulations for fixed beds were prepared by United Catalysts, Inc. (UCI). The sorbents were prepared as $0.5 \mathrm{~cm}$ cylindrical extrudates about $1.25 \mathrm{~cm}$ long. Sorbent preparation was also carried out by AMAX (Jha et al., 1988). Typically, an equimolar zinc oxide-iron oxide mixture was extruded with 2 to 5 percent bentonite binder by weight. The extrudates were calcined at 816 to $843^{\circ} \mathrm{C}$ for 2 to $4 \mathrm{hr}$ to produce the sorbent.

Sub-pilot scale testing of zinc ferrite sorbent was conducted by KRW using ceramic candle filters upstream of the sorbent vessel, which was a $0.61-\mathrm{m}$ diameter, 2.24-m high fixed bed that contained $864 \mathrm{~kg}$ of zinc ferrite. The outlet concentration of $\mathrm{H}_{2} \mathrm{~S}$ was consistently $<20$ ppmv before sulfur breakthrough (Grindley and Goldsmith, 1987; Haldipur et al., 1987; 1989). The tests demonstrated that a packed bed of zinc ferrite can provide high sulfur removal efficiencies with very low sulfur levels in the outlet gas, provided that an efficient particulate control device is located upstream of the absorption reactor. Previous tests using only a cyclone upstream of the sorbent bed resulted in unacceptable pressure drop through the bed because of particulate plugging, which resulted in limited sulfur adsorption capacity. 
The performance of zinc ferrite as a hot gas desulfurization sorbent was also evaluated by Wu et al. (1989) in packed-bed desulfurization reactors using a slipstream of coal gas from the Texaco entrained-flow gasifier at their Montebello, California, pilot plant. The $\mathrm{H}_{2} \mathrm{~S}$ con. ?nt of gas was between 1,600 and 14,500 ppmv. The zinc-ferrite sorbents were able to remove > 95.9 percent of $\mathrm{H}_{2} \mathrm{~S}$ from the coal gas prior to breakthrough. The sorbents were found to be unsuitable in the Texaco oxygen-blown entrained-bed gasification process because the reduction of zinc fer ite to iron carbide resulted in a severe loss of strength after exposure to the highly reducing coal gas.

Although considerable research was carried out on the development of zinc ferrite sorbents for fixed-bed applications, the fixed-bed reactor system itself has certain disadvantages. The need for valves operating at HTHP conditions and highly exothermic regeneration imposes severe limitations on the fixed-bed system. Also, the cyclic nature of the process means that both vessels have to withstand temperature swings and fluctuations occur in the tail-gas $\mathrm{SO}_{2}$ concentration.

\subsubsection{Moving-Bed Reactor System}

A moving-bed reactor s:/stem was developed by General Electric (GE) to overcome some of the limitations of the fixed-bed configuration and is currently undergoing demonstration. Coupled with a 24 tpd dry-ash fixed-bed gasifier, this system is expected to eliminate some of the problems encountered in the fixed-bed system but requires a more d!Irable sorbent (Gal et al., 1987; Cook et al., 1989).

\subsubsection{Fluidized-Bed Reactor System}

A fluidized-bed hot gas desulfurization system offers potential advantages compared to the fixed-bed and moving-bed systems. Fluid-bed reactors provide excellent gas-solid contact via vigorous agitation of small particles, minimize diffusional resistances, give faster overall kinetics, and allow pneumatic transport. A continuous steady-state operation is possible by conducting sulfidation and regeneration in separate fluidized beds and providing for continuous sorbent exchange between the two beds. Fluidized beds possess the capabilities of continuous addition and removal of sorbent and better control of the highly exothermic surbent regeneration. Sorbent can be injected into the regenerator to prevent or minimize sulfate formation. Solids segregation is prevented by vigorous solids agitation in the fluidized bed. Fluidized beds can withstand far greater particle loading in the process stream. Heat removal systems can also be incorporated in the sorbent regeneration bed. The disadvantages of fluid beds are that (1) the design is usually based on empirical correlations and significant art is involved in scale-up, and (2) a highly durable (attrition-resistant) sorbent, capable of withstanding stresses induced by rapid temperature swings, chemical transformations, and fluidization and iransport, is required.

High-pressure applications of fluid-bed reactors for hot gas desulfurization led to the development of the CONOCO and IHI processes. The CONOCO process (Curran et al., 1973) utilized a half-calcined domomite as the fluid-bed sorbent in a bubbling-bed reactor. The $\mathrm{H}_{2} \mathrm{~S}$ was captured as $\mathrm{CaS}$ at $843^{\circ} \mathrm{C}$ and the sorbent was regenerated in a second bubbling bed at $700^{\circ} \mathrm{C}$ using steam and $\mathrm{CO}_{2}$-rich stream. The integrated desulfurization regeneration system could remove up to 90 percent $\mathrm{H}_{2} \mathrm{~S}$ from fuel gas. In the $\mathrm{IHI}$ process, developed by 
Ishikawajima-Harima Heavy Industries of Japan (Sugitani et al., 1987; Hashimoto et al., 1989), there was a 40 tpd two-stage pressurized fluidized-bed air-blown gasifier coupled to a fluidizedbed hot gas desulfurization system based on iron oxide ore. The hot gas desulfurization system consisted of a two-stage bubbling fluidized-bed absorber, a two-stage fluidized-bed regenerator, and a tail-gas $\mathrm{SO}_{2}$ reducer to elemental sulfur using anthracite. Over 1,255 horits of operation, up to 95 percent desulfurization efficiency was claimed at absorber temperatures of 420 to 480 ${ }^{\circ} \mathrm{C}$ and $18 \mathrm{~atm}$ pressure. The iron oxide used in their process was an Australian iron ore crushed to a particle size of 100 to $250 \mu \mathrm{m}$. IHI is building a process demonstration plant of a 200 tpd coal capacity coupled with their hot gas desulfurization system. IHI researchers are conside ing the use of zinc-based sorbents for their process to achieve $99+$ percent removals and to eliminate excessive sorbent losses that presently occur due to attrition.

Despite successful development of the fluidized-bed hot gas desvlfurization systems, poor sorbent durability has remained a major obstacle. Therefore, with the DOE/METC sponsorship, Research Triangle Institute (RTI) began developing and testing durable zinc-based sorbents for fluidized-bed applications. A detailed description of sorbent development activities and reactor design is presented in this report.

\subsection{OBJECTIVE OF CURRENT WORK}

The objective of the base period of this project was to identify and demonstrate methods for enhancing the long-term chemical reactivity and mechanical strength of zinc ferrite sorbents to be used in a high-pressure fluid-bed reac'sr for removal of sulfur-bearing species from hot coal-derived gases.

\subsection{SCOPE OF CURRENT WORK}

The major milestones of this project included:

- Development of methods for manufacturing sorbents with attrition resistance (in fresh, sulfided, and regenerated states) comparable to commercial fluid catalytic cracking (FCC) catalysts along with high sulfur capacity and efficir רcy for hydrogen sulfide removal over numerous cycles.

- Design and construction of a versatile HTHP bench-scale fluidized-bed reactor facility capable of operation at pressures from 1 to 35 atm and temperatures from 400 to $800^{\circ} \mathrm{C}$ with an ori-line gas analysis system.

- Operation of the bench-scale unit over numerous sulfidation/regeneration cycles to obtain detailed data so that an unbiased ranking of the promising sorbents may be obtained.

- Generation of a database on sorbent properties and performance to oe used in the future for design and scaleup of commercial hot gas desulfurization systems. 


\subsection{BENCH-SCALE SORBENT TEST FACILITY}

\subsection{DESCRIPTION OF BENCH UNIT}

The cyclic (sulfidation/regeneration) desulfurization tests for sorbent development were carried out in a high-pressure batch bench-scale reactor designed for operation at pressures up to $35 \mathrm{~atm}$ and temperatures up to $788^{\circ} \mathrm{C}$. The fixed-bed sorbent test facility used in the previous DOE/METC contract (No. DE-AC21-86MC23126) was modified for fluid-bed operation (Gangwal et al., 1988). The modifications were made so that the facility could be used either in a fluid-bed or a fixed bed mode with minimum downtime during interconversion.

Figure 2-1 shows a schematic diagram of the modified test facility. For ease of transportation the unit was constructed as a skid-mounted system. Must of the system components were constructed with 316 and 304 stainless steel. All hot $\mathrm{H}_{2} \mathrm{~S}$-wetted parts were Alon-processed (a high-temperature aluminum vapor treatment) to prevent corrosion of stainless steel by suifur gases in the presence of steam.

The entire bench-scale test facility can te divided into five subsystems:

1. Gas delivery system,

2. Reactor assembly,

3. Data acquisition and process control,

4. Gas analysis system, and

5. Reactor off-gas venting system.

\subsubsection{Gas Delivery System}

The gas delivery system is capable of generating simulated coal gasifier gases representative of all types of gasitiers. Bottled gases were used for $\mathrm{CO}, \mathrm{H}_{2}, \mathrm{CO}_{2}, \mathrm{~N}_{2}, \mathrm{H}_{2} \mathrm{~S}, \mathrm{O}_{2}$, and air. $\mathrm{H}_{2} \mathrm{~S}$ was obtained as a mixture of either 10 percent $\mathrm{H}_{2} \mathrm{~S}$ in $\mathrm{N}_{2}$ or 9 percent $\mathrm{H}_{2} \mathrm{~S}$ in $\mathrm{H}_{2}$.

A battery of seven mass flow controllers capable of operation at pressures up to 100 atm was used to control the flow rate and composition of simulated coal gas. Deionized water was fed to a steam generator using a positive displacement pump to generate the steam. The benchscale facility is equipped with three water pumps to generate steam at any composition required in simulated coal gas. The gases were mixed in a gas manifold and sent to a preheater and a superheater for heating to a desired temperature. The preheater shown in Figure 2-2 works as a steam generator and is surrounded by a tubular furnace. The superheater (not shown in Figure $2-1$ ) consists of a $6.4-\mathrm{mm}$ tubing coiled around a $91-\mathrm{cm}$ long Inconel rod-heater. The preheated gases were sent to the reactor.

\subsubsection{Reactor Assembly}

The desulfurization reactor is shown in Figure 2-3. Based on American Society Mechanical Engineers (ASME) pressure vessel design code, the reactor system was designed to withstand up to $35 \mathrm{~atm}$ pressure at $788^{\circ} \mathrm{C}$. 


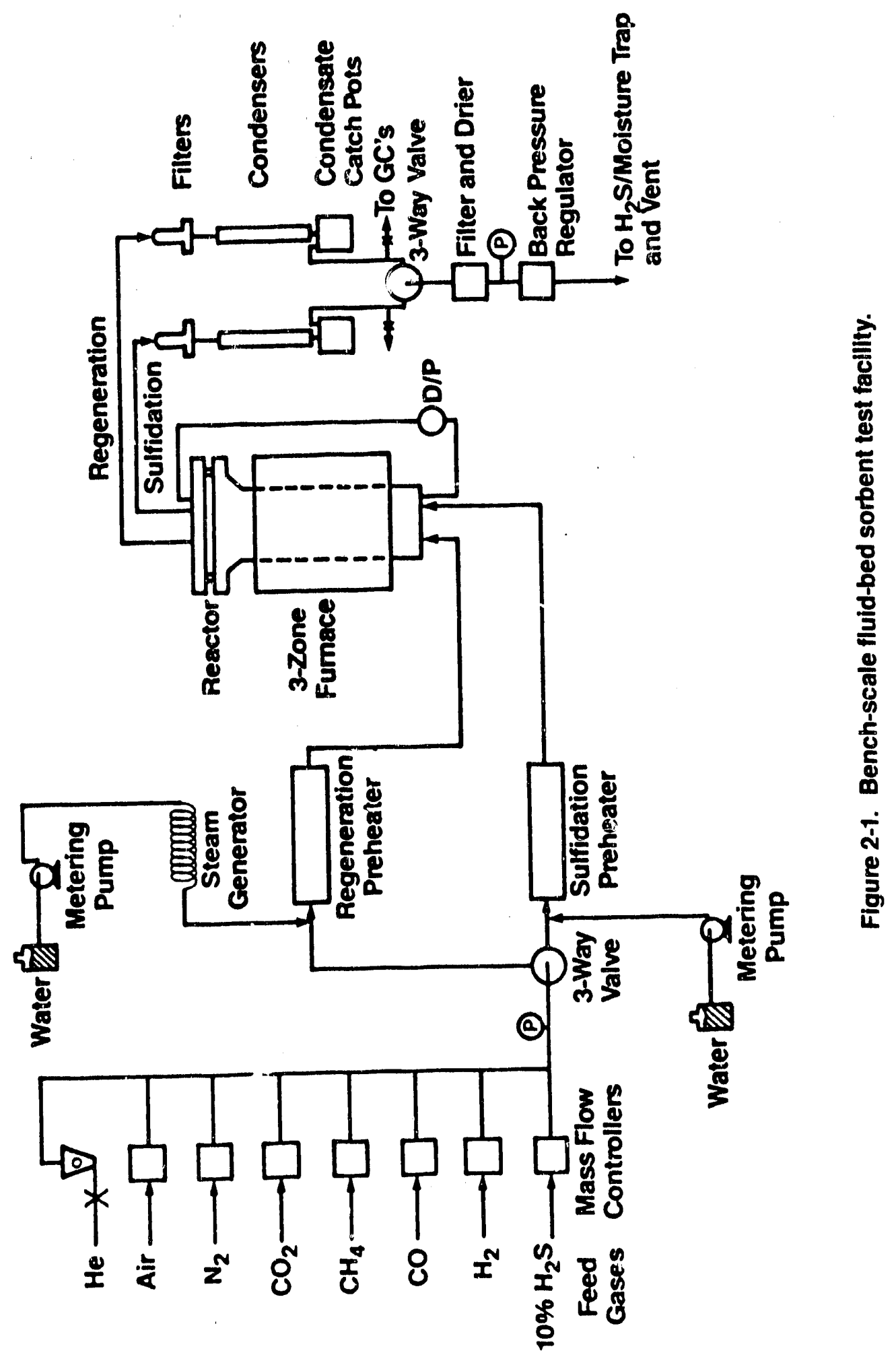



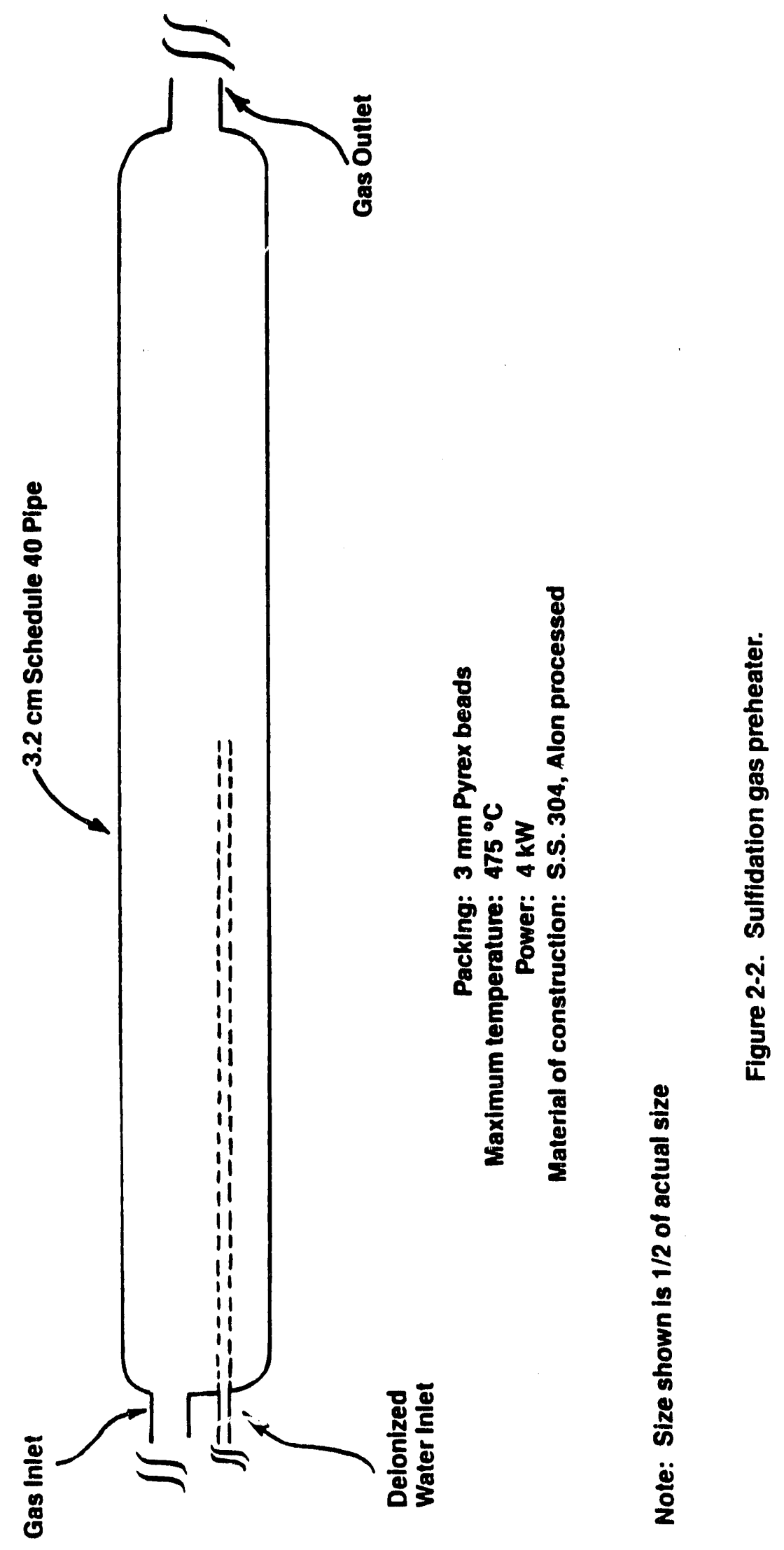


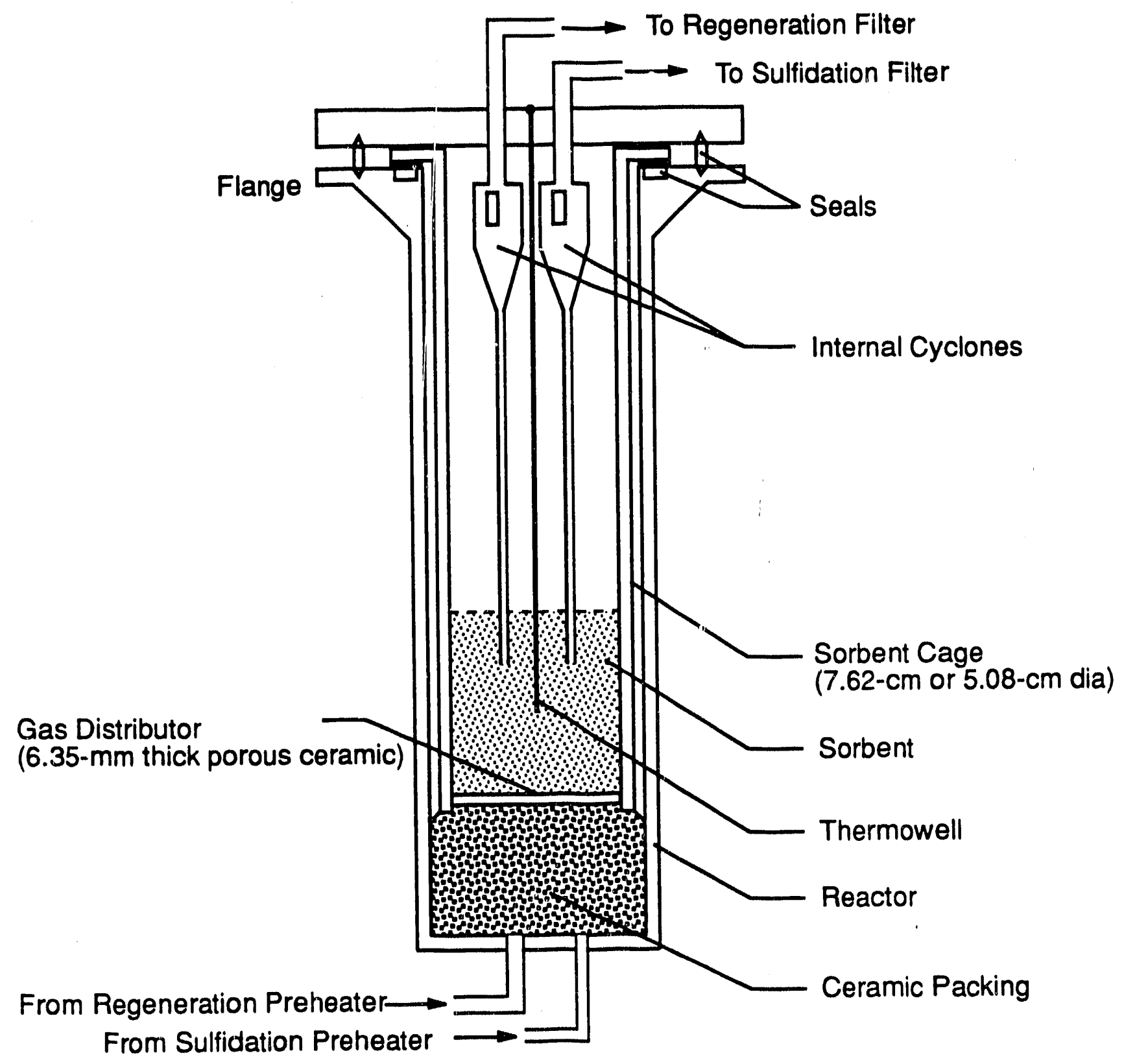

Figure 2-3. Fluid-bed reactor. 
The reactor has a rumovable cage for the sorbent which allows easy removal/oading of the sorbent. A unique feature of this construction, as shown in Figure ?-3, is that the top flange squeezes the main O-ring while pressing down on the cage squeezing secondary O-ring. There is essentially no pressure gradient across the secondary O-ring while eliminating gas bypassing around the cage.

The reactor system is capable of housing both $7.62-\mathrm{cm}$ and $5.1-\mathrm{cm}$ diameter sorbent cages. An $\alpha$-alumina distributor plate is enclosed in a stainless steel ring, which is welded at the bottom of each cage and acts as a distributor for the hot coal gas in the reactor. The 6.4-mm thick distributor was designed to provide uniform fluidization in the reactor. The distributor material was heat-treated at $871^{\circ} \mathrm{C}$ for $2 \mathrm{hr}$ prior to its use to eliminate any undesired tempering during high temperature reactor operation. The distributor was also tested in a cold-flow test facility to ascertain its capability of providing good quality fluidization prior to its use in the bench-scale reactor. A brief description of the cold-flow test facility is given later in this chapter.

The reactor is housed inside a 3-zone furnace. This 3-zone furnace, Model No. 26-29-3ZV, manufactured by Thermcraft, Inc. (Winston-Salem, NC) has a power rating of 8,150 watts. The furnace is equipped with separate electronic controllers for each zone and is capable of heating the reactor uo to $850^{\circ} \mathrm{C}$.

To separate elutriated particles from the clean gas, two cyclones were placed inside the reactor with their diplegs extending to the sorbent bed. Later, they were found not to be necessary and were removed because of insignificant particle elutriation from the reactor.

Ceramic thimble filters (see Figure 2-4) downstream of the reactor w/ere used to capture particulates from the sulfidation and regeneration exit lines prior to condensers. These filters were very effective in removing particles from the gas.

The reactor exit gas, after passing through the thimble filters, was cooled using heat exchangers. An individual cooling system was provided for both sulfidation and regeneration exit gases. Extensive cooling of regeneration exit gas was not necessary since regeneration was carried out without using steam. However, sulfidation exit gas containing 5 to 25 percent steam (depending on the nature of simulated coal gas) required efficient cooling to prevent water from entering the downstream gas chromatograph (GC) columns. Hence, a two-stage cooling was carried out. The gas was cooled in a double pipe heat exchanger with tap water flowing in the outer shell and then in an Inco Alloy C-276 condenser shown in Figure 2-5. In this condenser, ethylene glycol refrigerant was sirculated at a high velocity to completely condense the steam. The refrigerant circulation was maintained using a constant temperature bath equipped with a compressor and pump capable of cooling the refrigerant to $-7^{\circ} \mathrm{C}$. The steam condensate was occasionally drained from the catchpot into a measuring flask. At the end of each cycle the volume of the condensate was measured to obtain a material balance on water.

\subsubsection{Data Acquisition and Process Control}

Any HTHP system involving combustible and toxic gases needs an efficient data acquisition and control system to closely monitor the process. The following significant process 


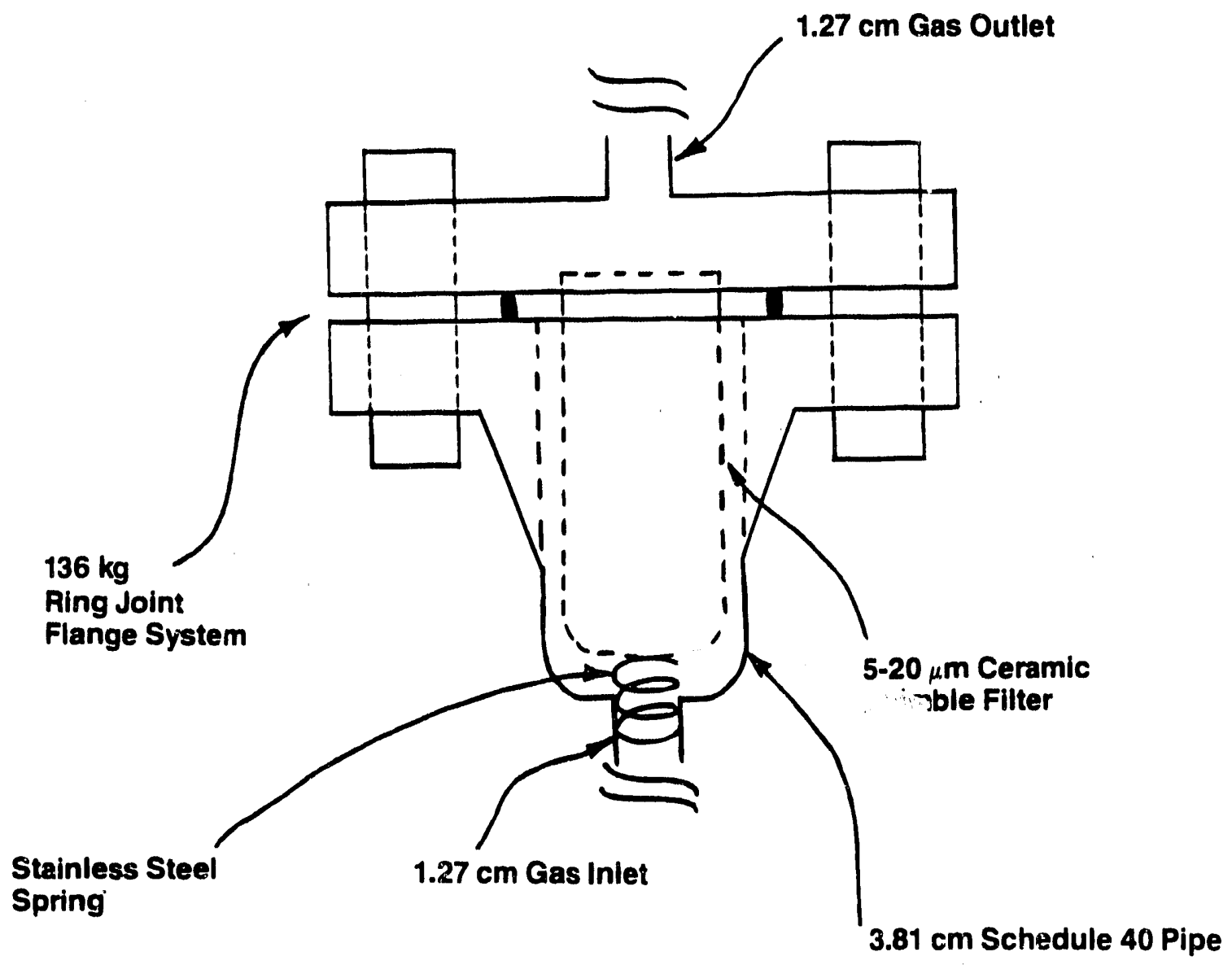

\footnotetext{
Material of construction: Stainless steel 304, Alon processed

Drawn to scale: $1 / 2$ of actual size

Separate but identical filters are used for regeneration gas and sulfidation gas
}

Figure 2-4. Ceramic thimble filters. 


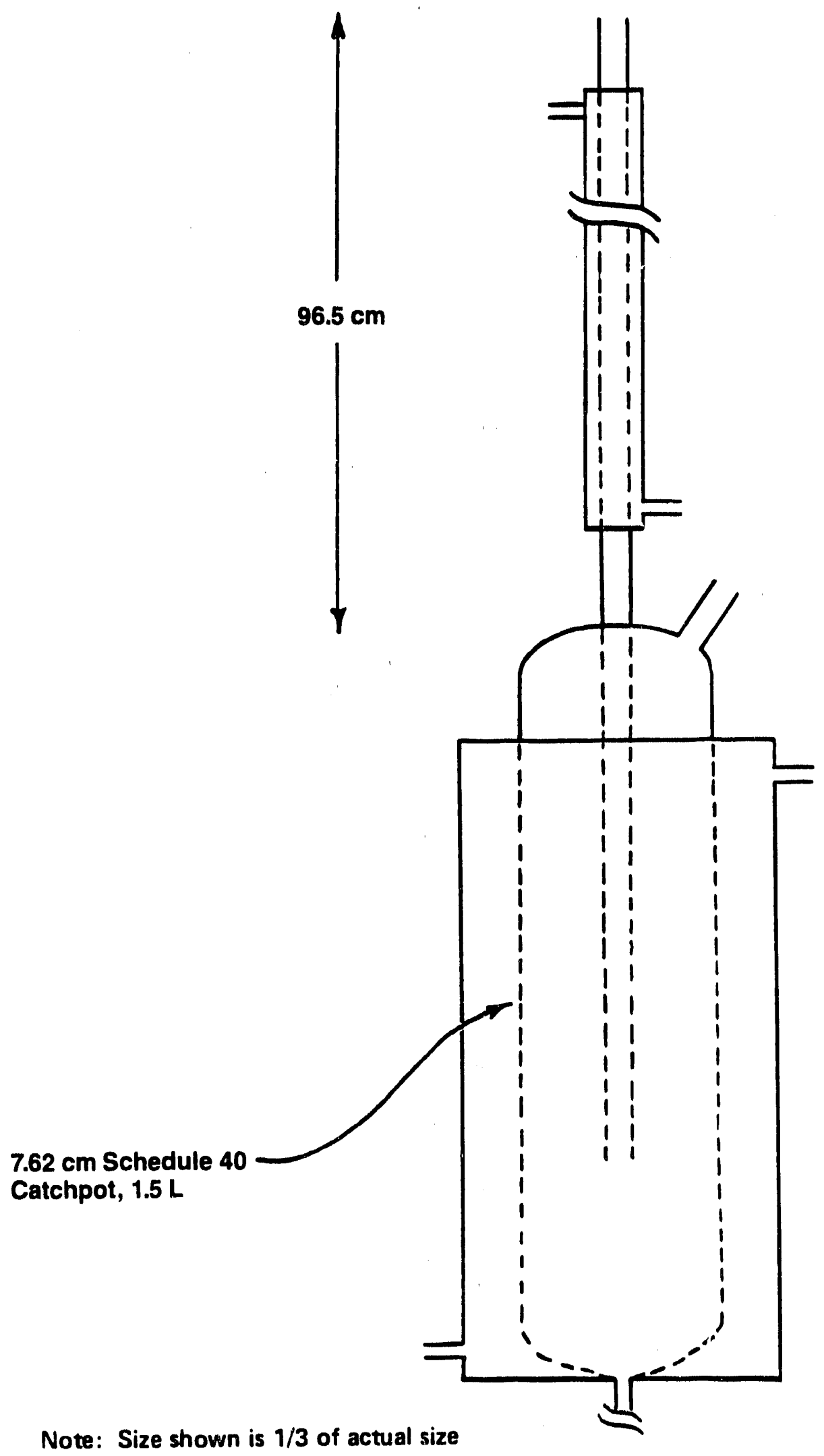

S.S. 304

Alon processed

Note: Size shown is $1 / 3$ of actual size

Figure 2-5. Sulfidation gas condenser. 
variables in the system are controlled within the set specifications:

- Temperature,

- Pressure, and

- Flow rate and composition of reactor inlet and outlet gases.

The reactor temperature was monitored at a bed inlet below the distributor, halfway in the bed and at bed outlet in the freeboard. The temperatures in the preheater, superheater, sulfidation, and regeneration filters were monitored using type-K thermocouples equipped with digital display and connected to a data-logger.

The flow rate of inlet gas to the reactor (in sulfidation and regeneration modes) was measured using seven pre-calibrated mass flow controllers from Brooks Instruments. The mass flow controllers were connected to a digital display and a data-logger which continuously recorded the flow rates of gases and temperatures.

Precise pressure control was provided by two back-pressure regulators in series. An onset of reactor plugging could be detected by an electronic differential pressure monitor. The regulators were protected from potential particle plugging by passing the gas through a Drierite trap and a Balston filter.

The data-logger, procured from Omega Instruments, is equipped with an alarm system that allows specification of each important process variable 's low and high limits. This system, very useful in providing a warning for low gas content in bottles and overheating/underheating of gases, consists of electronically activated relay coils and allows more than $100 \mathrm{hr}$ of continuous testing, if so desired.

Flow rate and composition of reactor outlet gases (sulfidation and regeneration) were measured using a dry gas meter and gas chromatographs, resfectively.

\subsubsection{Gas Analysis System}

A slipstream of the steam-free gas from the reactor (after condensers) is diverted to the gas analysis system shown in Figure 2-6. The gas samples are continuously withdrawn from this line past the condenser. An automated GC sampling system was used to analyze the inlet and outlet gas streams on-line. The outlet gas stream analysis system consists of two GCs, a Carle Series 400 AGC with a thermal conductivity detector (TCD) and a Varian 3300 with a flame photometric detector (FPD). The GCs are connected to separate Spectra Physics SP4270 integrators which continuously record the gas analysis. Multiple GC sampling valves and dual loops in the Varian FPD provide the capability of measuring $\mathrm{H}_{2} \mathrm{~S}$ and $\mathrm{COS}$ from 1,500 ppmv to less than 0.1 ppmv every $2 \mathrm{~min}$. A Chronosil-310 column is used to separate the gaseous components at $50{ }^{\circ} \mathrm{C}$. $\mathrm{SO}_{2}$ and $\mathrm{CS}_{2}$ can also be measured every $6 \mathrm{~min}$. Prior to each run, the Varian GC was calibrated using a standard gas sample.

High concentrations of $\mathrm{H}_{2} \mathrm{~S}, \mathrm{SO}_{2}$, and other bulk gases $\left(\mathrm{H}_{2}, \mathrm{CO}_{2}, \mathrm{~N}_{2}, \mathrm{O}_{2}, \mathrm{CH}_{4}\right.$ ana $\left.\mathrm{CO}\right)$ were measured every $25 \mathrm{~min}$ with the Carle-TCD to evaluate mass balance and the extent of shift reaction $\left(\mathrm{CO}+\mathrm{H}_{2} \mathrm{O} \rightarrow \mathrm{CO}_{2}+\mathrm{H}_{2}\right)$. 


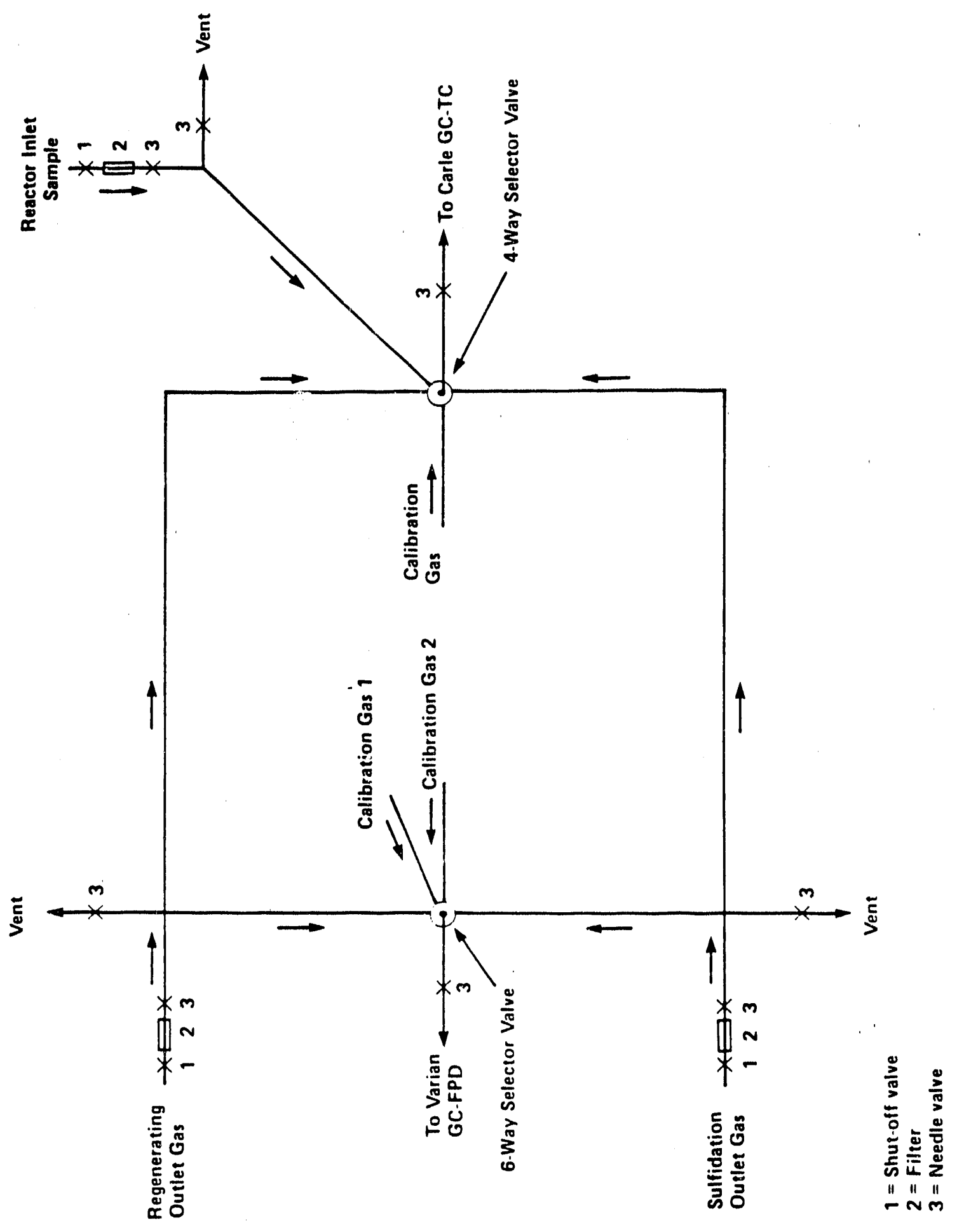

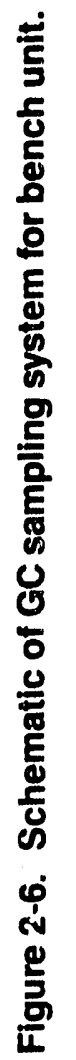




\subsubsection{Reactor Offgas Venting System}

Since the sulfidation exit gas contains toxic $\mathrm{CU}$ and $\mathrm{H}_{2} \mathrm{~S}$ and regeneration offgas contains toxic $\mathrm{SO}_{2}$, proper disposal becomes essential. Therefore, a high power blower was installed on the laboratory roof to dilute gases by a factor of 100 before emitting them into the atmosphere.

\subsection{COLD-FLOW MODEL}

Fluidization research has been primarily carried out at atmospheric pressure and only limited literature on high-pressure fluidization is available. Since the desulfurization reactor required HTHP operation, it was necessary to understand the sorbent fluidization behavior at hign pressures prior to actual testing under reacting conditions in the metal reactor.

To this end, two high-pressure see-through cold-flow models were designed and constructed from $5.08-\mathrm{cm}$ and $7.62-\mathrm{cm}$ polycarbonate pipes, respectively. A schematic diagram of a 7.62-cm cold-flow model is shown in Figure 2-7. This pipe is $9.5-\mathrm{mm}$ thick and capable of withstanding up to $80 \mathrm{~atm}$ pressure. The same ceramic distributor that was used in the reactor (see Section 2.1.2) was used to introduce the gas.

The see-through high-pressure cold-flow models were used to assess fluidization quality, avoid slugging in the hot reactor, avoid excessive entrainment, confirm distributor pressure drop, and aid in developing a startup and shutdown procedure for the HTHP reactor.

The test procedure included loading a known weight of the sorbent in the bed and then measuring the bed height. This provided an approximate measure of oed voidage. Nitrogen gas was used for fluidization and a thimble filter (similar to the filter used in the reactor [see Section 2.1.2]) was used for collection of entrained particles. A back-pressure regulator was provided to control system pressure and a differential pressure sensor was used to measure the pressure across the distributor and the sorbent bed.

The cold-flow model was operated at several pressures under conditions based on the design of the actual reactor (i.e., initial sorbent hed height, linear gas velocity). Because of the insignificant effect of temperature on fluidization, the cold-flow model, at least qualitatively, was representative of the fluidization behavior of the sorbent in the actual HTHP reactor.

\subsection{TEST PROCEDURE AND CONDITIONS}

After a number of bench-unit shakedown tests and a study of fluidization behavior in the cold-flow model, a bench-unit test procedure was developed. Bench-scale test conditions are shown in Table 2-1. A typical bench-unit run consisted of the following steps:

1. A known weight of the sorbent (typically $350 \mathrm{~g}$ ) in the desired particle size range $(-50+140$ mesh) was charged in the reactor.

2. The reactor was pressurized to a desired pressure (1.5 $\mathrm{MPa}$ typically) and heated to a desired temperature $\left(550\right.$ to $\left.650^{\circ} \mathrm{C}\right)$ with continuous passage of nitrogen through the reactor. 


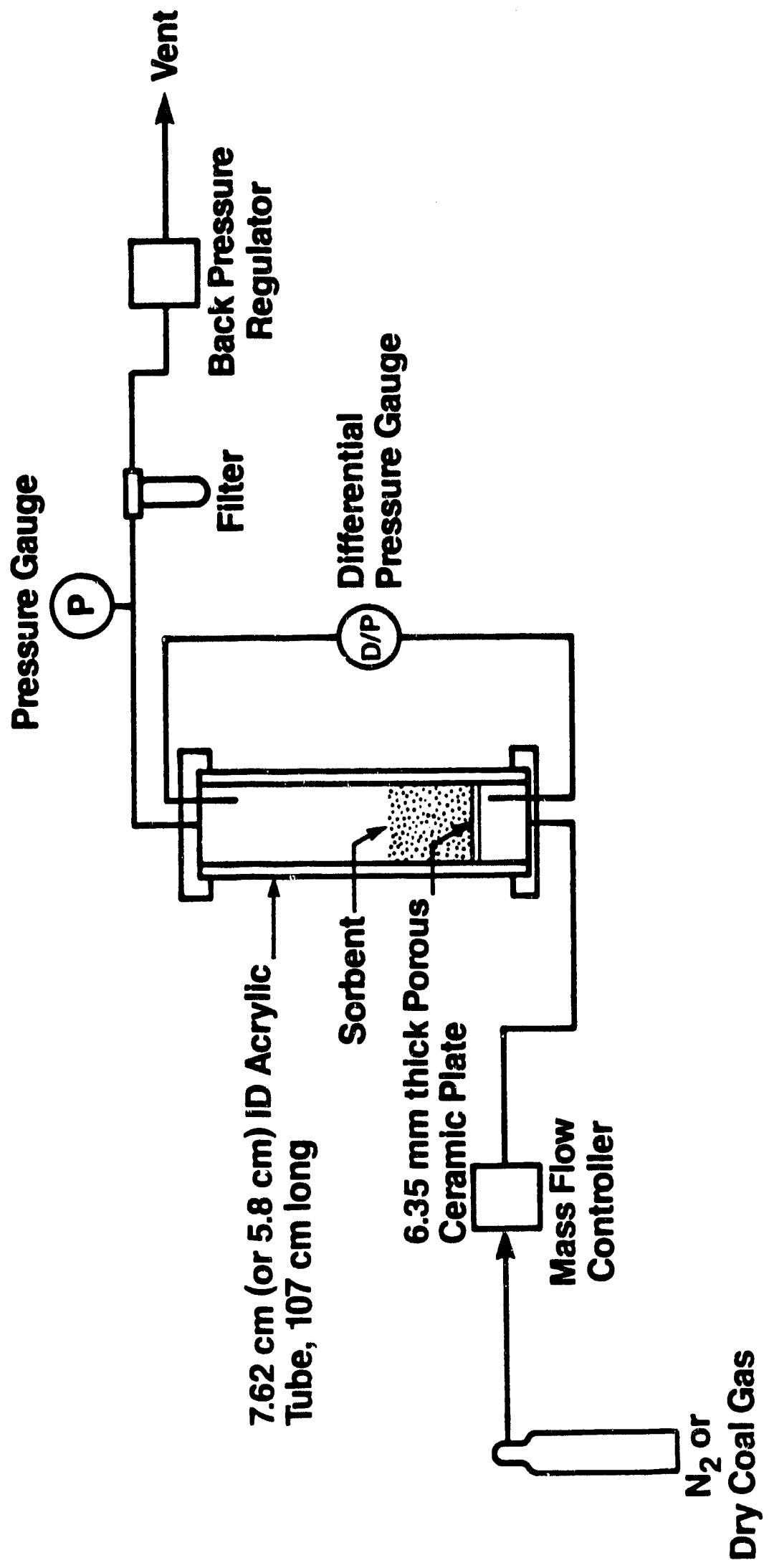

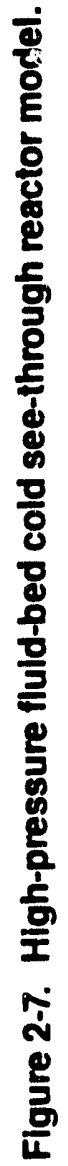


TABLE 2-1. BENCH-SCALE TEST CONDITIONS

\begin{tabular}{lllccc}
\hline \multirow{2}{*}{ Operating conditions } & \multicolumn{4}{c}{ Gas composition (volume percent) } \\
\cline { 3 - 6 } & & \multicolumn{2}{c}{ Sulfidation } & \multicolumn{2}{c}{ Regeneration } \\
\hline Pressure & $1.5 \mathrm{MPa}$ & $\mathrm{H}_{2}$ & $8-14$ & $\mathrm{O}_{2}$ & $2-3$ \\
Temperature & $530-800{ }^{\circ} \mathrm{C}$ & $\mathrm{CO}$ & $13-22$ & $\mathrm{~N}_{2}$ & Balance \\
Gas flow & $25-40 \mathrm{slpm}^{\mathrm{a}}$ & $\mathrm{CO}_{2}$ & $4-11$ & & \\
Uo/ $\mathrm{U}_{\text {nif }}{ }^{\prime}$ & $3.0-3.5$ & $\mathrm{H}_{2} \mathrm{~S}$ & 0.5 & & \\
Sorbent charge & $175-350 \mathrm{~g}$ & $\mathrm{H}_{2} \mathrm{O}$ & $15-20$ & & \\
$\begin{array}{l}\text { Sorbent average } \\
\text { particle size }\end{array}$ & $150-200 \mu \mathrm{m}$ & $\mathrm{N}_{2}$ & Balance & & \\
\hline \hline
\end{tabular}

"Standard liters per minute

" Ratio of superficial to minimum fluidization velocity

3. Sulfidation of the sorbent was carried out by flowing the simulated coal gas and was continued until the $\mathrm{H}_{2} \mathrm{~S}$ concentration in the reactor exit gas reached $500 \mathrm{ppmv}$ (breakthrough value).

4. Following the sulfidation, the reactor was switched to the regeneration mode by stopping the flow of sulfidation gas to the reactor and heating the reactor to the desired regeneration temperature again with continuous passage of nitrogen flowing through the reactor. Generally, the initial regeneration temperature was 50 to $150^{\circ} \mathrm{C}$ higher than the sulfidation temperature. Once the desired temperature was attained, the flow of regeneration gas was started. Regeneration was carried out using nitrogen as a diluent (in place of steam as used previously) until the outlet $\mathrm{SO}_{2}$ concentration was reduced to less than $250 \mathrm{ppmv}$.

5. Steps (2) to (4) were repeated for subsequent cycles.

At the end of the run, the sorbent was removed from the reactor and weighed to determine any loss of material due to elutriation. A post-test sorbent characterization was performed to evaluate changes caused by reaction. This characterization included determination of particle size distribution, attrition resistance, pore volume and pore diameter, BET surface area, thermogravimetric analysis (TGA) reactivity and $\mathrm{Zn}$ to $\mathrm{Fe}$ ratio. 


\subsection{SORBENT PREPARATION AND CHARACTERIZATION}

\subsection{SORBENT SELECTION}

The sorbent formulation selected for the base program of this project was zinc ferrite, $\mathrm{ZnFe}_{2} \mathrm{O}_{4}$, which is formed by heating an approximately equimolar mixture of zinc oxide ( $\mathrm{ZnO}$ ) and iron oxide $\left(\mathrm{Fe}_{2} \mathrm{O}_{3}\right)$ to a temperature of about $800^{\circ} \mathrm{C}$ in the presence of a suitable binder such as bentonite. The following solid-state reaction takes place:

$$
\mathrm{ZnO}+\mathrm{Fe}_{2} \mathrm{O}_{3} \rightarrow \mathrm{ZnFe}_{2} \mathrm{O}_{4}
$$

A significant database exists for fixed-bed formulations of zinc ferrite. In the past, fixedbed sorbents were manufactured by AMAX (Jha et al., 1988) and UCI as 4.8-mm cylindrica! extrudates and spherical pellets. UCI has also manufactured a number of zinc ferrite formulations for GE (Ayala et al., 1990) for their moving-bed hot gas desulfurization process by rounding out the cylindrical extrudates. The rounding process produced $3.2-\mathrm{mm}$ to $9.5-\mathrm{mm}$ ellipsoidal pellets which have better mechanical durability in a moving bed due to the elimination of sharp edges of the cylindrical extrudates. None of these commercially manufactured sorbents are applicable to fluidized-beds because:

- Particle size needed is in the range of 50 to $300 \mu \mathrm{m}$,

- The sorbent must be highly attrition resistant (mechanically durable), and

- At the same time, the sorbent must have acceptable chemical reactivity for $\mathrm{H}_{2} \mathrm{~S}$.

\subsection{SORBENT PREPARATION FOR FLUIDIZED-BED APPLICATIONS}

As discussed in the previous section, sorbents for fluidized-bed applications must be attrition resistant to withstand stresses induced by rapid temperature swings, chemical transformations, and fluidization and transport. The mechanical strength or durability of the sorbent can be enhanced by adding binders. To date, most of the zinc ferrite formulations have been prepared using bentonite as a binder at a level of 2 to 5 weight percent. Bentonite helps stabilize sorbent reactivity and increase its mechanical strength (Grim, 1980).

Excessive amounts of binder in the sorbent may enhance its durability at a cost of decreased chemical reactivity. Therefore, a tradeoff exists between the sorbent reactivity and mechanical durability which limits the binder content that can be used. For fluidized-bed applications, mechanical strength of the sorbent is usually of greater importance than its che mical reactivity because of stresses resulting from the constant circulation required between sulfider and regenerator.

During this project, the following techniques were investigated to prepare the sorbent in a desired particle size range for the fluidized-bed applications:

- Spray drying,

- Crushing/screening the extrudates,

- Impregnation, and

- Granulation. 


\subsubsection{Spray Drying}

In view of the maximum particle size limited to $300 \mu \mathrm{m}$ in a fluidized-bed hot gas desulfurization reactor, spray drying was initially chosen as a primary method of sorbent manufacture. Spray drying is a proven commercial method for prefaration of silica-aluminabased catalysts for FCC or for acrylonitrile manufacture. Typical FCC ratalysts range in particle size from 40 to $150 \mu \mathrm{m}$ with a mean about $80 \mu \mathrm{m}$.

All the sorbent manufacturing activities using the spray-drying technique in this project were carried out by UCI. UCI prepared a number of sorbent formulations by varying bentonite content and calcination temperature and by adding varying amounts of silica, aluicina, titania, and sodium alumino-silicate. Initial sorbents prepared using 5 percent bentonite, 5 percent silica, 5 percent alumina, and 5 percent titania and calcined at $871^{\circ} \mathrm{C}$ had very poor attrition resistance. However, TGA testing of these sorbents showed desirable capacity and reactivity.

To improve attrition resistance of the sorbent, UCI increased the binder level to 25 percent and 50 percent. In both cases agglomeration occurred and bricks rather than free-flowing particles were formed. 1 he bricks were crushed and tested for attrition resistance. Although these materials showed high attrition resistance, they no longer possessed sulfur capacity as shown by the TGA. At this point UCI decided to terminate their effort to produce a fluidizable zinc ferrite sorbent by spray drying.

\subsubsection{Cru hing and Screening the Extrudates}

Beciase spray drying was not successful in preparing attrition-resistant fluid-bed zinc ferrite, other techniques were examined. One technique included crushing the durable zincferrite pellets prepared by UCI $(\mathrm{T}-2465 \mathrm{M})$ and AMAX $(\mathrm{E}-44 \mathrm{~A})$ and screening the particles to obtain a desired particle size distribution. T-2465M was originally prepared by UCI for GE in a 20,000 lb batch for its moving-bed desulfurization pilot plant in the form of ellipsoidal pellets. This was chosen as a base sorbent for this project.

E-44A prepared as extrudates had been determined by AMAX to have the best overall performance (reactivity and durability) in the fixed-bed system among numerous sorbents tested. The preliminary evaluation of the crushing and screening method provided encouraging results with reasonable yield in the desired $-50+140$ mesh $(105-$ to $297-\mu \mathrm{m})$ size range.

While the crushing and screening method obviously gives high flexibility in the choice of the desired particle size distribution, it may not be the most viable commercial option because of the additional cost associated with crushing, screening, and recycling fines. The particles formed may be angular with sharp edges which may be subjected to high initial rates of attrition. Keeping this in mind, the next sorbent prepared by this method for multicycle testing in the bench scale-unit was subjected to a long-term $(32 \mathrm{hr})$ fluidization to remove sharp edges.

* A brief description of the attrition-resistance determination method and TGA testing is provided later in this chapter. 
$\mathrm{T}-2465 \mathrm{M}$ was crushed and screened to obtain the desired particle size distribution and designated T-2465MC where C stands for "crushed." This sorbent was then subjected to a $32-\mathrm{hr}$ fluidization in the cold-flow model to remove sharp edges. Table 3-1 shows the particle size distribution of the sorbent before and after fluidization.

This sorbent (prepared by subjecting the T-2465MC sorbent to $32-\mathrm{hr}$ cold-flow fluidization) was found to have similar capacity, chemical reactivity, and attrition resistance to $\mathrm{T}-2465 \mathrm{MC}$ which was tested in the bench-scale unit for 100 cycles. Results of this multicycle testing are reported in Chapter 4. During multicycle testing, the sorbent lost its chemical reactivity and attrition resistance significantly (discussed in Chapter 4 ).

TABLE 3-1. SORBENT PREPARATION BY 32-HOUR FLUIDIZATION IN THE 5.08-cm-I.D. COLD-FLOW MODEL

\begin{tabular}{|ccc|ccc||}
\hline Sorbent & $:$ & T-2465MC & \multicolumn{3}{|c||}{ Particle size distribution } \\
Test duration & $:$ & $32 \mathrm{hr}$ & Sieve & $\begin{array}{c}\text { Before test } \\
(\mathrm{wt} . \%)\end{array}$ & $\begin{array}{c}\text { After test } \\
\text { (wt.\%) }\end{array}$ \\
Temperature & $:$ & $22^{\circ} \mathrm{C}$ & +50 & 0.00 & 0.05 \\
Pressure & $:$ & $1 \mathrm{~atm}$ & $-50+60$ & 13.46 & 9.29 \\
Fluidizing gas & $:$ & Nitrogen & $-60+80$ & 44.83 & 57.62 \\
Flow rate & $:$ & $6.82 \mathrm{slpm}$ & $-80+100$ & 10.43 & 3.86 \\
U/N $\mathrm{nif}_{\text {Sorbent loaded }}$ & $:$ & 2.6 & $-100+120$ & 24.07 & 23.06 \\
Sorbent recovered & $:$ & $176.58 \mathrm{~g}$ & -140 & 0.00 & 3.20 \\
Initiai bed height & $:$ & $7.30 \mathrm{~cm}$ & TOTAL & 100.00 & 100.00 \\
Final bed height & $:$ & $7.46 \mathrm{~cm}$ & & & \\
Attrition resistance & $:$ & $95.1 \%$ & & & \\
\hline
\end{tabular}

\subsubsection{Impregnation}

At the beginning of this project, it was thought that spray drying might not produce particles above $150 \mu \mathrm{m}$. Since sorbent particles up to $300 \mu \mathrm{m}$ in diameter were of interest, an impregnation technique was investigated to prepare stable zinc-ferrite formulations of a larger particle size. Impregnation is commercially used in the catalyst industry for preparing numerous catalysts.

Fluidizable Norton $\gamma$-alumina and UCI $\alpha$-alumina powders were chosen for initial preparations. UCI $\alpha$-alumina was successfully loaded with up to 20 weight percent zinc ferrite. The preparation procedure consisted of impregnating a zinc and iron nitrates solution at a volume 
equal to the pore volume of the alumina. This was followed by drying $\left(120^{\circ} \mathrm{C}\right)$ and calcination at temperatures from 600 to $840^{\circ} \mathrm{C}$. The samples were tested for capacity by TGA. Sorbents calcined at temperatures up to $750^{\circ} \mathrm{C}$ quickly sulfided to their full capacity and were regenerable over 1.5 cycles, with no loss in capacity during the second cycle. The sample calcined at 840 ${ }^{\circ} \mathrm{C}$ did not attain full capacity. Despite acceptable levels of chemical reactivity, the attrition resistance of the sorbent prepared by this technique was found to be poor. On the other hand, tests were not successful with the $\gamma$-alumina, which showed poor reactivity, presumably due to a strong chemical interaction of the reactive alumina with the active $\mathrm{ZnO}$ and $\mathrm{Fe}_{2} \mathrm{O}_{3}$.

A comparison of TGA reactivities of zinc-ferrite sorbent prepared by impregnation and by crushing and screening showed that the sorbent prepared by the latter method had significantly higher chemical reactivity and attrition resistance than the sorbent prepared using the impregnation technique. Hence, further efforts for producing sorbents by impregnation were terminated.

\subsubsection{Granulation:}

One potential sorbent manufacturing technique that emerged as successful during the course of the present study was granulation. A number of zinc ferrite sorbent formulations were prepared using this technique. The details of the granulation technique are proprietary and RTI is considering the patentability of this technique. These formulations were calcined at RTI at 800 ${ }^{\circ} \mathrm{C}$ for $2 \mathrm{hr}$. TGA testing of these formulations indicated that the granulated sorbents possessed capacity' and attrition resistance that were as good as or better than the T-2465MC prepared by crushing and screening. Results of bench-scale testing of L-7 (discussed in Chapter 4) showed that the drop in sulfur capacity and attrition resistance on multicycle testing was much less pronounced than the T-2465MC sorbent.

Following the successful preparation and encouraging performance of zinc-ferrite sorbent prepared by this technique in the bench-scale unit, $1 \mathrm{ft}^{3}$ of L-7 sorbent was prepared at RTI and delivered to DOE/METC for testing in METC's pilot-scale hot gas desulfurization system.

\subsection{Sorbent Characterization}

Sorbents were characterized using a variety of techniques prior to testing at the bench scale. The most important sorbent characteristics include sulfur capacity (defined as $g$ of sulfur adsorbed per $100 \mathrm{~g}$ of sorbent), regenerability, and attrition resistance. Other sorbent properties of importance include pore volume distribution, BET surface area, particle size distribution, weight percent of $\mathrm{ZnO}$ and $\mathrm{Fe}_{2} \mathrm{O}_{3}$, and X-ray diffraction (XRD) phases. Sorbent sulfur capacity and regenerabiliiy were measured with a thermogravimetric analyzer using procedures similar to those developed for fixed-bed sorbents (Woods et al., 1989). The attrition resistance of the sorbent was measured using an attrition tester similar to one described by Anderson and Pratt (1985).

\subsubsection{Thermogravimetric Analysis}

The progress of a gas-solid noncatalytic reaction can be followed quite easily by monitoring the change in mass of the solid. The sulfidation of metal oxide increases the mass of the sorb it pellet/powder while reduction and regeneration reactions decrease the mass. If the 
stoichiometry of the reaction is known, the change in solid mass can be directly related to the extent of conversion. Thermogravimetric analyzers are used for these types of studies.

RTI has a DuPont 1090 Thermal Analysis System interfaced with an IBM PC and a Hewlett Packard Plotter. Figure 3-1 shows a schematic of the TGA system. In this system, a battery of rotameters connected to various gas cylinders can provide a wide range of gas compositions. A Harvard Apparatus syringe pump capable of operating in the 0.005 to 5.00 $\mathrm{mL} / \mathrm{min}$ range can provide steam at any desired flow rate.

A standard TGA test consisted of two sulfidations at $550^{\circ} \mathrm{C}$ with an interim regeneration at $650^{\circ} \mathrm{C}$. Each sulfidation was preceded by a reduction at $550^{\circ} \mathrm{C}$ for $30 \mathrm{~min}$. The sorbent powder (typically a 10 to $50 \mathrm{mg}$ sample) was placed in a platinum pan for the TGA tests. The gases used in the TGA are shown in Table 3-2.

The sulfidation gas is typical of the KRW gasifier with additional steam to prevent sooting. Preliminary tests were conducted to determine TGA sample size and gas flow requirements to minimize the mass transfer effects, although the mass transfer effects in the available range of these parameters could not be completely eliminated.

TGA testing of sorbents was conducted for both screening and determining the loss in sorbent capacity and reactivity due to testing in the bench-scale unit.

TABLE 3-2. COMPOSITION OF TGA TEST GASES

\begin{tabular}{cccc}
\hline $\begin{array}{c}\text { Composition } \\
\text { (volume \%) }\end{array}$ & Reduction & Sulfidation & Regeneration \\
\hline $\mathrm{CO}_{2}$ & 4.89 & 4.89 & 0.00 \\
$\mathrm{CO}$ & 17.50 & 17.47 & 0.00 \\
$\mathrm{H}_{2}$ & 11.35 & 11.38 & 0.00 \\
$\mathrm{~N}_{2}$ & 46.36 & 45.43 & 78.51 \\
$\mathrm{H}_{2} \mathrm{O}$ & 19.90 & 19.90 & 19.87 \\
$\mathrm{O}_{2}$ & 0.00 & 0.00 & 1.62 \\
$\mathrm{H}_{2} \mathrm{~S}$ & 0.00 & 0.53 & 0.00 \\
TOTAL & $\mathbf{1 0 0 . 0 0}$ & $\mathbf{1 0 0 . 0 0}$ & $\mathbf{1 0 0 . 0 0}$ \\
\hline \hline
\end{tabular}




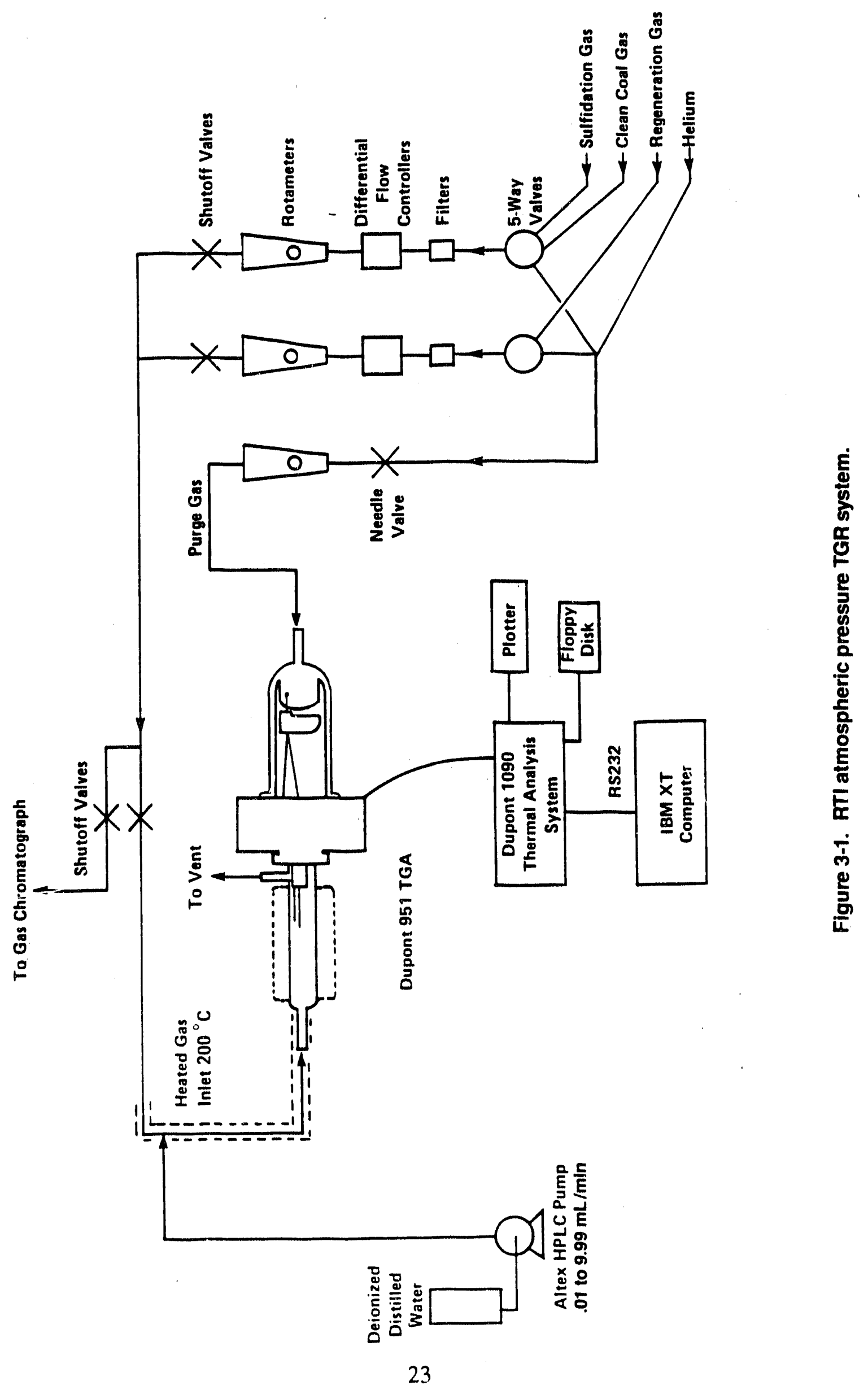




\subsubsection{Particle Size Analysis (PSA)}

Most sorbent particle size analyses during the project were conducted using a sieve train and a sonic sifter. Standard Tyler sieves were used to produce various particle size cuts. Since a major fraction of the sorbent used was coarser than 200 mesh $(75 \mu \mathrm{m})$, sieving worked very effectively although it was time consuming.

A Micromeritics Sedigraph 5100 was also acquired during this project but was not used as it was found to be unsuitable for measuring particle size distribution for zinc ferrite because the sorbent particles could not be dispersed.

\subsubsection{Pore Size Distribution}

Measurement of pore volume, pore volume distribution and median pore diameter using mercury intrusion provides a direct indication of the diffusional resistances associated with adsorption of $\mathrm{H}_{2} \mathrm{~S}$ and hence the reactivity of the sorbent. At RTI this is done with an Auto Pore II 9220 instrument manufactured by Micromeritics Instrument Company. The instrument is rated at $414 \mathrm{MPa}(60,000 \mathrm{psi})$ maximum and is capable of characterizing pores as small as $6 \mathrm{~nm}$, well below the desirable pore size of the sorbent which normally ranges between 150 and $350 \mathrm{~nm}$. Sulfidation in very small micropores can lead to pellet weakening/cracking. When the bigger sulfur atom replaces the smaller oxygen atom, stresses are created on small pore walls. These stresses can eventually lead to cracking and mechanical disintegration of the sorbent.

Mercury porosimetry is based on equilibrated intrusion of mercury into a porous material as a function of pressure. The sample is evacuated, immersed in mercury, and the mercury pressure on the sample is isostatically increased causing mercury to intrude into the pores. The displaced pore volume is inversely proportional to applied pressure. This permits a direct measurement of pore size and volume and provides the basis for providing related information.

The instrument is highly automated (interfaced with an IBM PC) and provides the following information:

- Pore volume,

- Median pore diameter (diameter at $50 \%$ intrusion),

- Pellet density (skeletal),

- Macro porosity (>50 $\mathrm{nm}$ ), and

- Tables and plots for

- cumulative pore volume vs. pressure and/or pore diameter

- differential pore volume vs. pressure and/or pore diameter.

\subsubsection{BET Surface Area}

BET surface area is an important property used in correlating sorbent reactivity with physical and chemical structure of the sorbent. Other properties include pore size and pore volume distributions, which have been discussed in the previous section. 
The most common method of measuring surface area and the one used routinely in most catalyst/sorbent studies is the BET method developed by Brunauer, Emmett and Teller (1938). The BET surface area is measured using a Quantasorb analyzer system at RTI. The surface area measurement in this system is based on the volume of nitrogen uptake by a known amount of sample at liquid nitrogen temperature $\left(-196^{\circ} \mathrm{C}\right)$. An outgassing station with a heating mantle is provided to degas the sample prior to measurement. Sample cells can be quickly interchanged between outgassing and measuring stations using quick-connect fittings that seal them from the atmosphere. Nitrogen is first adsorbed onto the sample at $-196^{\circ} \mathrm{C}$ by flowing a nitrogen-helium stream of known composition (in the range of 10 to 30 percent nitrogen) over the sample. Two mass flow controllers are used to accurately mix the gases in the required ratio. The sample is then quickly desorbed by placing the sample cell in warm water. The nitrogen desorption peak is measured by a calibrated thermal conductivity detector and integrated to yield the volume (and mass therefrom) of nitrogen adsorbed. This procedure is repeated for at least two other compositions in the 10 to 30 percent $\mathrm{N}_{2}$ range if a three-point surface area is desired. The mass adsorbed at different partial pressures is plotted using the standard BET equation. The details of the BET method and the plotting parameters are covered in several standard surface chemistry and kinetics texts (e.g., Satterfield, 1980).

\subsubsection{Attrition Resistance}

Attrition of the sorbent in fluidized-bed reactors is presently the biggest unknown in the design and operation of hot gas desulfurization systems. According to Zenz and Othmer (1960), purely mechanical attrition due to the collision of masses of particles in a fluidized-bed is relatively small. The principal cause of attrition during desulfurization is believed to be chemical transformations occurring in the sorbent, particularly in $\mathrm{Fe}_{2} \mathrm{O}_{3}$ reduction and zinc vaporization.

Sorbent attrition in the desulfurization reactor results in the production of fines that are entrained in the gas and lost. This lost sorbent must be replaced to maintain the desulfurization efficiency.

Bemrose and Bridgwater (1987) provide a comprehensive review of attrition test methods. The attrition rate for sorbents used in fixed-bed and moving-bed reactors is normally measured using ASTM procedure D-4058 (ASTM, 1981). However, for sorbents and catalysts used in fluidized-bed systems, there are no standard tests available. RTI has developed an attrition tester following the design of a high-velocity air jet apparatus by Forsythe and Hertwig (1949), also described by Anderson and Pratt (1985). Figure 3-2 shows RTI's attrition tester:

This device consists of a 2.54-cm i.d. quartz tube with a single 0.4-mm hole gas inlet and has the capability of cold and hot attrition tests as well as in-situ sulfidation and regeneration. During a typical attrition test of $1 \mathrm{hr}$ with a 50 -cc sorbent bed, the nitrogen gas flow was adjusted to $7 \mathrm{slpm}$ (at room temperature) to generate sonic velocity through the hole, which in turn provided high shearing and turbulence to the sorbent. The high shearing presumably produces measurable attrition and would simulate attrition in commercial fluid-bed reactors over a much longer period. The test was not intended to develop attrition rate data on an absolute basis, but instead was used to develop a measure of relative resistance to attrition to compare the different sorbents. 


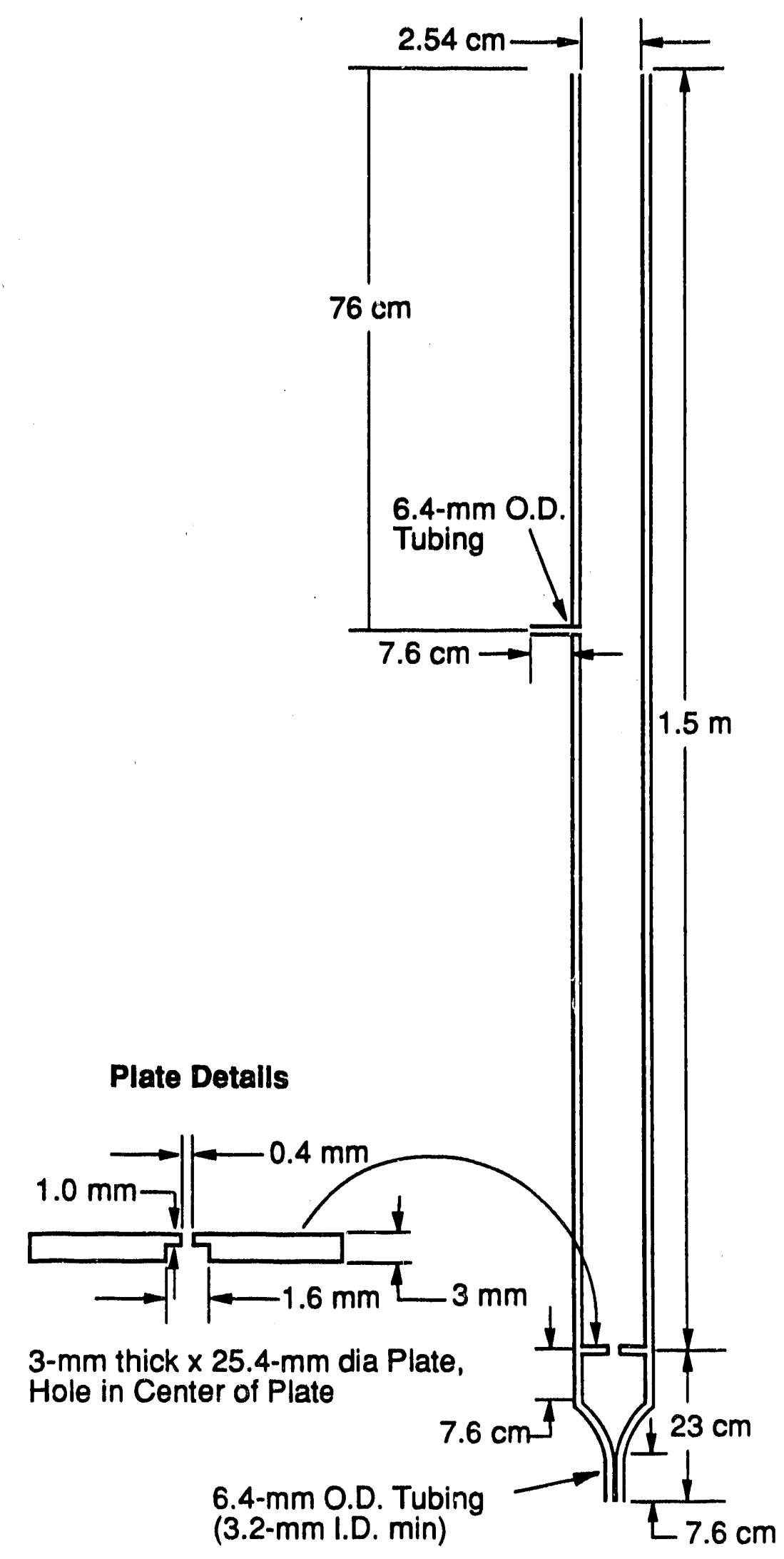

Not to Scale

Figure 3-2. Quartz attrition tube. 
The particle size distribution of the samply was measured before and after the test to determine the amount of fines produced below a wesignated cut point. For the particle size range of sorbent used is the bench-scale testing, i.e. $-50+140$ mesh, 140 mesh $(105 \mu \mathrm{m})$ was designated as the cut point. The attrition resistance $\left(A_{R}\right)$ was arbitrarily defined as

$$
A_{R}=100\left[1-\frac{B}{A}\right]
$$

where $A=$ Original sorbent amount tested less initial amount of fines (below cut point),

B = Increase in amount of fines of (below cut point) after test.

If $F$ is the weight of the sorbent initially charged in the attrition tube and $P$ is weight recovered, and $x$ and $y$ are the fractions of fines (below cut point) in feed and recovered sorbent, respectively, then $A_{R}$ can be written as:

$$
A_{R}=100\left[1-\left(\frac{F-P}{F}+(y-x)\right)\right] .
$$

Rearranging the above expression yields

$$
A_{R}=100\left[\frac{P}{F}-(y-x)\right]
$$

or

$$
A_{R}=100\left[\frac{\text { Sorbent after test }}{\text { Sorbent before test }} \text { - Increase in fraction of fines }\right] \text {. }
$$

A commercially available FCC catalyst was initially subjected to an attrition test in this device. The attrition resistance of the FCC catalyst was determined to be close to 100 percent. This attrition tester was also used for high temperature attrition testing, e.g., at $650^{\circ} \mathrm{C}$. The gas flow was adjusted to yield the same velocity through the tube as the room temperature test. The results showed that high-temperature attrition resistance for sorbents was higher than roomtemperature attrition resistance. The high-temperature attrition resistance measurements were thus not critical and were therefore terminated.

\subsubsection{Determination of Zinc and Iron Contents}

Zinc and iron contents of fresh and reacted sorbent samples were measured to determine any zinc loss that occurred during testing. Samples were analyzed by an Inductively Coupled Plasma (ICP) technique using a Leeman Plasma-Spec Sequential Spectrometer. Prior to the testing of actual samples, the spectrometer was calibrated using 200 and 0 ppm solutions of $\mathrm{Zn}$ and $\mathrm{Fe}$. $\mathrm{Zn}$ and $\mathrm{Fe}$ wavelengths are $213.86 \mathrm{~nm}$ (with a 3-sec integration time) and $259.94 \mathrm{~nm}$ (with a 2 -sec integration time), respectively.

A $0.05 \mathrm{~g}$ sorbent sample is weighed into a $120 \mathrm{~mL}$ microwave digestion vessel. The sample is dissolved in an acid mixture containing $3 \mathrm{~mL} \mathrm{HNO}, 2 \mathrm{~mL} \mathrm{HF}$, and $1 \mathrm{~mL} \mathrm{HCl}$ and digested for about $20 \mathrm{~min}$. The vessel is cooled and contents of the vessel are transferred to a 
$100 \mathrm{~mL}$ volumetric flask. The sample prepared is analyzed using ICP as described above. Duplicate samples are run to get an average value. 


\subsection{RESULTS AND DISCUSSION}

In order to determine long-term chemical reactivity and mechanical durability of various zinc ferrite sorbent formulations, ten multicycle tests were carried out in the bench-scale fluidized-bed reactor system. A complete description of the bench-scale reactor system along with the test procedure used has been presented in Chapter 2 of this report.

Prior to testing in the bench-unit, all sorbent formulations were screened using the TGA and other structural property measurements as discussed in Chapter 3 . Only the sorbents with acceptable TGA reactivity (sulfur capacity and regenerability) and attrition resistance were selected for bench-scale testing.

Table $4-1$ shows the sorbent formulations and operating conditions used for various benchscale runs, numbered sequentially as they were carried out. The initial five runs were conducted with crushed and screened T-2465MC zinc-ferrite sorbent (except the fourth run with AMAX sorbent) because it was the best available formulation at the time. Later runs were conducted with Norton and enhanced sorbents prepared by granulation.

The sulfidation gas used in all ten runs was a simulated KRW (Kellogg-RustWestinghouse originally, and now Kellogg) fluid-bed gasifier gas containing approximately 4,500 ppm of $\mathrm{H}_{2} \mathrm{~S}$. An average composition of sulfidation gas is given in Table 4-2. A higher steam content was used in the simulated gas than the actual gasifier gas to prevent iron carbide formation, excessive zinc-ferrite reduction, and zinc vaporization during sulfidation.

The total gas flow rate (including flow of steam) to the reactor was kept at approximately 35 standard liters per minute $\left(\mathrm{U} / \mathrm{N}_{\mathrm{nf}} \approx 3\right.$; to ensure adequate fluidization in the reactor. During sulfidation, in addition to $\mathrm{H}_{2} \mathrm{~S}$ removal, carbon monoxide present in sulfidation gas undergoes the shift reaction

$$
\mathrm{CO}+\mathrm{H}_{2} \mathrm{O}-\mathrm{CO}_{2}+\mathrm{H}_{2} \text {. }
$$

The shift reaction is catalyzed by zinc ferrite. Conversion of $\mathrm{CO}$ by the shift reaction depends on temperature and partial pressure of reactant and product species. While at $550^{\circ} \mathrm{C}$, 10 to 15 percent of the $\mathrm{CO}$ present in cosi gas was converted to $\mathrm{CO}_{2}$ and $\mathrm{H}_{2}$, at $650^{\circ} \mathrm{C}$ the extent of $\mathrm{CO}$ conversion was considerably higher, ranging from 25 to 35 pricent. The results thus indicated that equilibriu $\mathrm{m}$ of the shift was not achieved at $550^{\circ} \mathrm{C}$.

Regeneration of the sulfided sorbent was carried out with a gas containing 2 to 3 percent $\mathrm{O}_{2}$ in nitrogen at maximum temperatures up to $760^{\circ} \mathrm{C}$ and similar gas flow rates were used. Previous fixed-bed experience with zinc ferrite showed that $760^{\circ} \mathrm{C}$ was required to prevent sulfate formation (Gangwal et al., 1988). Table 4-3 shows the nominal regeneration conditions used in most of the runs. The end of regeneration was indicated when $\mathrm{SO}_{2}$ in the offgas fell below 250 pprnv. 


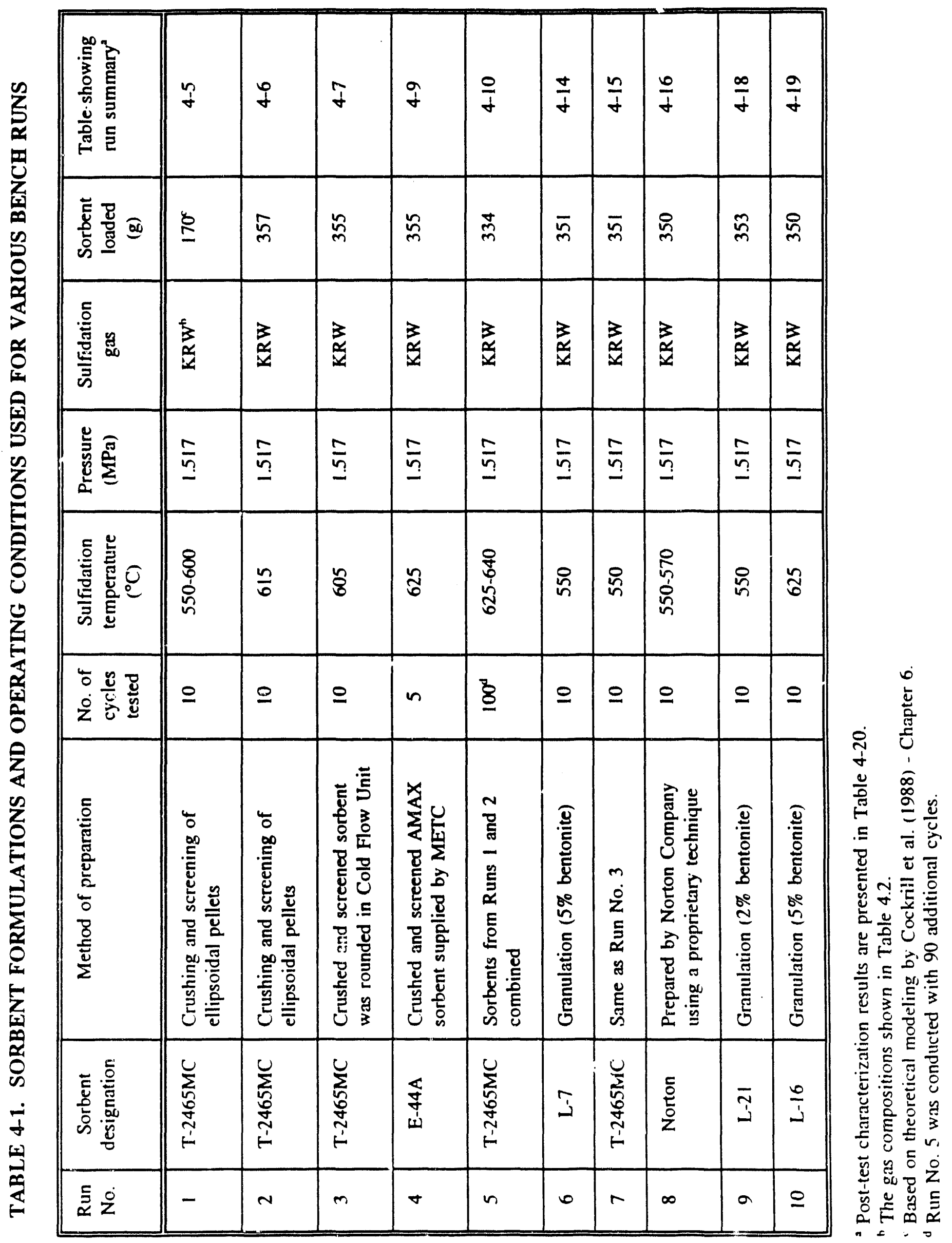


TABLE 4-2. NOMINAL COMPOSITION OF SULFIDATION GAS

\begin{tabular}{lc}
\hline Gas & $\begin{array}{r}\text { Composition } \\
\text { (volume \%) }\end{array}$ \\
\hline $\mathrm{H}_{2}$ & 9.00 \\
$\mathrm{CO}_{2}$ & 5.00 \\
$\mathrm{H}_{2} \mathrm{O}$ & 19.00 \\
$\mathrm{H}_{2} \mathrm{~S}$ & $0.45^{\wedge}$ \\
$\mathrm{N}_{2}$ & Balance \\
$\mathrm{CO}$ & 16.00 \\
\hline \hline
\end{tabular}

- 4500 ppm by volume.

b Approximately 50 percent.

TABLE 4-3. REGENERATION CONDITIONS FOR ZINC FERRITE TESTS

\begin{tabular}{ll}
\hline \hline Starting temperature & $=675^{\circ} \mathrm{C}$ \\
Pressure & $=1.5 \mathrm{MPa}^{\mathrm{a}}$ \\
Air flow rate & $=3.6 \mathrm{slpm}$ \\
Nitrogen flow rate & $=29.5 \mathrm{slpm}$ \\
Total gas flow rate & $=33.1 \mathrm{slpm}$ \\
$\mathrm{U} / \mathrm{U}_{\mathrm{mr}}$ & $=3.0-3.5^{\mathrm{a}}$ \\
\hline \hline
\end{tabular}

- Matched to sulfidation.
The principal reason for choosing nitrogen rather than steam as a diluent was ease of operation. Regeneration was significantly simpler to perform in the fluidized-bed system than in the fixed-bed system studied under a previous contract (DE-AC21-86MC23126). Regeneration was typically started at about $700{ }^{\circ} \mathrm{C}$ to provide a maximum bed temperature of $760{ }^{\circ} \mathrm{C}$ to prevent significant residual sultate formation. Furthermore, no reductive regeneration was necessary, as it was for the fixed-bed system.

The temperature rise of 50 to $60^{\circ} \mathrm{C}$ in the regeneration reaction in the fluidizedbed system was significantly lower than that in the fixed-bed reactor. This was due to better mixing of sulfided and unsulfided sorbent and efficient heat dissipation. The temperature profile during regeneration, as shown in Figure 4-1, indicates a parabolic profile during the first hour which attains a plateau around $760{ }^{\circ} \mathrm{C}$. It remains constant there for awhile, then drops very quickly, indicating the end of regeneration.

The rest of this chapter describes the pertinent details of each run in chronological order. Since it is not possible to include all experimental data for each cycle, data are summarized in tabies for each run.

\subsection{RUN NO. 1 - 10-CYCLE TESTING OF T-2465MC SORBENT}

Following the modifications to the bench-scale facility (discussed in Chapter 2) and a shakedown test with T-2465MC sorbent, the first 10-cycle test was carried out to determine optimum operating conditions. The zinc-ferrite sorbent T-2465MC used in this test and in the next few runs was prepared by crushing and screening the ellipsoidal pellets of T-2465MC prepared for GE by UCI. Table 4-4 shows the properties of T-2465MC sorbent pellets.

A summary of experimental data obtained during each cycle is presented in Table 4-5. For the first four cycles, a sulfidation temperature of about $550^{\circ} \mathrm{C}$ was used. The next six cycles were carried out at a sulfidation temperature of $600^{\circ} \mathrm{C}$. 


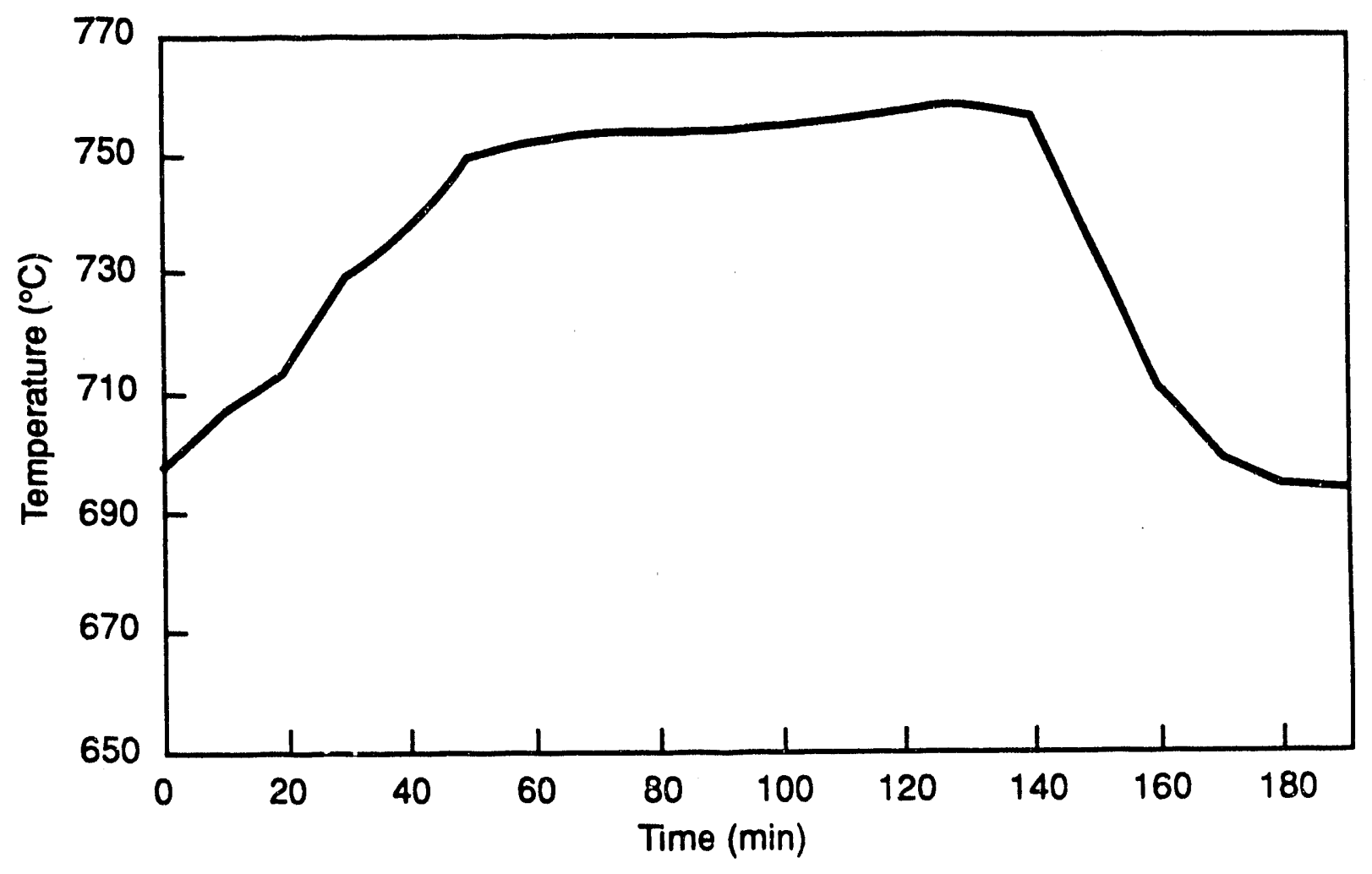

Figure 4-1. Temperature profile during regeneration. 
TABLE 4-4. PHYSICAL PROPERTIES OF T-2465MC SORBENT PELLETS

\begin{tabular}{ll}
\hline Zinc oxide & $: 34.0 \%$ (by weight) \\
Iron oxide & $: 64.0 \%$ (by weight) \\
Bentonite & $: 2 \%$ \\
Size & $: 0.32$ to $0.95 \mathrm{~cm}\left(1 / 8\right.$ to $\left.3 / 8^{\prime \prime}\right)$ \\
Shape & $:$ Ellipsoidal \\
Calcination temperature & $: 843{ }^{\circ} \mathrm{C}$ \\
Bulk density & $: 1.44 \mathrm{~g} / \mathrm{cm}^{3}$ \\
Pellet density & $: 2.57 \mathrm{~g} / \mathrm{cm}^{3}$ \\
Surface area & $: 4.6 \mathrm{~m}^{2} / \mathrm{g}$ \\
Pore volume & $: 0.2 \mathrm{~m}^{2} / \mathrm{g}$ \\
Mean pore diameter & $: 1958 \AA$ \\
Crush strength & $: 10.2 \mathrm{~kg} / \mathrm{pellet}$ \\
Attrition resistance & $: 95.4 \%$ \\
Theoretical sulfur capacity & $: 39 \mathrm{~g} / 100 \mathrm{~g}$ sorbent \\
\hline \hline
\end{tabular}

Prior to this run, a cold-flow model test was carried out to examine fluidization behavior of the sorbent. $v$ an ous values of $U / U_{\text {nf }}$ ranging from 0.86 to 3.0 were used and fluidization behavior was observed. It was found that the optimum $\mathrm{U} / \mathrm{U}_{\mathrm{mf}}$ ratio was about 3.0 , above which slugging might occur.

The results of Run 1 indicated that breakthrough (defined as $\mathrm{C}_{\mathrm{H}_{2} \mathrm{~S}}$, out $/ \mathrm{C}_{\mathrm{H}_{2} \mathrm{~S}}$, in $=0.1$ ) was achieved in a very short time, indicating either bypassing or insufficient packed height.

The amount of sorbent used in the reactor during this run was $179 \mathrm{~g}$. This number was obtained by modeling following the approach of Cockrill et al. (1988) and using Kunii and Levenspiel's bubbling-bed model (a brief description of the modeling approach is presented in Chapter 6). This model predicted a breakthrough time (defined as time to reach an outlet $\mathrm{H}_{2} \mathrm{~S}$ concentration equal to 10 percent of the inlet) of about $2 \mathrm{hr}$. The actual breakthrough time for this run, as shown in Figure 4-2, was only $0.5 \mathrm{hr}$. The model calculations had assumed an infinitely fast intrinsic rate constant. TGA tests, however, suggested that the intrinsic rate of reaction, in addition to gas and emulsion phase transfer rates, could represent a resistance to reaction. Also, the low intrinsic rate could probably be due to the fact that the sorbent was not reduced quickly enough; $\mathrm{ZnFe}_{2} \mathrm{O}_{4} \rightarrow \mathrm{ZnO}+\mathrm{Fe}_{3} \mathrm{O}_{4}$. Hence, various modifications were made in the model and are discussed in Chapter 6.

\subsection{RUN NO. 2 - 10-CYCLE TESTING OF T-2465MC SORBENT}

To alleviate the rapid $\mathrm{H}_{2} \mathrm{~S}$ breakthrough observed during Run No. 1, the sorbent charge to the reactor was doubled and $357 \mathrm{~g}$ of the sorbent were loaded. Estimated superficial contact time for this test was $2.9 \mathrm{sec}$ as compared to $1.6 \mathrm{sec}$ for Run No. 1. The superficial contact time 


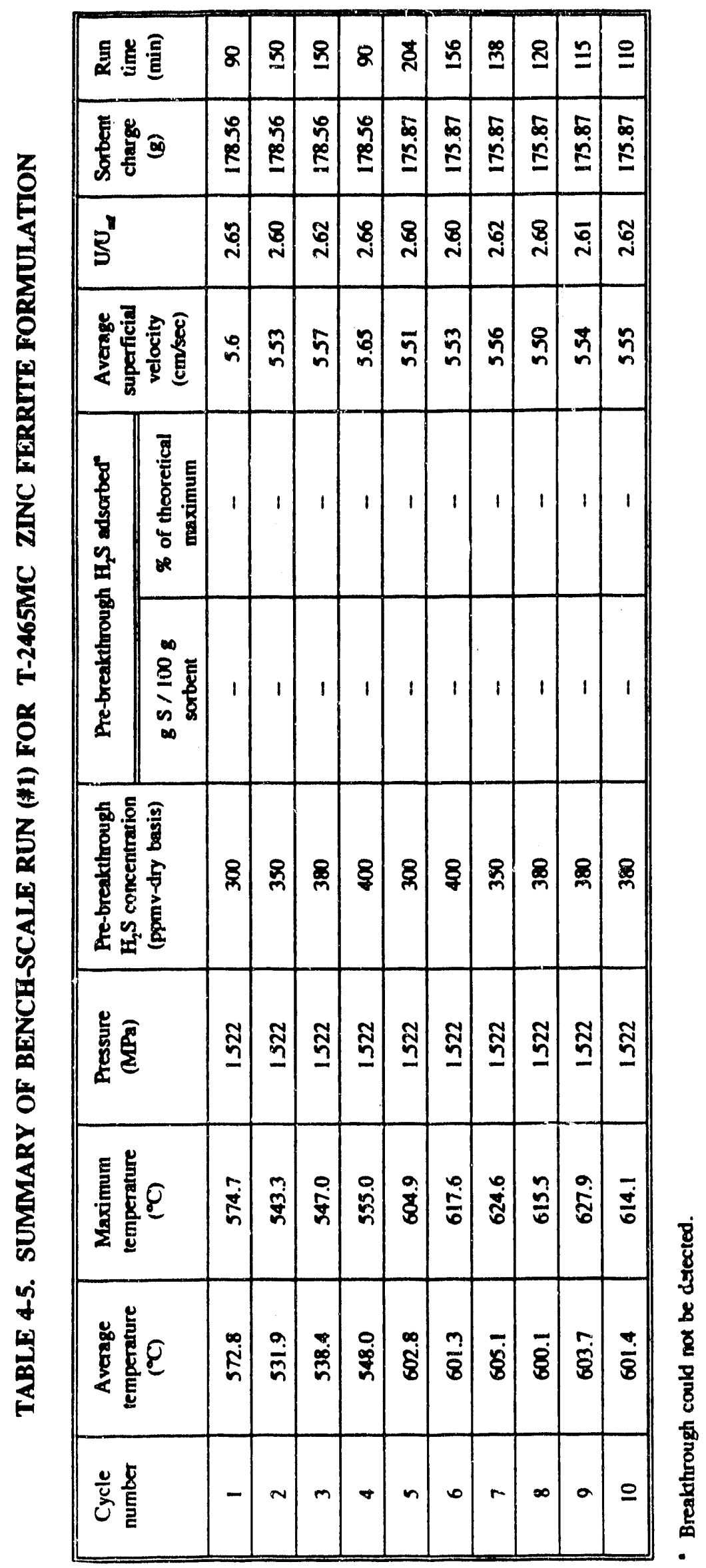




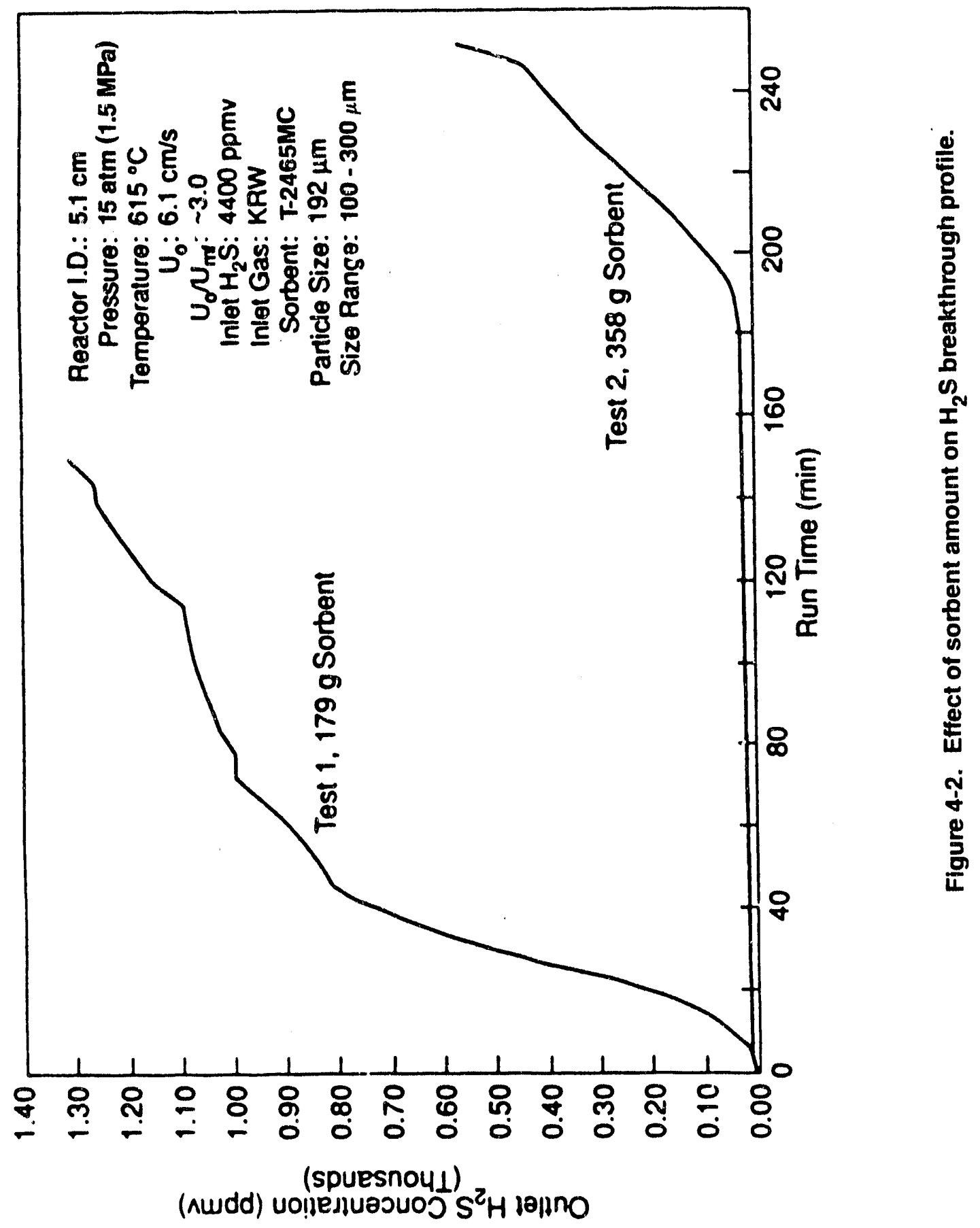


was calculated by dividing the extended bed height (approximately 1.3 times the static bed height observed in cold-flow model) by superficial velocity. The static bed height was estimated from the particle density $(2.57 \mathrm{~g} / \mathrm{cc})$ assuming a bed voidage of 0.4 .

Figure 4-2 shows the first cycle $\mathrm{H}_{2} \mathrm{~S}$ breakthrough curves for Runs 1 and 2 . Doubling the contact time signilicantly improves the scrubbing efficiency. Based on this finding, a $350 \mathrm{~g}$ sorbent charge was used as standard in all further runs.

Table 4-6 presents a summary of experimental data obtained for this run during each cycle. The attrition resistance of the sorbent, as indicated later in Table 4-20, was 94.3 and 78.0 percent before and after the test, respectively. Also, there was a significant increase in the fines content $(<100 \mu \mathrm{m})$ due to the reaction. Poor attrition resistance and fines generation on testing were possibly caused by the presence of sharp edges created by crushing the sorbent. Therefore, it was decided to eliminate the sharp edges by a long duration fluidization in the cold-flow unit.

\subsection{RUN NO. 3 - 10-CYCLE TESTING OF T-2465MC SORBENT (ROUNDED)}

The T-2465MC sorbent rounded in the cold flow model was used in this test. As usual, 10 cycles were carried out under essentially the same conditions as those used for Run No. 2. Table 4-7 gives the summary of pertinent experimental data obtained during each cycle. The attrition resistance after 10 cycles, reported later in Table 4-20, marginally improved from 78.1 percent for Run No. 2 to 81 percent for this run. Hence, rounding was not an effective method of preventing attrition loss. These results suggested that most of the loss was probably due to chemical transformations.

\subsection{RUN NO. 4 - 5-CYCLE TESTING OF AMAX E-44A SORBENT}

The sorbent designated E-44A, an extrudate preparation by AMAX, was found to be among the best by AMAX for fixed-bed applications (Jha et al., 1988). To determine its performance in a fluid-bed system, this sorbent was obtained from AMAX and was crushed and screened to a particle size of 100 to $300 \mu \mathrm{m}$. Table 4-8 shows the physical and chemical properties of this sorbent as specified by AMAX. Of particular note is the Ruthner process iron oxide used for this sorbent. This inexpensive iron oxide is available as a waste product of steel plants.

A 5-cycle bench-scale test was carried out with this sorbent under conditions essentially similar to those used for Runs 2 and 3. A summary of experimental data obtained during each cycle is presented in Table 4-9. The sorbent had excellent sulfur capacity (ranging from 12 to $19 \mathrm{~g}$ per $100 \mathrm{~g}$ of sorbent). However, sulfur capacity dropped sharply during the fifth cycle.

To investigate the drop in sulfur capacity, this run was tei minated after cycle 5 and the sorbent bed was examined. It was found that $62 \mathrm{~g}$ of sorbent (out of $356 \mathrm{~g}$ originally loaded) were deposited on the sulfidation filter. The particle size analysis of the remaining sorbent in the reactor showed a sharp decrease in average particle size from $136.5 \mu \mathrm{m}$ to $113.7 \mu \mathrm{m}$ with 


\begin{tabular}{|c|c|c|c|c|c|c|c|c|c|c|c|}
\hline \multicolumn{2}{|c|}{ 㤩首䨘 } & : & 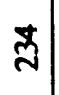 & సి & $\stackrel{\infty}{m}$ & \pm & $\bar{n}$ & $\stackrel{\infty}{\varrho}$ & 3 & $\mathscr{8}$ & $\stackrel{\Phi}{\infty}$ \\
\hline \multicolumn{2}{|c|}{ 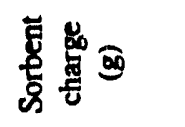 } & $\overline{\vec{n}}$ & $\overline{5}$ & $\overline{\overline{5}}$ & 官 & 京 & $\frac{\vec{n}}{n}$ & 㐫 & gू & 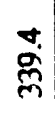 & 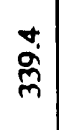 \\
\hline \multicolumn{2}{|l|}{$2^{\prime \prime}$} & $\stackrel{m}{\text { ọ }}$ & $\stackrel{0}{0}$ & $\underset{m}{\delta}$ & $\underset{m}{\stackrel{H}{m}}$ & $\underset{m}{t}$ & $\stackrel{n}{m}$ & $\stackrel{5}{m}$ & $\stackrel{n}{\tilde{m}}$ & \$ & $\stackrel{2}{2}$ \\
\hline \multicolumn{2}{|c|}{ 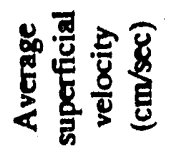 } & ్ㅐㅇ & \begin{tabular}{l}
\multirow{}{0}{} \\
.
\end{tabular} & $\frac{0}{0}$ & กี่ & $\overline{\text { ปี }}$ & $\mathbb{Z}$ & ปิ & $\overline{\tilde{\vartheta}}$ & $\frac{0}{6}$ & o. \\
\hline \multirow{2}{*}{ 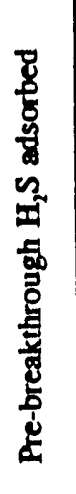 } & 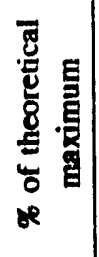 & 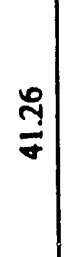 & 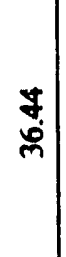 & 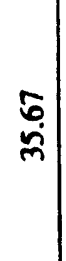 & $\frac{g}{\vec{n}}$ & $\stackrel{\circ}{\stackrel{2}{N}}$ & $\hat{n}$ & స్ల & 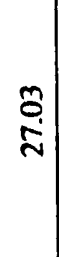 & ì & 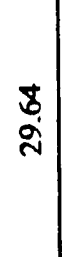 \\
\hline & 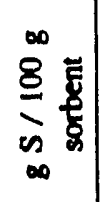 & $\begin{array}{l}8 \\
0 \\
0\end{array}$ & $\overline{\tilde{Z}}$ & $\begin{array}{l}\bar{a} \\
\stackrel{m}{2}\end{array}$ & $\underset{\infty}{\infty}$ & $\begin{array}{l}n \\
0\end{array}$ & $\frac{7}{a}$ & 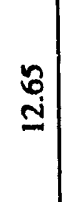 & $\begin{array}{l}\text { जे } \\
\text { Q }\end{array}$ & $\underline{n}$ & $\underline{n}$ \\
\hline \multicolumn{2}{|c|}{ 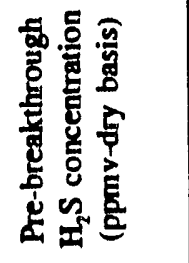 } & $\stackrel{\circ}{v}$ & 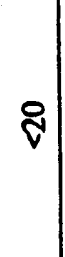 & ষ্ণ & $\underset{\nabla}{\nabla}$ & 疋 & i & రి & 요 & 尺 & \& \\
\hline \multicolumn{2}{|c|}{ 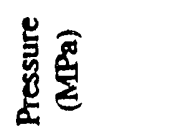 } & $\underline{\Xi}$ & สี & $\begin{array}{l}\mathcal{Z} \\
\beth\end{array}$ & ปี & สี & ָี & ปี & $\stackrel{\widetilde{\sim}}{\beth}$ & ปี & $\stackrel{\Sigma}{\beth}$ \\
\hline \multicolumn{2}{|c|}{ 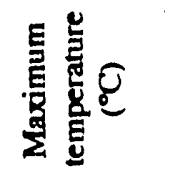 } & $\frac{\Upsilon}{\overparen{D}}$ & 8 & $\begin{array}{l}a \\
\dot{0} \\
0\end{array}$ & $\underset{\frac{1}{0}}{\frac{\pi}{0}}$ & $\begin{array}{l}0 \\
\dot{8} \\
\end{array}$ & ర్రి & శ్రి & 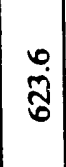 & จุ & $\ddot{0}$ \\
\hline \multicolumn{2}{|c|}{ 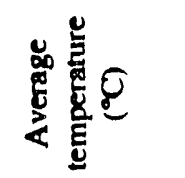 } & 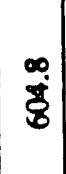 & $\stackrel{\mathfrak{I}}{\mathfrak{I}}$ & $\stackrel{\infty}{\stackrel{\infty}{J}}$ & $\begin{array}{l}n \\
8 \\
8\end{array}$ & $\begin{array}{l}\infty \\
\stackrel{i}{0}\end{array}$ & $\frac{2}{6}$ & \begin{tabular}{l}
$\infty$ \\
\multirow{\Delta}{0}{}
\end{tabular} & $\frac{\infty}{0}$ & $\frac{\pi}{5}$ & $\frac{n}{6}$ \\
\hline \multicolumn{2}{|c|}{ 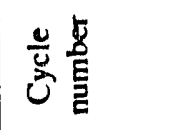 } & - & $N$ & $m$ & $\nabla$ & $n$ & 0 & $r$ & $\infty$ & $a$ & $\stackrel{0}{0}$ \\
\hline
\end{tabular}




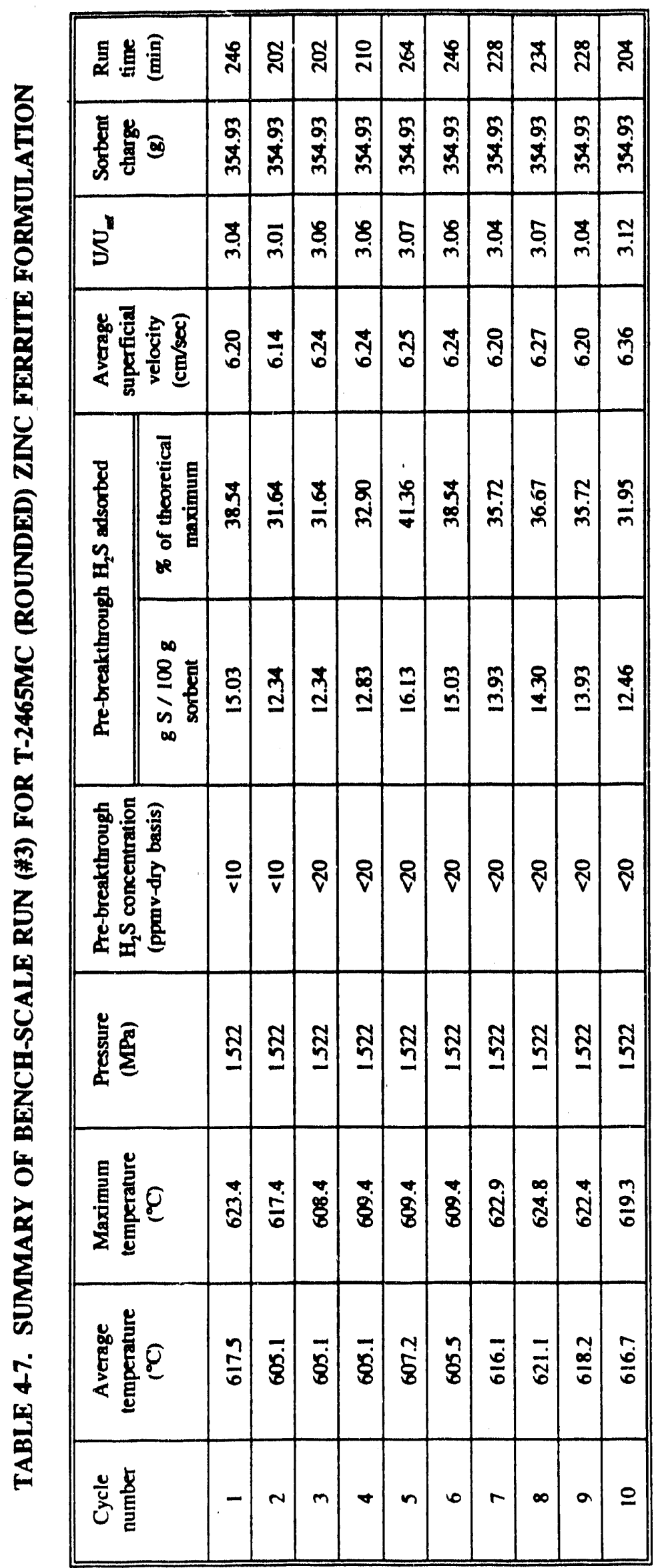


TABLE 4-8. PHYSICAL AND CHEMICAL PROPERTIES OF E-44A SORBENT

\begin{tabular}{lll}
\hline \hline Iron oxide type & $:$ & Ruthner Process \\
$\mathrm{ZnO}_{\mathrm{Fe}} \mathrm{O}_{3}$ ratio & $:$ & 1.0 \\
Bentonite & $:$ & $2 \%$ \\
Organic binder & $:$ & $815^{\circ} \mathrm{C}, 0.5 \mathrm{hr}$ \\
Calcination condition & $:$ & 1.33 \\
Bulk density $(\mathrm{g} / \mathrm{cc})$ & $:$ & 2.0 \\
Crush strength $(\mathrm{kg} / \mathrm{mm})$ & $:$ & 98.7 \\
Attrition resistance $(\%)$ & $:$ & 2.92 \\
Surface area $\left(\mathrm{m}^{2} / \mathrm{g}\right)$ & $:$ & 0.22 \\
Total pore volume $(\mathrm{cm} / \mathrm{g})$ & 1110 \\
Average pore radius $(\AA)$ & $:$ & \\
Porosity $(\%)$ & $:$ & 46.1 \\
$\quad$ Pores $>0.18 \mu \mathrm{m}$ & $:$ & 52.3 \\
$\quad$ Pores $>0.012 \mu \mathrm{m}$ & $:$ & 26.6 \\
Zinc (wt. \%) & $:$ & 43.9 \\
Iron (wt. \%) & $:$ & 0.018 \\
Silfur (wt. \%) & 0.02 \\
Chlorine (wt. \%) &
\end{tabular}

attrition resistance of 76 percent. Due to an unacceptable level of attrition, further testing of this sorbent was terminated. This run, however, showed that no direct correlation exists between sorbent performance in fixed bed and fluid bed.

\subsection{RUN NO. 5 - 100-CYCLE TESTING OF T-2465MC SORBENT}

The objective of this run was to determine the long-term (i.e., over 100-cycles) chemical reactivity and mechanical durability of zinc ferrite sorbent T-2465MC. The sorbent used for this run was obtained by combining the remaining spent sorbent from Runs 1 and 2, which had already undergone 10 cycles. The combined sorbent was subjected to 90 additional cycles. A summary of experimental data obtained during each cycle is presented in Table 4-10.

After every 10 cycles, the bed material was removed and analyzed for particle size distribution. Figure 4-3 shows that the mean particle size of the sorbent did not decrease significantly. The mean particle size of the fresh sorbent was $192 \mu \mathrm{m}$, and after 100 cycles it became $180 \mu \mathrm{m}$. Table 4-11 shows the particle size distribution and attrition resistance of the fresh sorbent after 10 cycles and after 100 cycles, while Figure 4-4 shows the sorbent wiight as a function of cycle number. It is clear from this figure that the sorbent was steadily lost from the bed over 100 cycles. The initial weight of the sorbent charged in the reactor was $357 \mathrm{~g}$; and after 100 cycles the amount collected from the reactor was $190 \mathrm{~g}$. Thus, the total material loss was $167 \mathrm{~g}$. This included a material loss of approximately $17 \mathrm{~g}$ caused by loading and unloading of the sorbent after every 10 cycles from sorbent characterization. Thus, approximately 47 


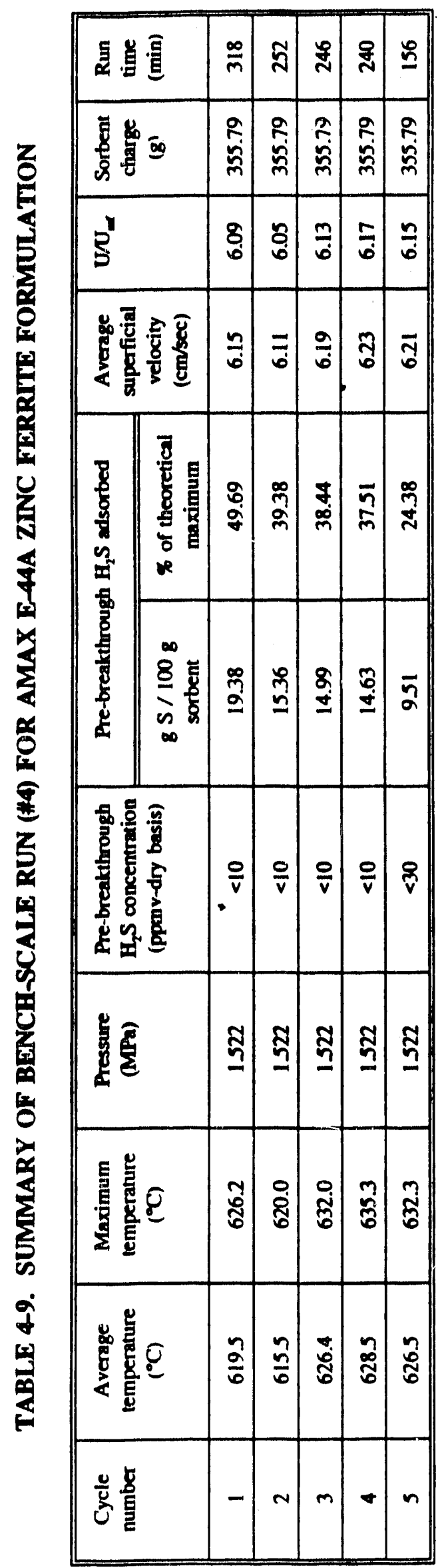




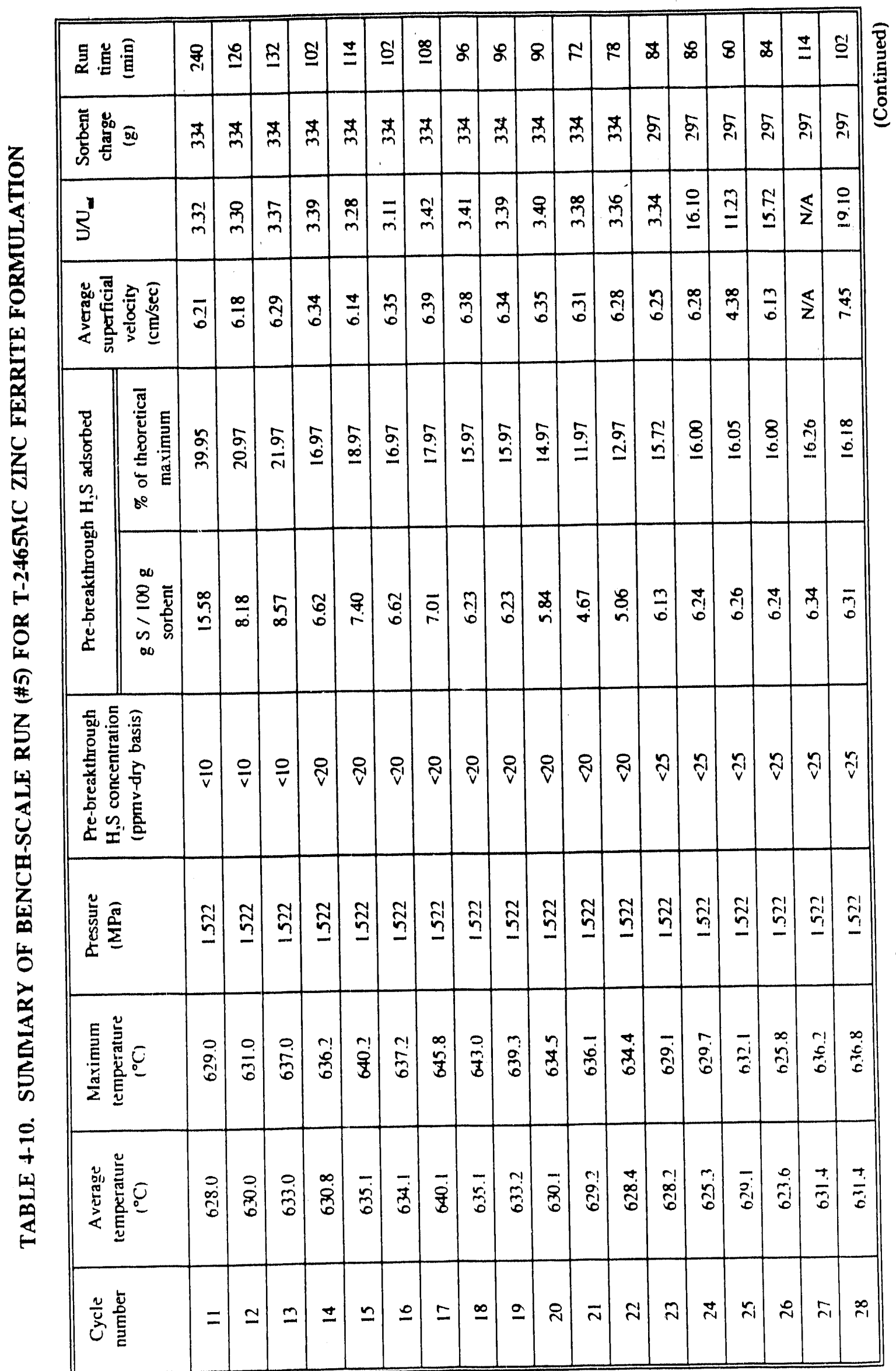




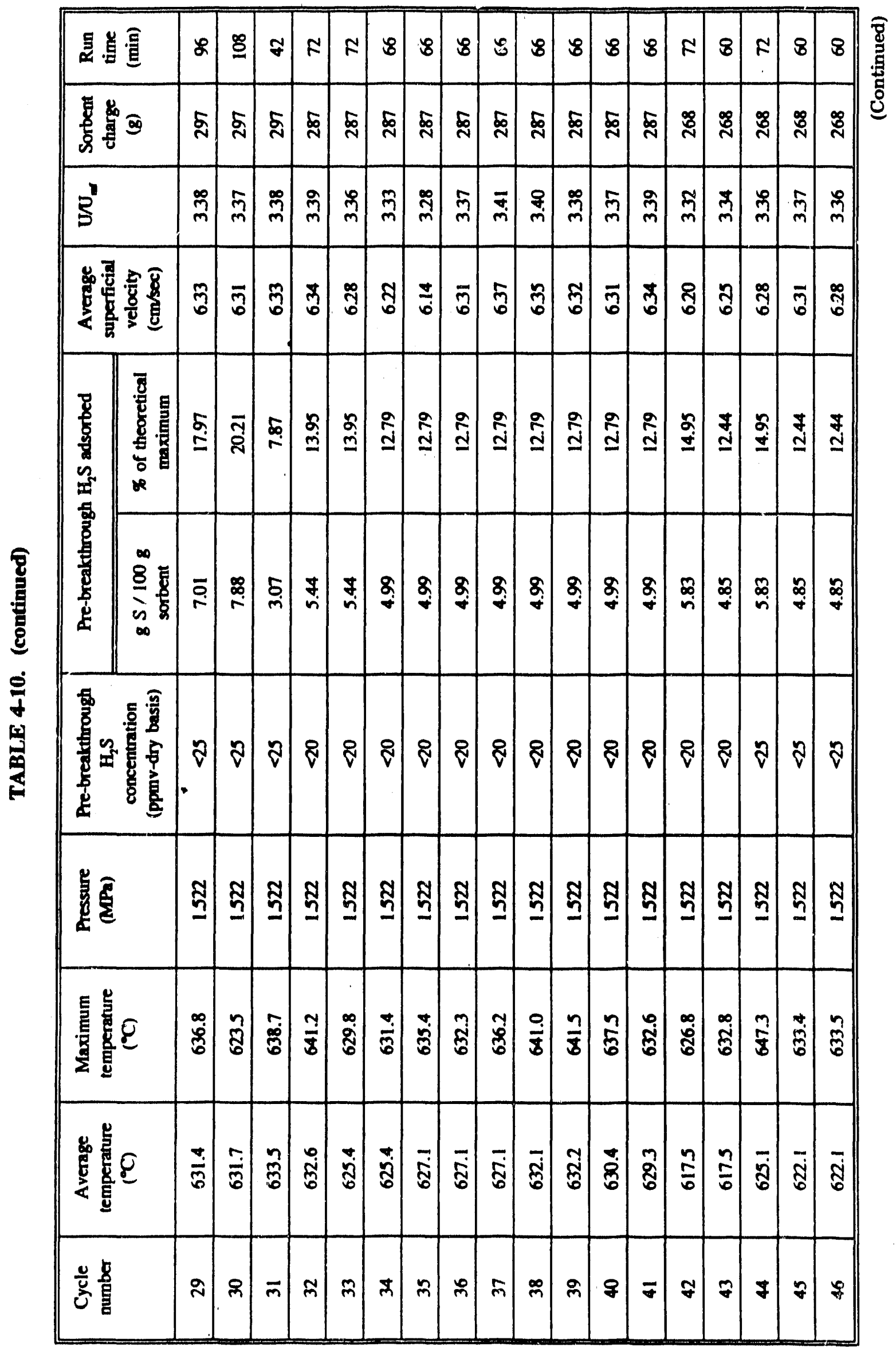




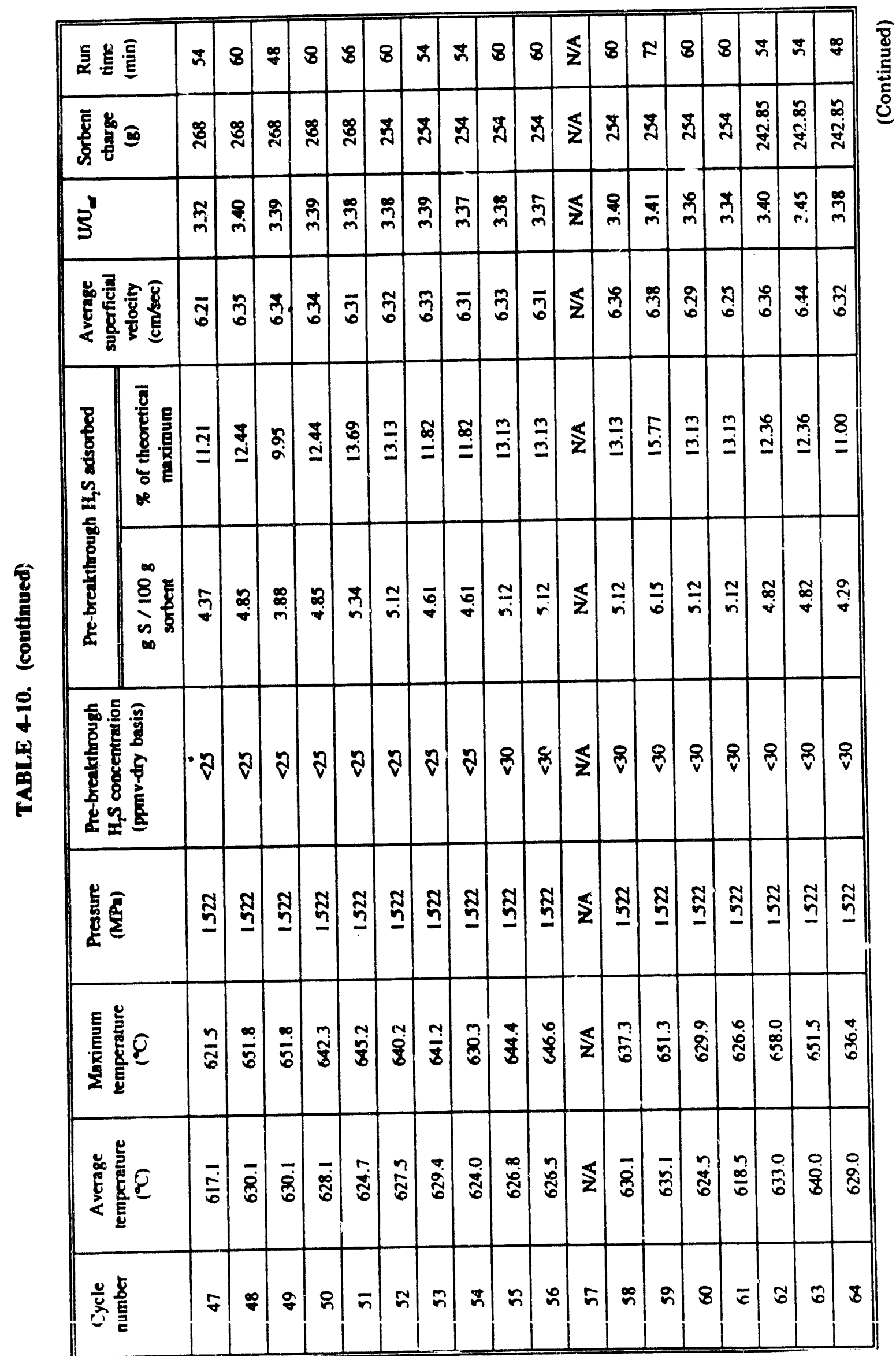




\begin{tabular}{|c|c|c|c|c|c|c|c|c|c|c|c|c|c|c|c|c|c|c|}
\hline 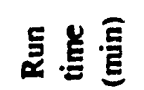 & $q$ & $\stackrel{\infty}{q}$ & 8 & मे & ह & \& & म & $\mathcal{F}$ & $\mathcal{F}$ & జొ & 8 & q & 이 & ల్లి & p & ळ & $\stackrel{\infty}{\infty}$ & ஜ \\
\hline
\end{tabular}

\begin{tabular}{|c|c|c|c|c|c|c|c|c|c|c|c|c|c|c|c|c|c|}
\hline & & & & & & & & & & & & & & & & & \\
\hline 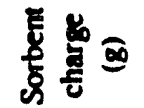 & 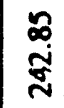 & 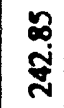 & $\left|\begin{array}{l}0 \\
\dot{u} \\
\end{array}\right|$ & $\mid \begin{array}{l}8 \\
\mathfrak{j} \\
\end{array}$ & 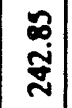 & $\mid$ & $\begin{array}{l}\infty \\
\stackrel{a}{\sim} \\
\end{array}$ & $\bar{\phi}$ & $\overline{\dot{\omega}}$ & $\overline{\tilde{\omega}}$ & $\bar{\phi}$ & $\bar{\phi}$ & $\overline{\tilde{n}}$ & $\nexists$ & $\overline{\dot{p}}$ & ळి & \\
\hline
\end{tabular}

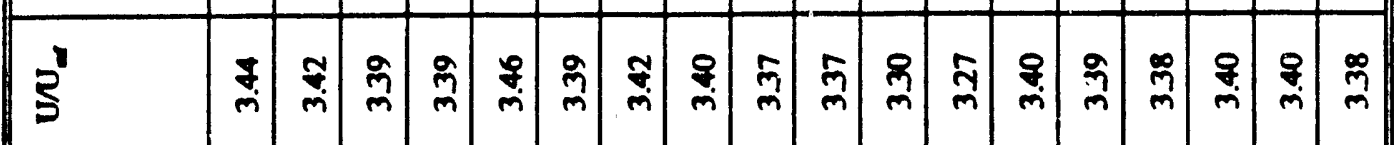

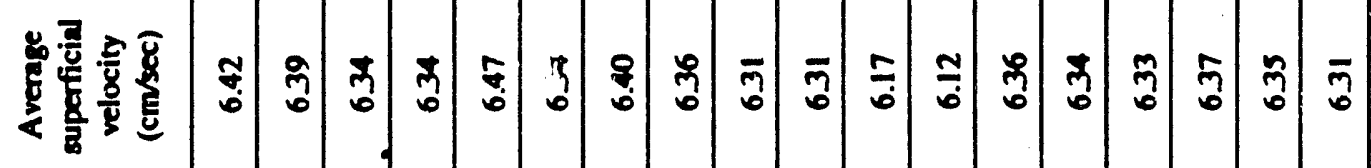

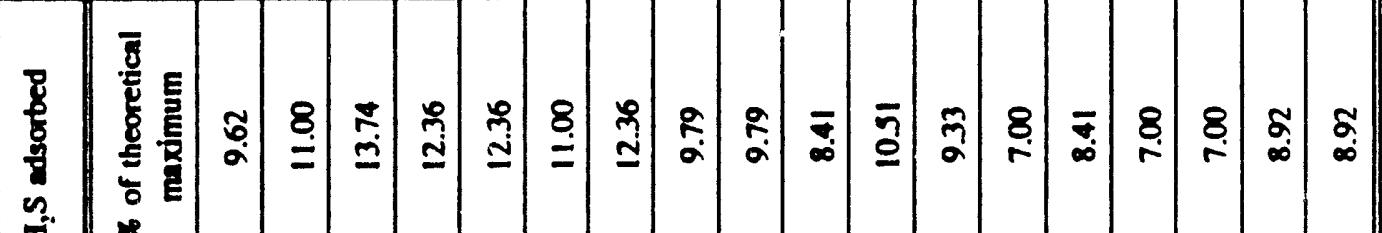

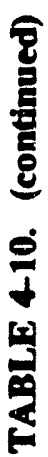

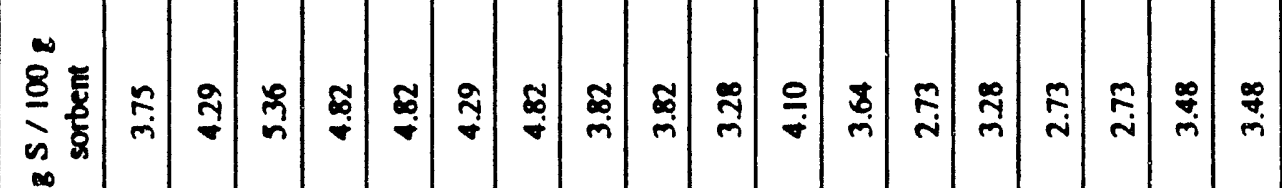

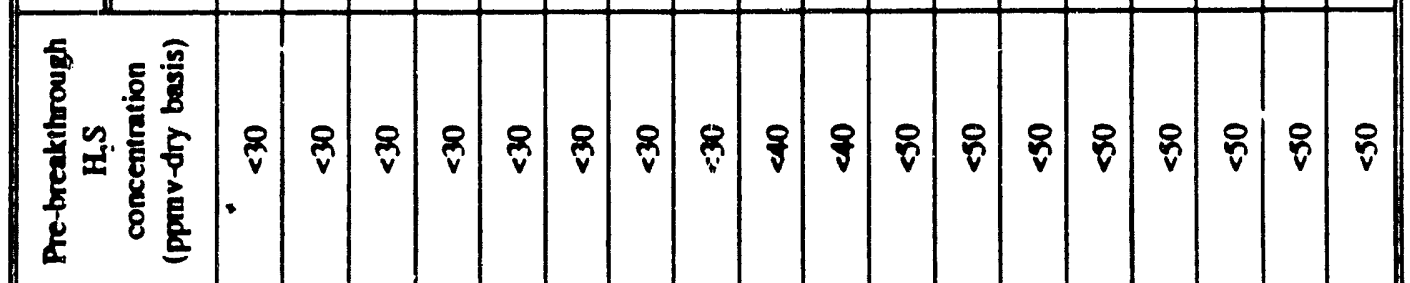

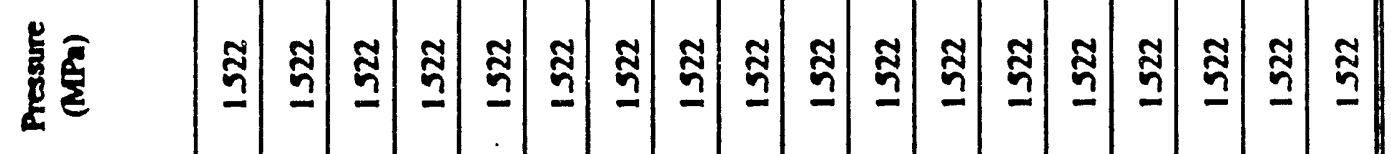

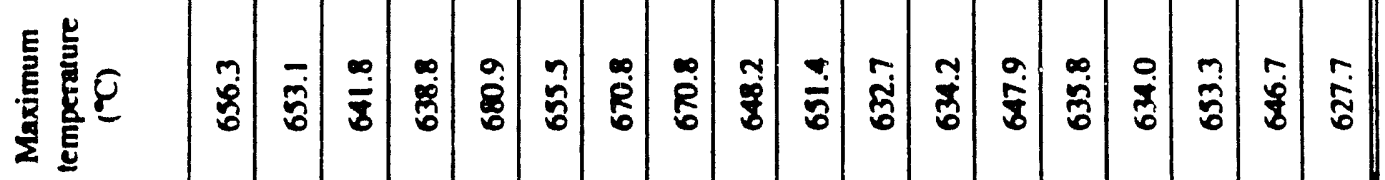

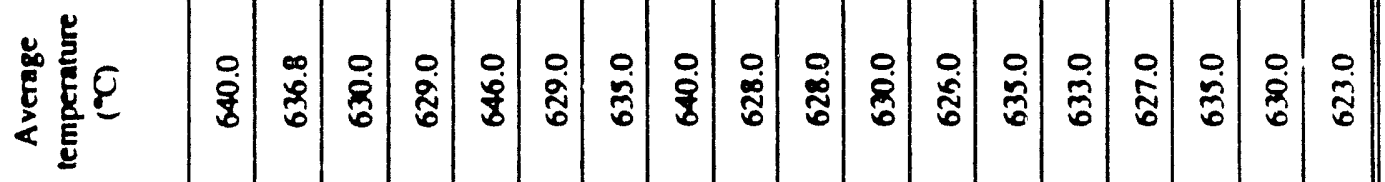

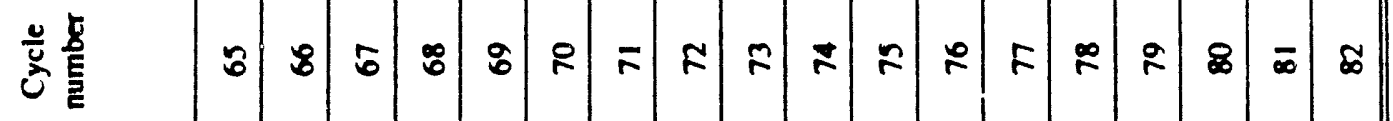




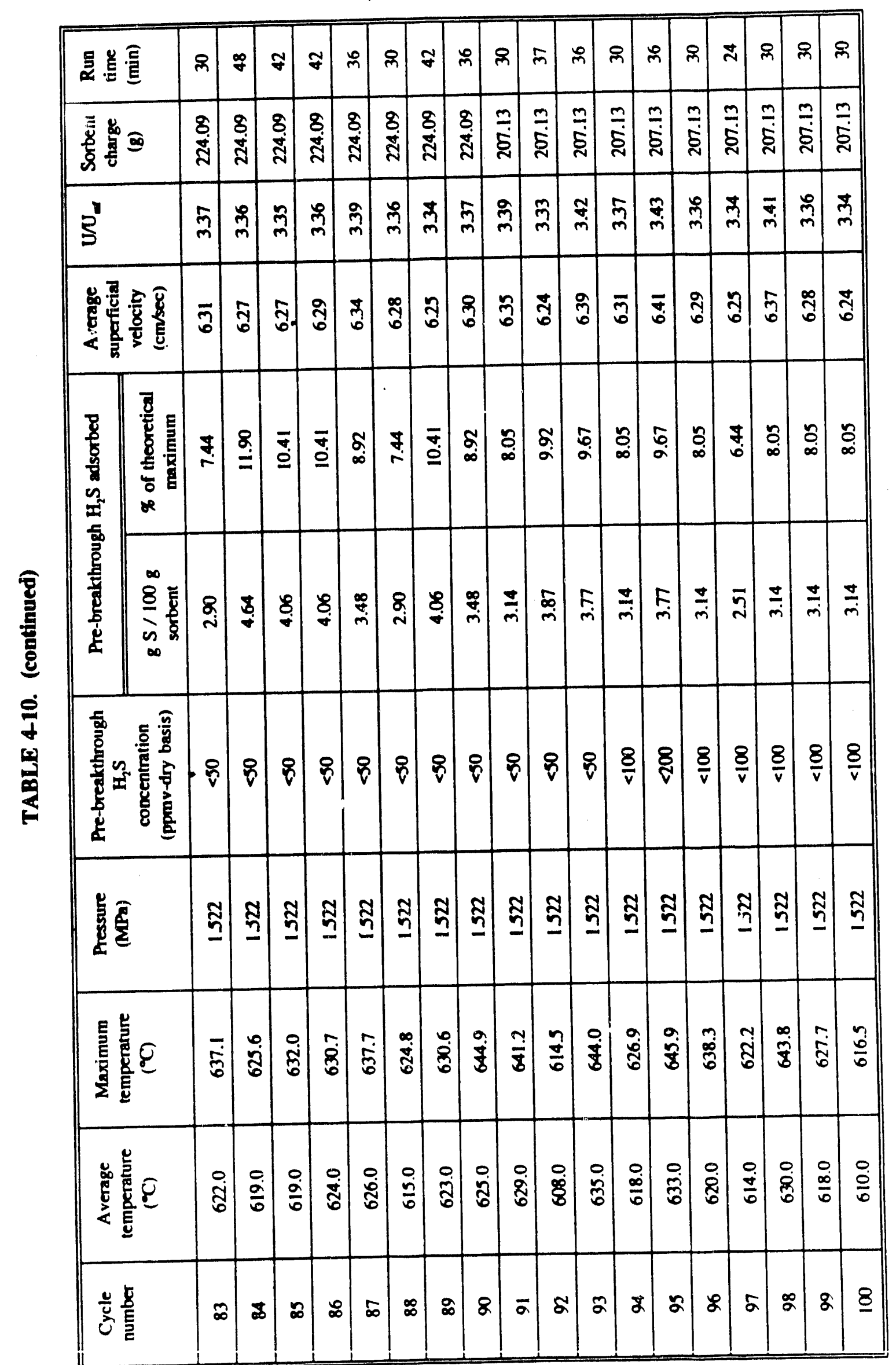




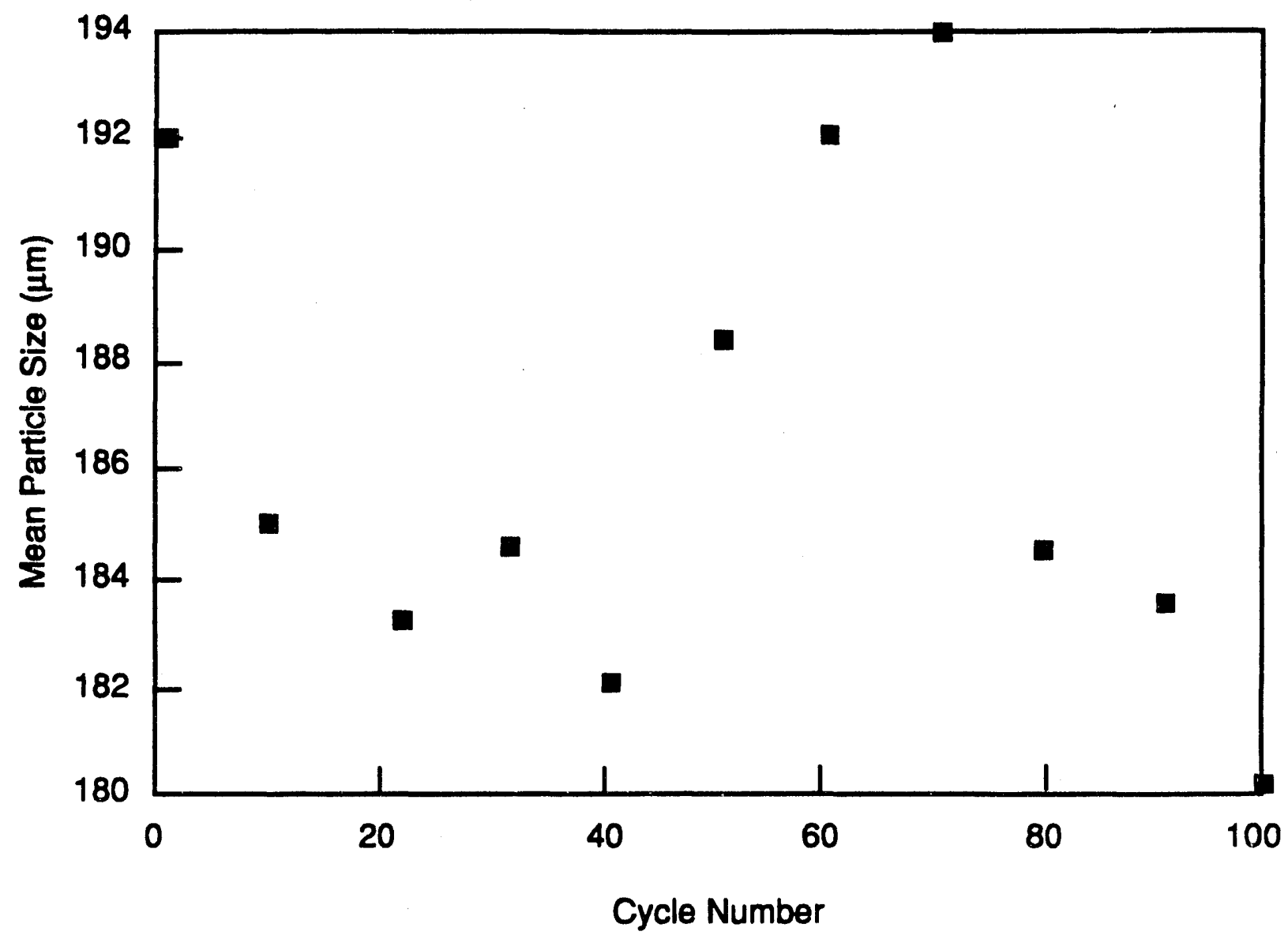

Figure 4-3. Sorbent mean particle size in a fluldized-bed reactor. 


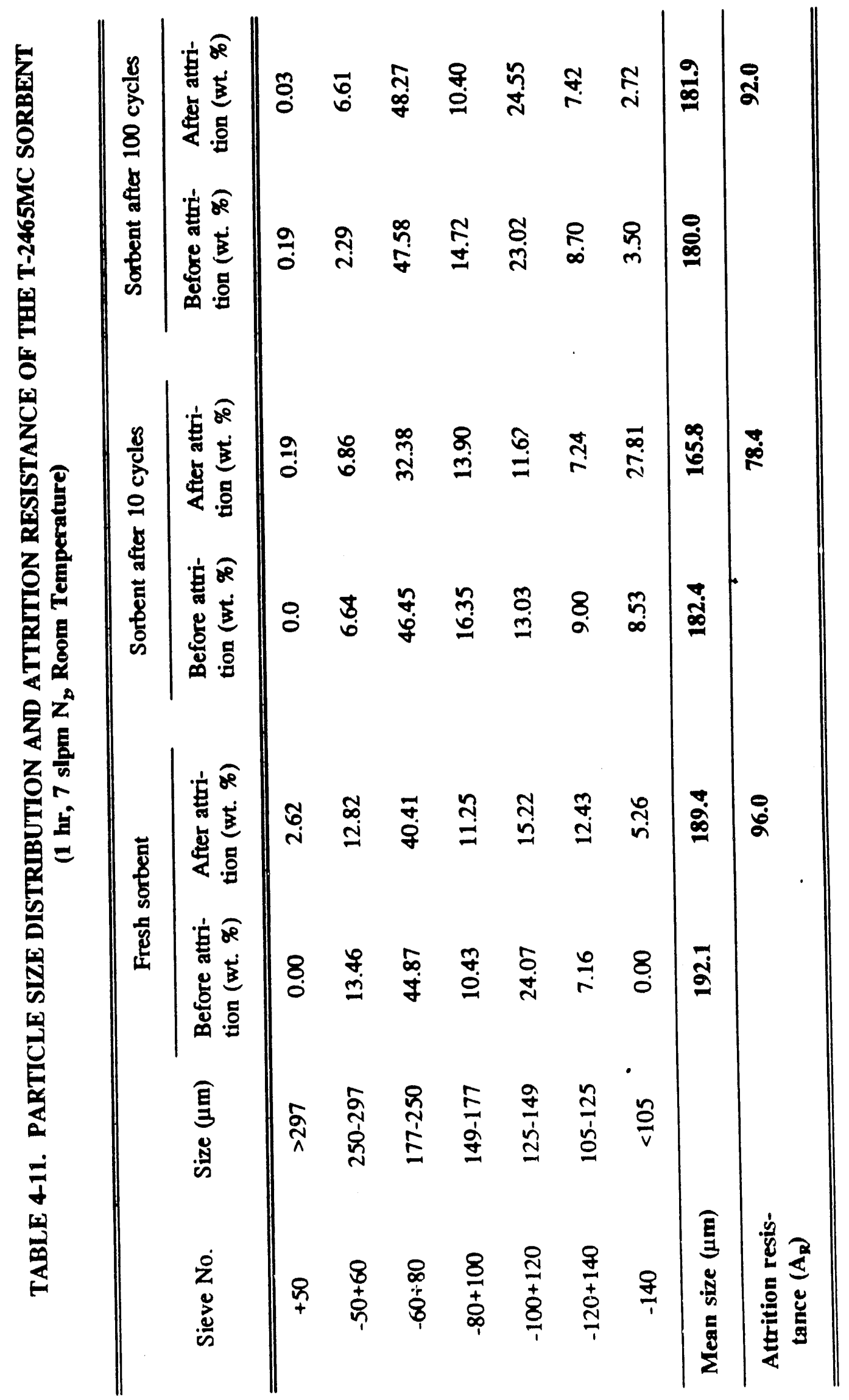




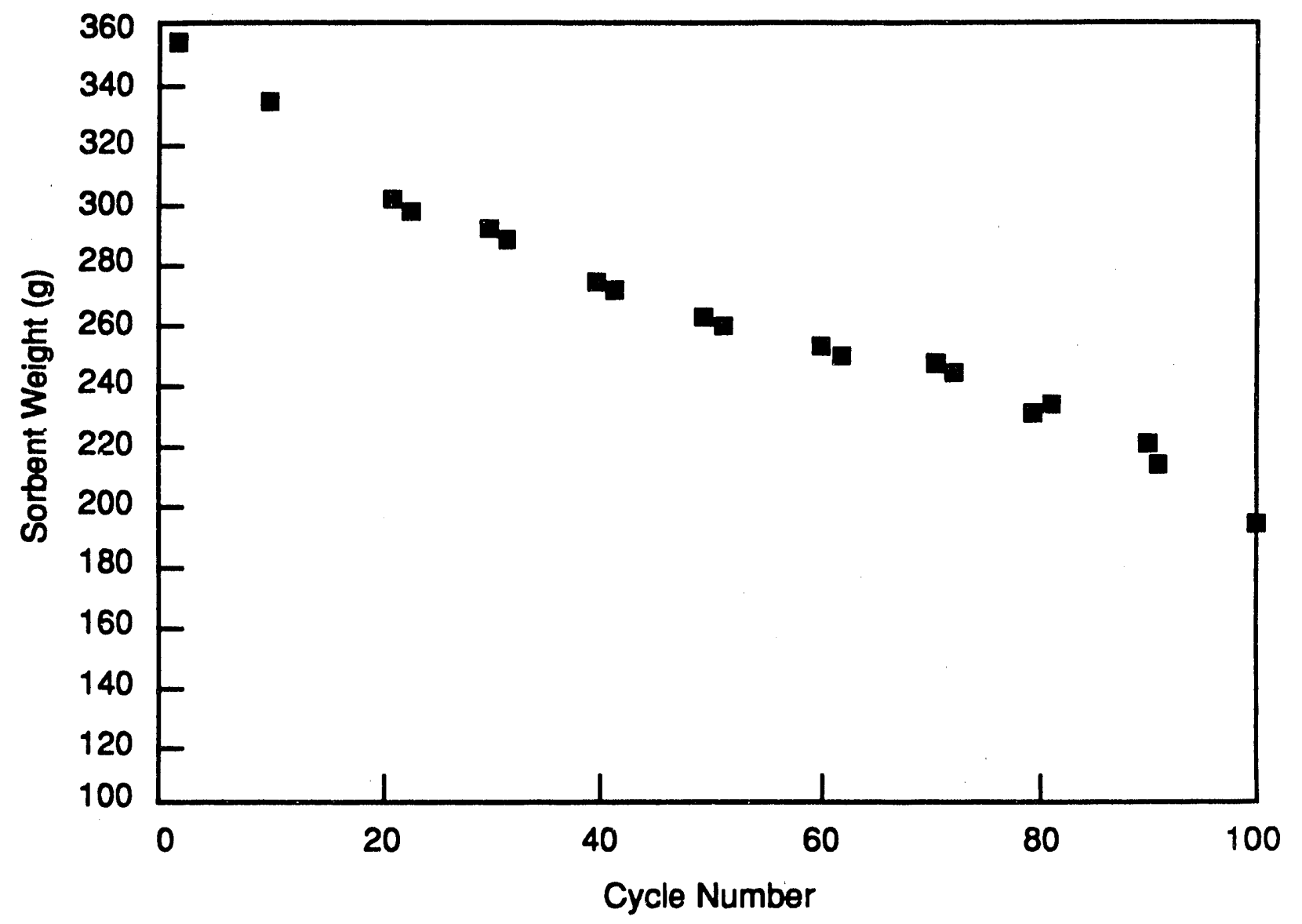

Figure 4-4. Sorbent loss in a fluidized-bed reactor. 
percent of the sorbent from the bed was lost because of attrition/carryover and sorbent loading/unloading. Actual losses caused by attrition and carryover were 42 percent.

Figure 4-5 shows the sulfur loading capacity as a function of cycle number. Data used for this figure are reported in Table 4-10. Figure 4-5 shows that sulfur capacity for the first cycle is $16 \mathrm{~g} \mathrm{~S} / 100 \mathrm{~g}$ fresh sorbent while the capacity at the end of 100 cycles is only $3 \mathrm{~g} \mathrm{~S} / 100 \mathrm{~g}$. The sulfur capacities are calculated at an $\mathrm{H}_{2} \mathrm{~S}$ breakthrough of 500 ppmv. Figure 4-5 also shows that sulfur capacity dropped rapidly over the first 30 cycles and stabilized somewhat over the remaining 70 cycles. The average sulfur capacity over 100 cycles was approximately 5 percent. The loss in capacity over 100 cycles could be explained by a combination of reasons, such as:

- Loss in reactivity caused by changes in the chemical and physical characteristics of the sorbent, and

- Loss of sorbent in the reactor due to elutriation causing a reduction in contact time (due to decreased bed height).

The $\mathrm{H}_{2} \mathrm{~S}$ content of reactor exit gas, however, was consistently below 20 ppmv as reported in Table 4-10.

To further investigate the reduction in sorbent capacity and attrition resistance, the structural and chemical properties of fresh sorbent were compared to that of the 100 cycle material (this comparison is shown later in Table 4-20).

The reduction in pore volume and surface area is consistent with the loss in sorbent sulfur capacity. The median pore diameter increased significantly, indicating the collapse of smaller pores into larger pores. This increase in pore diameter is probably related to the high attrition loss as discussed later. The pore size distribution of the reacted sample was significantly broader than that of the fresh sample. The zinc loss from the sorbent was approximately $8 \mathrm{wt}$. percent over 100 cycles. It was expected that a lower temperature of operation $\left(538\right.$ to $\left.566^{\circ} \mathrm{C}\right)$ would significantly reduce the zinc loss. Hence, a 10 -cycle run was made with $\mathrm{T}-2465 \mathrm{MC}$ at $550{ }^{\circ} \mathrm{C}$ to confirm this observation (Run No. 7) (discussed in Section 4.7).

The loss in reactivity of the sorbent appears to be primarily due to changes in pore structure characteristics. The TGA sulfur capacity (arbitrarily defined as weight fraction at 120 min secund sulfidation - for further discussion see Section 3.3.1 in Chapter 3) decreased from 1.082 tu 1.058, as shown later in Table 4-20. Attrition resistances $\left(A_{R}\right)$ of the fresh sorbent, the sorbent after 10 cycles, and the sorbent after 100 cycles were 96 percent, 78.4 percent, and 92 percent, respectively, as shown in Table 4-11. Thus, attrition resistance decreased, bottomed out, and then increased with cycling.

Based on the above results, it was hypothesized that although there may be some mechanical attrition loss initially, most of the loss after cycle 10 was due to chemical transformations leading to sorbent particle weakening, breakup, and carryover. Two principal 


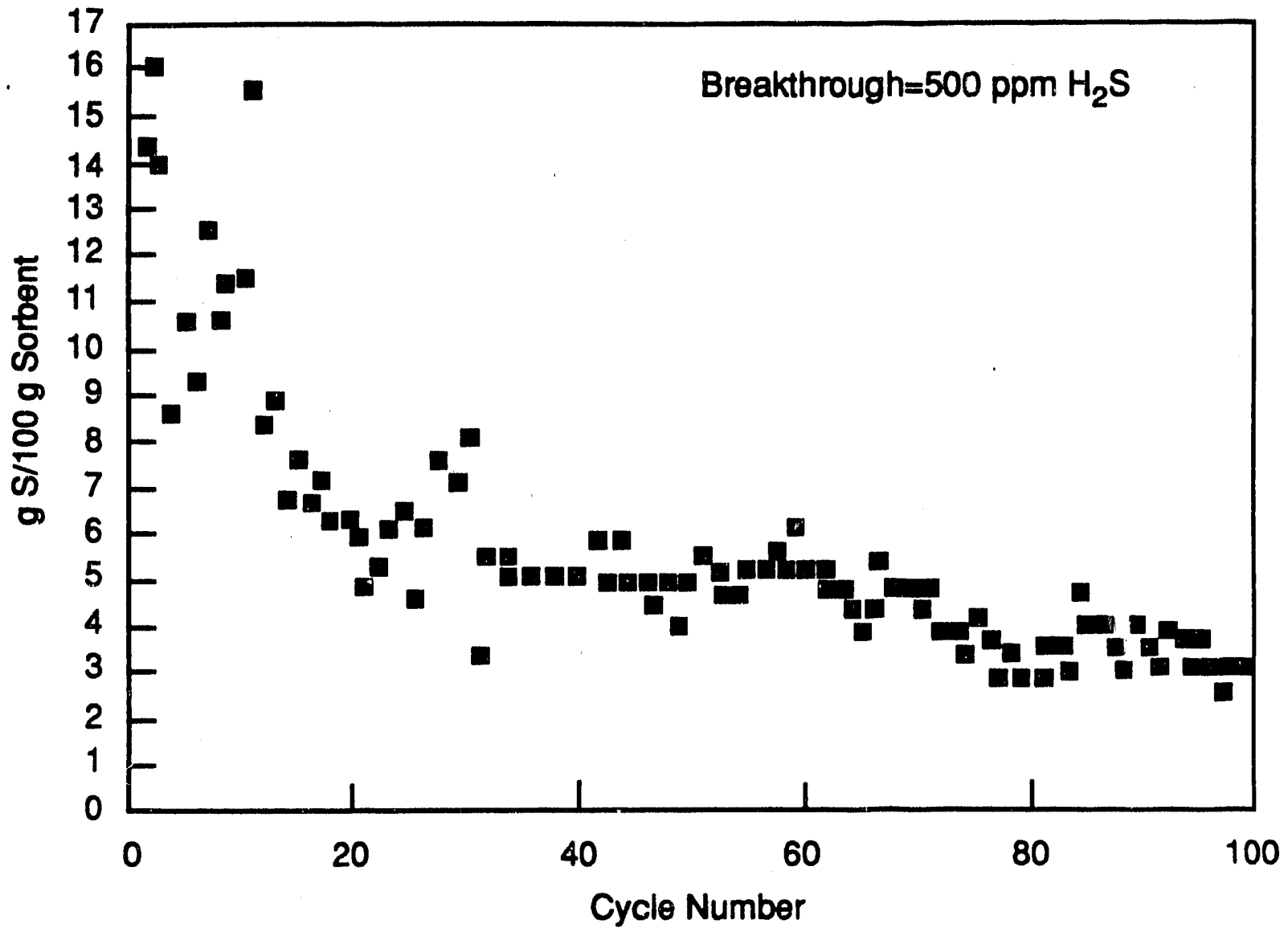

Figure 4-5. Sorbent capacity in a fluldized-bed reactor. 
detrimental reactions are postulated to be a reduction of $\mathrm{Fe}_{2} \mathrm{O}_{3}$ to $\mathrm{FeO}$ or carbide and $\mathrm{ZnO}$ to $\mathrm{Zn}$ followed by zinc evaporation. The above hypothesis was supported by subjecting a 10-cycle material to cold-flow fluidization at the same $U / U_{\text {nff }}$ as in the reactor for $20 \mathrm{hr}$ (typical time required from cycle 10 to 20 ). In $20 \mathrm{hr}$ only 0.45 percent of the material was lost and only 0.17 percent of fines was generated. In contrast, under reaction conditions, nearly 10 percent of the material was lost during cycles 11 to 20 .

The sorbent recovered from the reactor after 100 cycles of testing was analyzed for carbon content and no significant carbon was detected in the sorbent $(<0.005 \%)$.

To further explain the lower than expected sulfur capacity of the sorbent after 100 cycles, samples were analyzed using XRD analysis to determine various crystal phases. Three sorbent samples were sent to Dr. John Renton of West Virginia University for the XRD analysis. These samples included fresh T-2465MC sorbent, the sorbent recovered from the reactor after 100 cycles of testing, and the sorbent sulfided in the 101 st cycle at $625^{\circ} \mathrm{C}$. Table $4-12$ shows the results.

One important point is that the diffraction data collected here preclude the quantification of phases with concentrations less than 2 to 3 wt. percent even with relatively crystalline phases. Nonetheless, the results reported in Table 4-12 indicate the concentration of franklinite (zinc ferrite) phase drops during testing. Also, this analysis indicates very insignificant carbide formation.

TABLE 4-12. XRD-ANALYSIS OF T-2465MC SORBENTS (wt.\%)

\begin{tabular}{cccc}
\hline \hline XRD-phase & Fresh T-2465MC & $\begin{array}{c}\text { 100-cycle used } \\
\text { T-2465MC }\end{array}$ & $\begin{array}{c}\text { 101-cycle sulfided } \\
\text { T-2465M }\end{array}$ \\
\hline $\mathrm{ZnSO}_{4}$ & 0.6 & 1.5 & 0.7 \\
$\mathrm{ZnSO}_{4} \cdot \mathrm{H}_{2} \mathrm{O}$ & 1.6 & 0.0 & 1.4 \\
$\alpha-\mathrm{ZnS}$ & 0.0 & 0.6 & 6.7 \\
$\beta-\mathrm{ZnS}$ & 0.7 & 0.0 & 11.7 \\
$\mathrm{ZnO}$ & 1.3 & 9.1 & 12.0 \\
$\mathrm{Fe}_{2} \mathrm{O}_{3}$ & 1.6 & 8.0 & 3.7 \\
$\mathrm{ZnFe}_{2} \mathrm{O}_{4}$ & 90.3 & 76.3 & 60.5 \\
$\mathrm{FeS}$ & 2.3 & 3.2 & 1.4 \\
$\mathrm{Fe}_{3} \mathrm{C}$ & 1.6 & 0.5 & 1.1 \\
$\mathrm{FeO}^{1.3}$ & 0.0 & 0.8 & 0.8 \\
\hline
\end{tabular}


Having verified that attrition loss is predominantly due to chemical reaction, further tests were conducted at a lower sulfidation temperature (about $550^{\circ} \mathrm{C}$ ). Also, sorbent formulations prepared using alternate methods, e.g., granulation, were tested. These results are discussed in Section 4.6.

\subsection{RUN NO. 6 - 10-CYCLE TESTING OF L-7 SORBENT}

In order to improve mechanical durability of the sorbent over long-term use, alternate manufacturing methods were investigated. One such method was granulation as was discussed in Chapter 3.

Of the 21 formulations prepared using the granulation technique, measurement of TGA reactivity and attrition resistance showed that L-7 and L-21 were the most promising formulations. Therefore, both formu-

TABLE 4-13. PHYSICAL PROPERTIES OF L-7 SORBENT

\begin{tabular}{ll}
\hline Zinc oxide & $: 32 \%$ (by weight) \\
Iron oxide & $: 63 \%$ (by weight) \\
Bentonite & $: 5 \%$ \\
Preparation method & $:$ Granulation \\
Particle size & $: 100-400 \mu \mathrm{m}$ \\
Calcination temperature & $: 800{ }^{\circ} \mathrm{C}(2 \mathrm{hr})$ \\
BET surface area & $: 5.19 \mathrm{~m}^{2} / \mathrm{g}$ \\
Pore volurne & $: 0.255 \mathrm{~cm}^{3} / \mathrm{g}$ \\
Mean pore diameter & $: 1648 \AA$ \\
Attrition resistance & $: 90 \%$ \\
Theoretical sulfur capacity & $: 37.8 \mathrm{~g} \mathrm{~S} / 100 \mathrm{~g}$ sorbent \\
\hline
\end{tabular}
lations were subjected to 10-cycle testing. Table 4-13 shows the physical properties of L-7 sorbent.

A 10-cycle test with L-7 sorbent was made in the bench-scale reactor facility. The sulfidation temperature for this run was kept between 550 and $575{ }^{\circ} \mathrm{C}$, approximately $75^{\circ} \mathrm{C}$ lower than the previous run to test the hypothesis that excessively high temperatures lead to accelerated chemical attrition. The sulfidation data for each cycle are presented in Table 4-14.

The sulfur capacity data in Table 4-14 show that the capacity drops rapidly over the first four cycles, but it stabilizes to a significant extent thereafter. The sorbent loss due to attrition/carryover is only 1 percent, which is significantly lower than that observed in Runs 1 , 2, and 5. As shown later in Table 4-20, the mean particle size and the attrition resistance of the sorbent before and after the test did not change significantly. In fact, an encouraging increase in attrition resistance from 90 to 95 percent was observed. The drop in sorbent sulfur capacityshown by a TGA reactivity test (data reported later in Table 4-20) was insignificant.

\subsection{RUN NO. 7 - 10-CYCLE TESTING OF T-2465MC AT $550^{\circ} \mathrm{C}$}

In view of the significant loss in chemical reactivity and attrition resistance of T-2465MC at $625^{\circ} \mathrm{C}$ (Run No. 5) and the excellent performance shown by $\mathrm{L}-7$ sorbent, a 10-cycle test was made with T-2465MC sorbent at the lower temperature of $550^{\circ} \mathrm{C}$. This test had the following two specific purposes: 


\begin{tabular}{|c|c|c|c|c|c|c|c|c|c|c|}
\hline 恙曾冒 & $\Xi$ & $\stackrel{\infty}{=}$ & ્ㅗ & $\stackrel{\infty}{\sim}$ & $\stackrel{\infty}{\sim}$ & 8 & 8 & $F$ & 8 & 8 \\
\hline 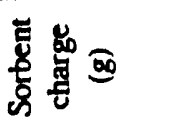 & $\begin{array}{l}= \\
\frac{\pi}{n}\end{array}$ & 三 & $=\frac{\vdots}{\dot{n}}$ & $\begin{array}{l}= \\
\bar{n} \\
\bar{n}\end{array}$ & $\begin{array}{l}= \\
\overline{\dot{n}} \\
\end{array}$ & $\begin{array}{l}= \\
\bar{n} \\
\bar{m}\end{array}$ & $\begin{array}{l}\bar{\vdots} \\
\bar{n} \\
\bar{n}\end{array}$ & = & $\frac{\overline{1}}{\bar{n}}$ & $\begin{array}{l}\equiv \\
\frac{5}{n}\end{array}$ \\
\hline$\sum^{1}$ & $\begin{array}{l}q \\
m \\
m\end{array}$ & $\stackrel{\vartheta}{m}$ & $\begin{array}{l}\infty \\
m \\
m\end{array}$ & $\begin{array}{c}\infty \\
m \\
m\end{array}$ & $\stackrel{\infty}{m}$ & $\stackrel{\stackrel{m}{m}}{m}$ & $\stackrel{\stackrel{m}{m}}{m}$ & 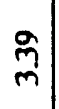 & $\frac{q}{m}$ & $\begin{array}{l}\stackrel{p}{m} \\
m\end{array}$ \\
\hline 䙢焉 & $\begin{array}{l}\infty \\
\infty \\
n\end{array}$ & $\begin{array}{l}\infty \\
\text { n. }\end{array}$ & $\begin{array}{l} \pm \\
\dot{n}\end{array}$ & $\begin{array}{c}n \\
n \\
n\end{array}$ & $\frac{n}{n}$ & $\underset{n}{f}$ & $\begin{array}{l}F \\
n\end{array}$ & $\begin{array}{l}0 \\
\vdots \\
n\end{array}$ & $\begin{array}{l}\infty \\
\dot{n} \\
n\end{array}$ & $\vec{i}$ \\
\hline 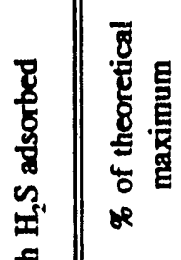 & ฟี & సे & $\begin{array}{l}8 \\
9 \\
9\end{array}$ & $\stackrel{\curvearrowright}{\beth}$ & $\stackrel{n}{\stackrel{n}{\beth}}$ & $\begin{array}{l}2 \\
0 \\
0\end{array}$ & $\begin{array}{l}\stackrel{0}{0} \\
0 \\
0\end{array}$ & $\stackrel{E}{E}$ & $\stackrel{\bar{\infty}}{a}$ & $\begin{array}{l}2 \\
\hat{0} \\
0\end{array}$ \\
\hline 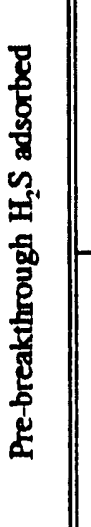 & $\underset{\infty}{\stackrel{\alpha}{\infty}}$ & $\begin{array}{l}\tilde{~} \\
\infty\end{array}$ & $\underset{r}{\sigma}$ & $\begin{array}{l}\infty \\
\dot{\sigma}\end{array}$ & $\underset{+}{\infty}$ & $\underset{\forall}{\infty}$ & $\stackrel{\infty}{\mathscr{q}}$ & $\frac{r}{\dot{y}}$ & $\bar{r}$ & $\stackrel{\infty}{\&}$ \\
\hline 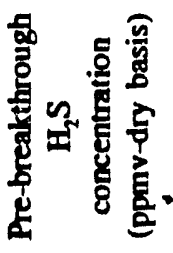 & రి & $\frac{O}{v}$ & $\frac{O}{v}$ & $\frac{O}{v}$ & $\frac{O}{v}$ & $\frac{O}{v}$ & 음 & $\frac{O}{v}$ & $\stackrel{0}{\mathrm{v}}$ & $\frac{\mathrm{O}}{\mathrm{v}}$ \\
\hline 总总 & สี & $\tilde{ユ}$ & ป & ฟี & สี & $\begin{array}{l}\text { ปี } \\
\text { }\end{array}$ & ปี & ปี & ปี & ฟี \\
\hline 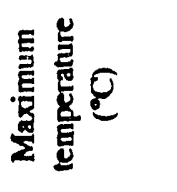 & 胥 & 5 & हे & $\stackrel{q}{W}$ & 芯 & 员 & 号 & $\bar{n}$ & $\tilde{n}$ & 8 \\
\hline 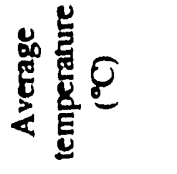 & $\tilde{D}$ & $\tilde{n}$ & 宫 & 黑 & 昌 & f & 徣 & 果 & में & $\overrightarrow{\tilde{n}}$ \\
\hline 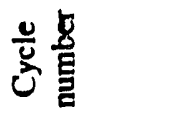 & - & $N$ & $m$ & $\nabla$ & $n$ & 0 & $r$ & $\infty$ & $a$ & 은 \\
\hline
\end{tabular}


- To provide data to determine the effect of temperature $\left(550\right.$ vs. $\left.625^{\circ} \mathrm{C}\right)$ on chemical reactivity and mechanical strength of the sorbent, and

- To provide data for comparison of performances of L-7 and T-2465MC under identical conditions and hence determine the effect of method of manufacture on sorbent performance.

The data obtained during sulfidation for each cycle are summarized in Table 4-15.

The material lost due to attrition/carryover during 10 cycles was approximately 5 percent. This loss was significantly lower than a 10 percent loss at $625^{\circ} \mathrm{C}$. This indicates that the loss is significantly reduced by lowering the temperature, which may be attributed to reduced "chemical" attrition caused by reduction of iron oxide. Overall, however, the T-2465MC sorbent had significantly greater loss (5 percent) as opposed to L-7, which underwent only about 1 percent loss under identical conditions.

The sulfur capacity of T-2465MC sorbent at $550^{\circ} \mathrm{C}$ was considerably lower than that at $625^{\circ} \mathrm{C}$ which suggests that $\mathrm{H}_{2} \mathrm{~S}$ adsorption is partially controlled by intrinsic chemical reaction. The temperature's effect on sorbent performance is discussed in detail in Chapter 5.

\subsection{RUN NO. 8 - 10-CYCLE TESTING OF NORTON SORBENT}

In addition to granulation, other sorbent manufacturing techniques were also investigated. Norton Company (Akron, Ohio), which manufactures specialized ceramics and catalysts for flue gas desulfurization, was contacted. Norton agreed to prepare a few zinc ferrite formulations using a proprietary technique. The raw materials $\left(\mathrm{ZnO}, \mathrm{Fe}_{2} \mathrm{O}_{3}\right.$, and bentonite) were sent to Norton and a number of formulations were received.

After TGA screening tests, it was decided to test one of the formulations for a 10-cycle run. The run was conducted under conditions identical to those in Runs 6 and 7. The data obtained during sulfidation are reported for each cycle in Table 4-16. The sulfur capacity of the sorbent decreased rapidly over the first five cycles, but remained fairly stable thereafter. Also, the sorbent loss due to elutriation, as reported later in Table 4-20, was negligible. The attrition resistance of the fresh sorbent was 87 percent, but it dropped to 52 percent after testing. On the other hand, the average particle size increased by 5 percent. Increase in the average particle size and the sharp drop in attrition resistance can be attributed to the formation of weak agglomerates during testing which, in turn, were broken during the attrition test under high gas velocities. This hypothesis was further supported by measurements of BET surface area of fresh and reacted sorbents as shown later in Table 4-20, which decreased by 60 percent. During a discussion of these results with the Norton Company, it was found that a low melting point binder had been used in the formulation. Further testing of Norton sorbents was not conducted. 


\begin{tabular}{|c|c|c|c|c|c|c|c|c|c|c|}
\hline 悬曾亘 & $\mathscr{2}$ & ఫ్రి & $\stackrel{\infty}{m}$ & 2 & $\$$ & 8 & $\stackrel{\infty}{R}$ & $\mathcal{F}$ & 呙 & $\mathscr{q}$ \\
\hline 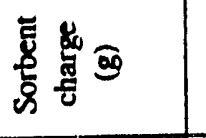 & $\begin{array}{l}\infty \\
0 \\
0 \\
0\end{array}$ & $\begin{array}{l}0 \\
\stackrel{0}{0} \\
\stackrel{m}{m}\end{array}$ & $\begin{array}{l}\text { : } \\
\stackrel{0}{0} \\
\text { D. }\end{array}$ & $\begin{array}{l}\infty \\
0 \\
0 \\
m\end{array}$ & 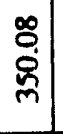 & 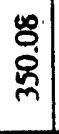 & $\frac{n}{\circ}$ & 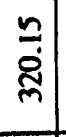 & $\frac{n}{\dot{m}}$ & $\frac{n}{\dot{0}}$ \\
\hline $2^{\prime \prime}$ & 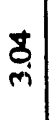 & $\frac{0}{m}$ & $\frac{O}{m}$ & $\begin{array}{l}\text { ț } \\
m\end{array}$ & हे & $\frac{0}{m}$ & $\frac{ \pm}{m}$ & $=$ & $\frac{m}{m}$ & $\stackrel{\sim}{m}$ \\
\hline 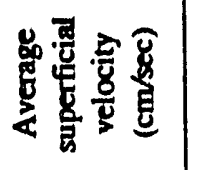 & $\begin{array}{l}0 \\
\ddot{n} \\
n\end{array}$ & $\begin{array}{l}\& \\
\dot{n}\end{array}$ & $\begin{array}{l}8 \\
\text { n. } \\
.\end{array}$ & $\begin{array}{l}\text { aे } \\
\text { r. }\end{array}$ & $\begin{array}{c}\infty \\
\dot{i} \\
\dot{n}\end{array}$ & $\begin{array}{l}8 \\
\dot{n}\end{array}$ & $\begin{array}{l}\infty \\
\dot{n}\end{array}$ & $\begin{array}{c}\tilde{\delta} \\
\dot{n} \\
\dot{n}\end{array}$ & $\begin{array}{l}\infty \\
\dot{n} \\
\end{array}$ & $\begin{array}{l}\infty \\
\dot{n} \\
n\end{array}$ \\
\hline 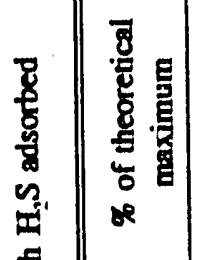 & $\begin{array}{l}\stackrel{\sim}{4} \\
\underline{u}\end{array}$ & $\begin{array}{l}0 \\
\vdots \\
\vdots\end{array}$ & $\frac{\delta}{\sim}$ & $\begin{array}{l}\stackrel{\sim}{4} \\
\underline{\underline{n}}\end{array}$ & $\tilde{\oplus}$ & 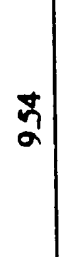 & $\begin{array}{l} \pm \\
\grave{m} \\
m\end{array}$ & $\stackrel{\infty}{\stackrel{n}{n}}$ & $\stackrel{\infty}{2}$ & $\underset{\infty}{\overparen{D}}$ \\
\hline 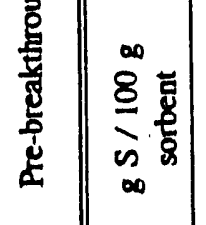 & s. & $\stackrel{q}{r}$ & $\tilde{\infty}$ & ڤू & 오 & $\begin{array}{c}\mathbb{N} \\
m\end{array}$ & $\underset{n}{\stackrel{\infty}{n}}$ & $\underset{\sim}{\mathbf{N}}$ & $\underset{n}{8}$ & 금 \\
\hline 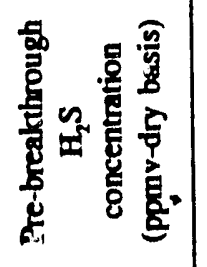 & 8 & జี & \& & ָิ & $\mathscr{F}$ & ષ્ઠ & శి & ণి & జి & $\stackrel{\mathbb{Q}}{ }$ \\
\hline 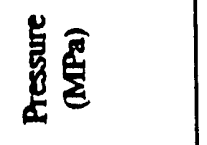 & ปี & ปู & ปี & ปี & ปี & $\underline{\text { ปี }}$ & ปี & สี & ปี & ปี \\
\hline E & $\begin{array}{l}a \\
\tilde{n}\end{array}$ & $\overline{\check{n}}$ & $\begin{array}{l}9 \\
8 \\
8\end{array}$ & $\tilde{\sim}$ & $\begin{array}{l}0 \\
\infty \\
n \\
n\end{array}$ & $\begin{array}{l}0 \\
8 \\
\end{array}$ & พั) & : & $\begin{array}{l}0 \\
\stackrel{8}{8} \\
n\end{array}$ & $\begin{array}{c}0 \\
\infty \\
\infty\end{array}$ \\
\hline 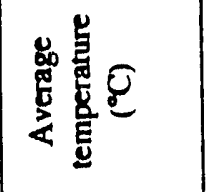 & $\begin{array}{l}n \\
\tilde{n}\end{array}$ & 幽 & $\begin{array}{l}\infty \\
\infty \\
\tilde{n} \\
n\end{array}$ & zे & $\tilde{n}$ & 莴 & $\frac{m}{n}$ & 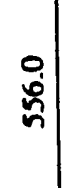 & స్ & $\overrightarrow{8}$ \\
\hline 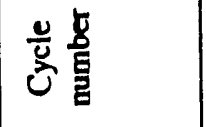 & - & $N$ & $m$ & $\sigma$ & $n$ & 0 & $r$ & $\infty$ & $a$ & 은 \\
\hline
\end{tabular}




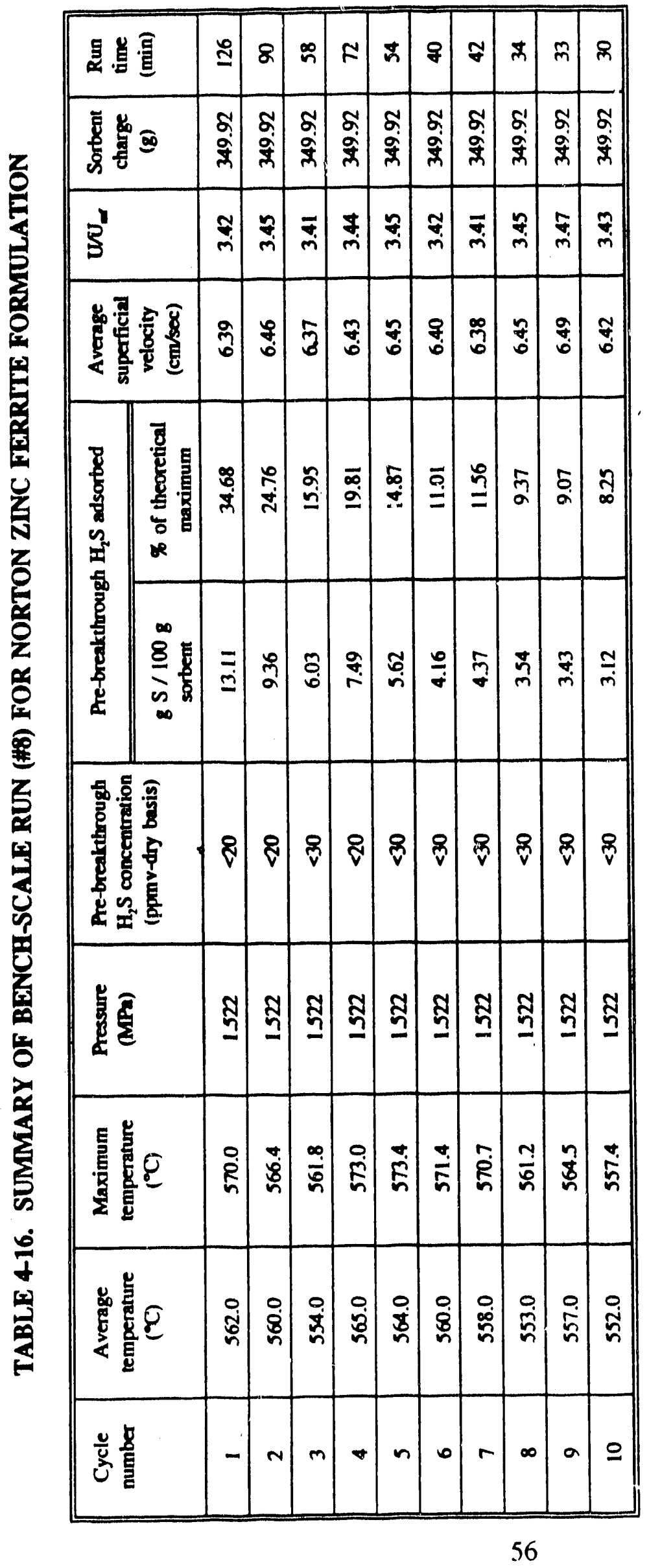




\subsection{RUN NO. 9 - 10-CYCLE TESTING OF L-21 SORBENT}

As discussed earlier, the screening tests indicated that L-7 and L-21 are the best candidates based on their TGA reactivity and attrition resistance. The details of the 10-cycle testing of L-7 sorbent has been given in Section 4.6. The principal difference between these sorbents was that L-21 had 2 percent bentonite whereas L-7 contained 5 percent bentonite; otherwise they were prepared under identical conditions. Table 4-17 shows the physical properties of L-21 sorbent. Thus, this test was expected to show the effect of bentonite content on sorbent durability.

\section{TABLE 4-17. PHYSICAL PROPERTIES OF L-21 SORBENT}

\begin{tabular}{ll}
\hline Zinc oxide & $: 34 \%$ (by weight) \\
Iron oxide & $: 64 \%$ (by weight) \\
Bentonite & $: 2 \%$ \\
Preparation it-sthod & $:$ Granulation \\
Particle size & $: 100-400 \mu \mathrm{m}$ \\
Calcination temperature & $: 800^{\circ} \mathrm{C}(2 \mathrm{hr})$ \\
BET surface area & $: 4.46 \mathrm{~m}^{2} / \mathrm{g}$ \\
Pore volume & $: 0.229 \mathrm{~cm}^{3} / \mathrm{g}$ \\
Mean pore diameter & $: 1574 \AA$ \\
Attrition resistance & $: 90 \%$ \\
Theoretical sulfur capacity & $: 39 \mathrm{~g} \mathrm{~S} / 100 \mathrm{~g}$ sorbent
\end{tabular}

A 10-cycle test was conducted with this sorbent at a sulfidation temperature in the range of 550 to 575 ${ }^{\circ} \mathrm{C}$. Table 4-18 presents a summary of data obtained during sulfidation for each cycle. As can be seen, the sorbent had a very high capacity in the first cycle, but it dropped rapidly and more or less stabilized at about $5 \mathrm{~g}$ $\mathrm{S} / 100 \mathrm{~g}$ sorbent after the 6th cycle. The loss in the reactor due to elutriation was very insignificant, i.e., less than 0.5 percent. As reported later in Table 4-20, the average particle size decreased by approximately 5 percent. The mean

pore diameter and BET surface area changed by a factor of 2 . The attrition resistance of the sorbent, however, increased from 90 to 96 percent.

A comparison of desulfurization performance of $\mathrm{L}-7$ and $\mathrm{L}-21$ revealed that $\mathrm{L}-7$ was a superior sorbent to L-21. This will be discussed in Chapter 5.

\subsection{RUN NO. 10 - 10-CYCLE TESTING OF L-16 SORBENT}

With the emergence of $\mathrm{L}-7$ as a superior desulfurization sorbent in the sulfidation temperature range of 550 to $575^{\circ} \mathrm{C}$, it was decided to test this sorbent at a higher sulfidation temperature $\left(625^{\circ} \mathrm{C}\right)$. This run was designed to show the effect of temperature on the performance of $\mathrm{L}-7$ zinc ferrite sorbent.

There was not sufficient $\mathrm{L}-7$ sorbent in the required particle size range, so $\mathrm{L}-16$ was used for this test. L-16 was prepared under conditions identical to those for L-7 except for a lower granulation speed used. TGA reactivity and attrition resistance of L-16 were comparable with L-7 sorbent. 


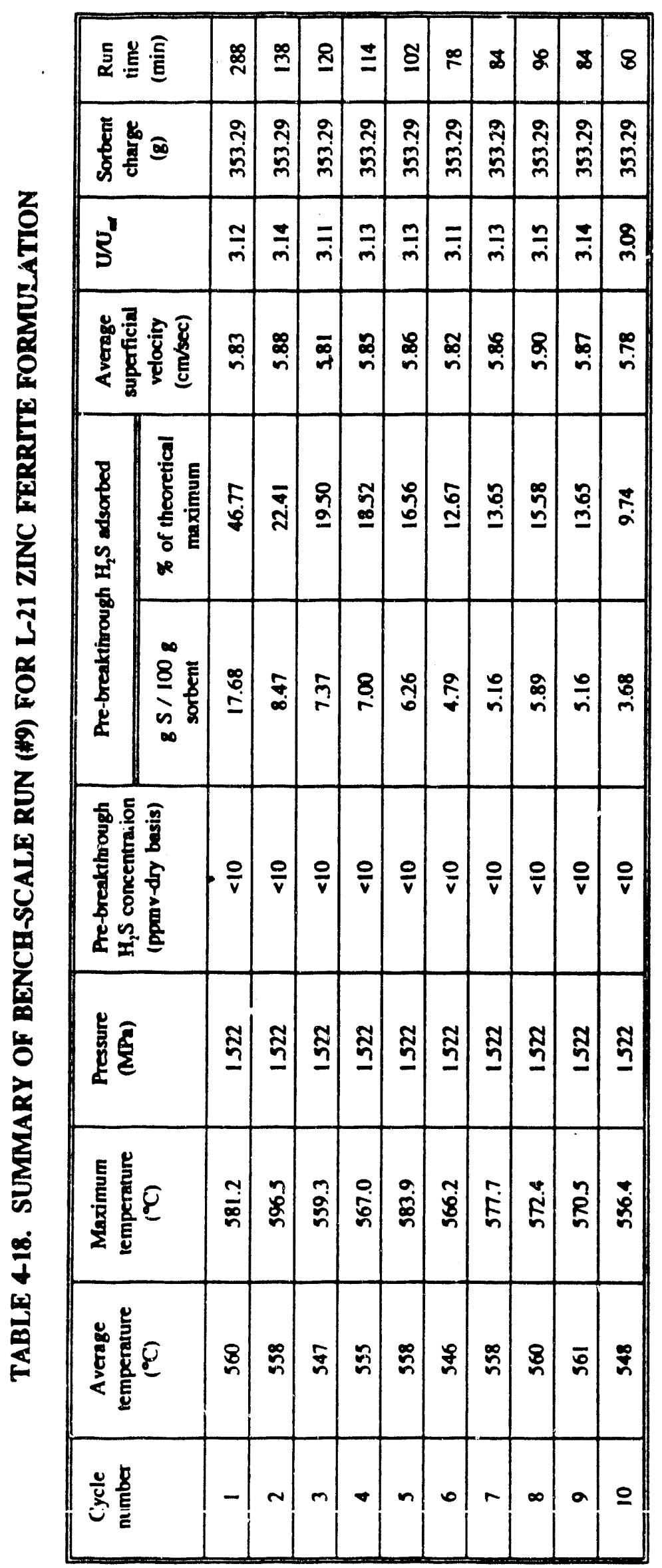


A 10-cycle test was conducted with L-16 sorbent and pertinent experimental data are reported in Table 4-19 for each cycle. The sulfur capacity decreased from 14.46 to 5.19 percent over 10 cycles.

The attrition resistance of the sorbent decreased significantly from 83.5 to 67.5 percent over 10 cycles. This indicated that although essentially no material was lost, the sorbent had significantly weakened at higher temperature. Also, as reported in Table 4-20, significant reduction in the BET surface area and mercury pore volume was observed, which correlated with loss in reactivity. Evidently, zinc loss measured by $\mathrm{Zn}$ to $\mathrm{Fe}$ ratio before and after the test was very insignificant.

An attempt was made to interpret the data collected during these 10 runs. The significant findings are discussed in Chapter 5. 


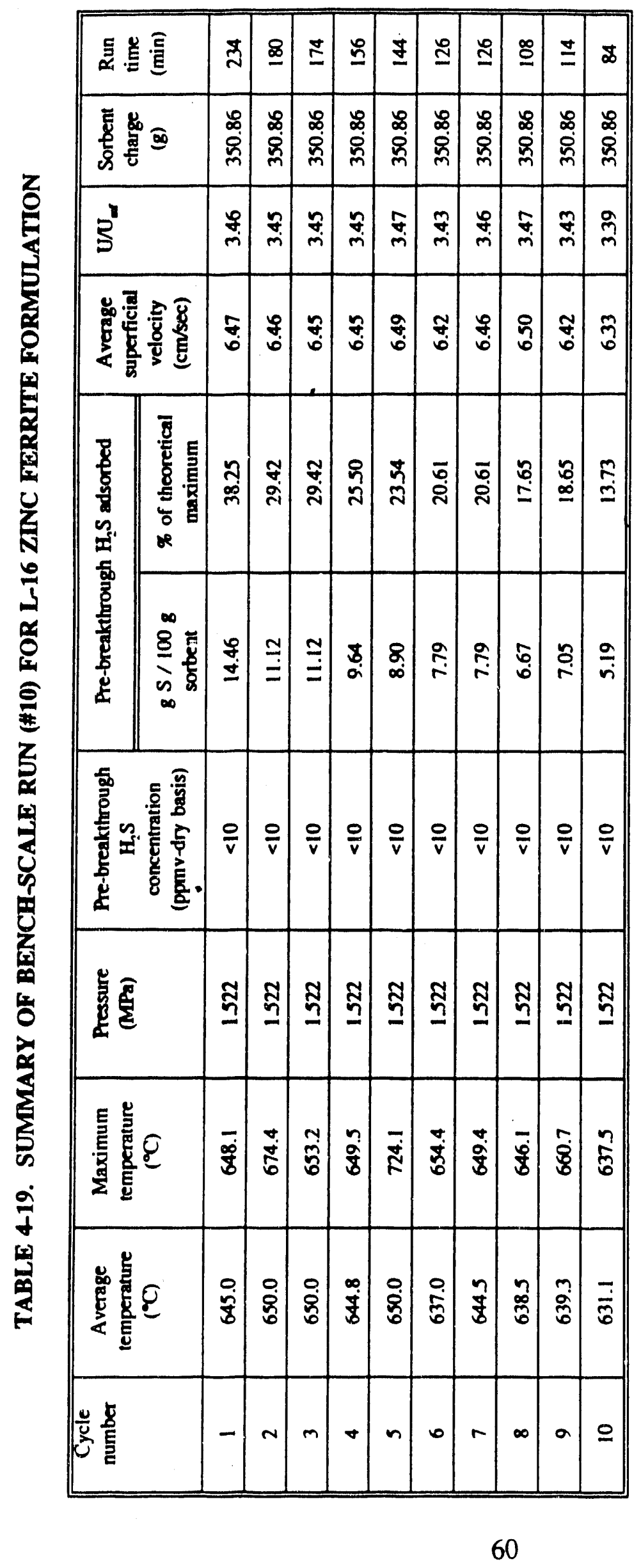




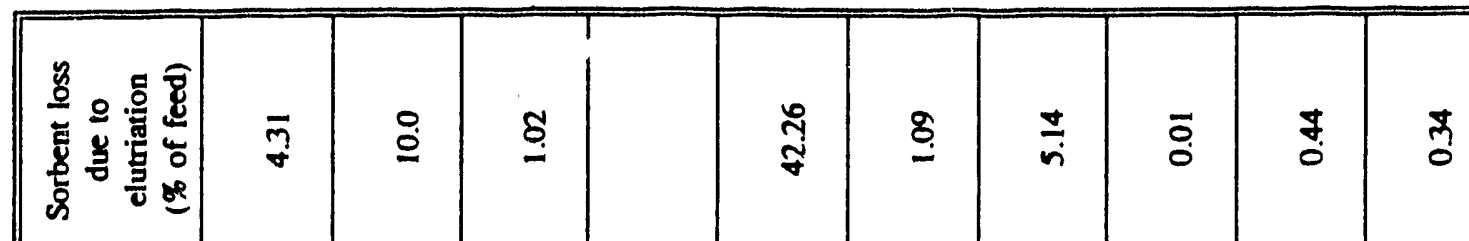

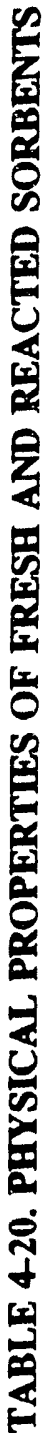

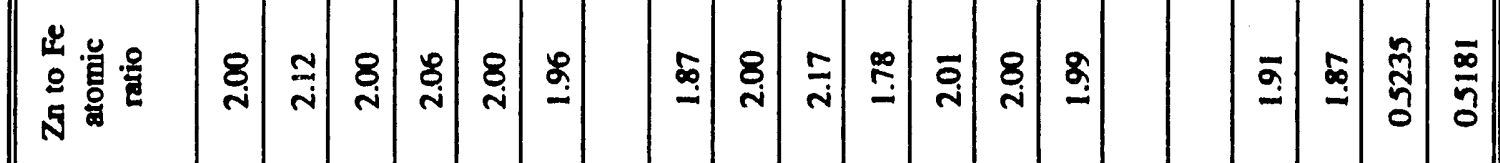

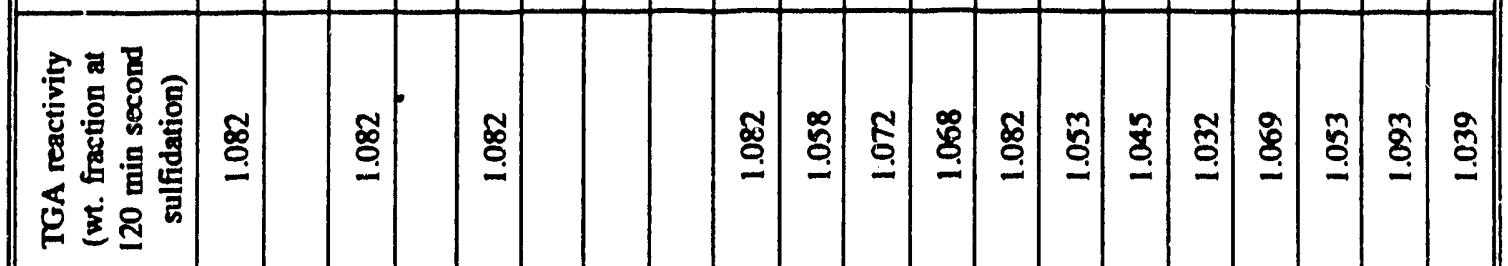

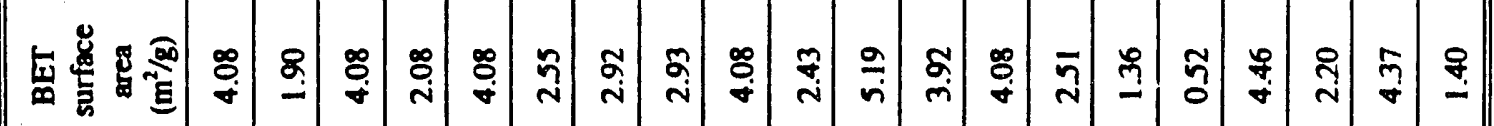

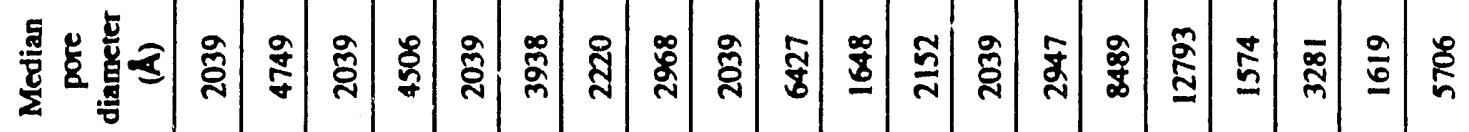

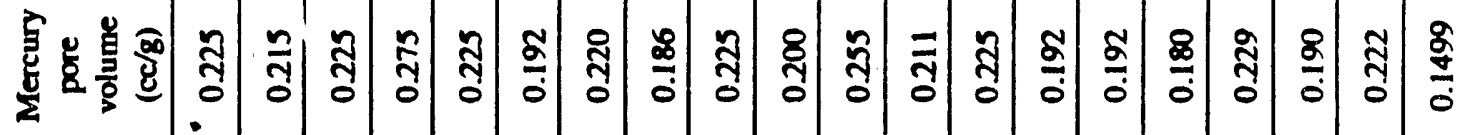

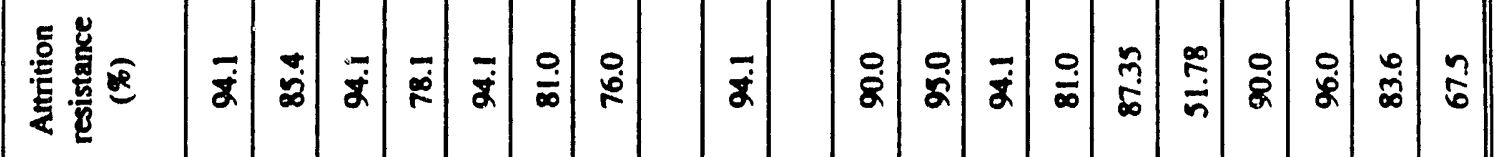

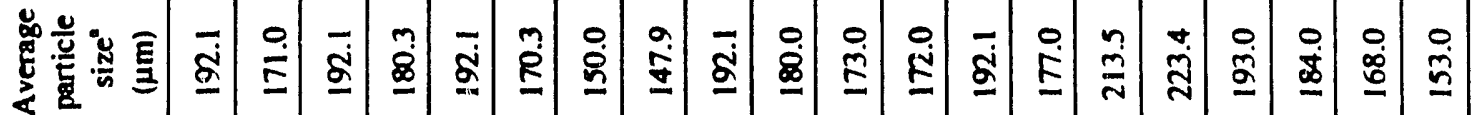

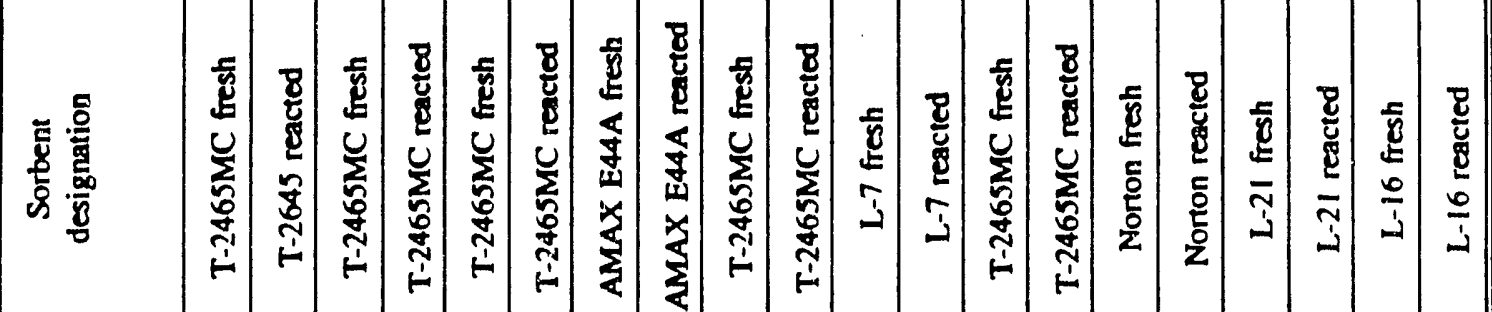

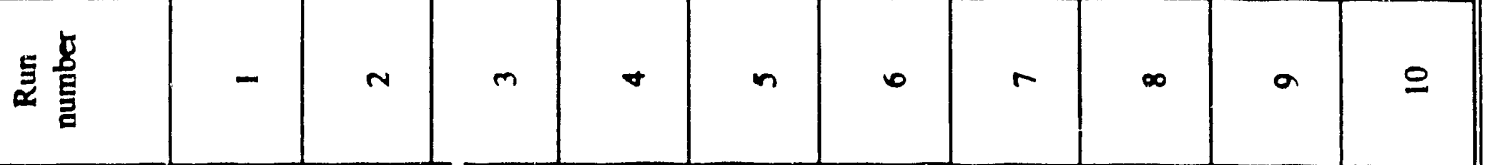

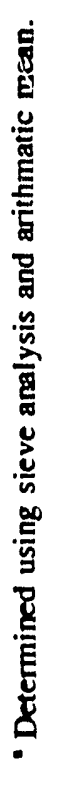




\subsection{DATA ANALYSIS}

Analysis of experimental data obtained during bench-scale testing was carried out to evaluate the effect of variables. The variables that were studied included:

- Method of sorbent preparation,

- Sulfidation temperature, and

- Bentonite content of the sorbent.

The effect of each of these variables is outlined below.

\subsection{METHOD OF SORBENT PREPARATION}

As discussed in Chapter 3, the main obstacle to commercialization of the hot-gas desulfurization technology is the manufacture of chemically reac ive and mechanically durable sorbent formulations. A number of sorbent manufacturing methods were investigated to overcome this obstacle. As discussed in Chapter 3, these included crushing of durable pellets and screening, impregnation, granulation, spray drying, etc. Methods that initially showed feasibility were crushing and screening, and granulation. Bench-scale testing of sorbents prepared using these two methods was conducted to study the effect of the manufacturing method on sorbent performance (i.e., sulfur capacity and attrition resistance) and results were reported in Chapter 4.

Figure 5-1 compares the sulfur capacities of T-2465MC, L-7, L-21, and Norton zinc ferrite formulations at $550{ }^{\circ} \mathrm{C}$ using KRW-type sulfidation gas. All of these sorbents contained 2 percent bentonite except $L-7$, which contained 5 percent bentonite. It is clear from Figure 5-1 that all of the formulations show very high capacity in early cycles, but the capacity decreases with successive cycles. At the end of the 10th cycle, all four formulations have a sulfur capacity ranging from 3 to $4 \mathrm{~g}$ per $100 \mathrm{~g}$ of sorbent, which is about 10 percent of the theoretical capacity of zinc ferrite.

Figure 5-2 shows the attrition resistances of the four formulations mentioned above in fresh and reacted states. The attrition resistance $\left(A_{R}\right)$ of $T-2465 \mathrm{M}$ at $550^{\circ} \mathrm{C}$ dropped from 94.1 to 81 percent, while for the Norton sorbent, $A_{R}$ decreased from 87 to 51 percent. On the other hand, for both the L-7 and L-21 formulations, $A_{R}$ increased from 90 to 96 perceit, respectively. Since sulfur capacities of the four sorbents were comparable as shown in Figure 5-1, the formulations prepared by granulation appeared to be significantly superior based on attrition resistance.

Figure 5-3 shows the sorbent loss in the reactor due to elutriation (carryover). At $550^{\circ} \mathrm{C}$, T-2465MC sorbent shows the greater loss compared to L-7 and L-21 formulations. Based on these results, it is clear that although sulfur capacities of the four formulations are comparable, formulations prepared by granulation have significantly higher attrition resistance and undergo a smaller loss due to elutriation compared to T-2465MC.

Desulfurization performances of $\mathrm{T}-2465 \mathrm{MC}$ and $\mathrm{L}-16$ sorbents at a sulfidation temperature of $625^{\circ} \mathrm{C}$ are shown in Figure 5-4. The sulfur capacity of T-2465MC at $625^{\circ} \mathrm{C}$ is significantly 


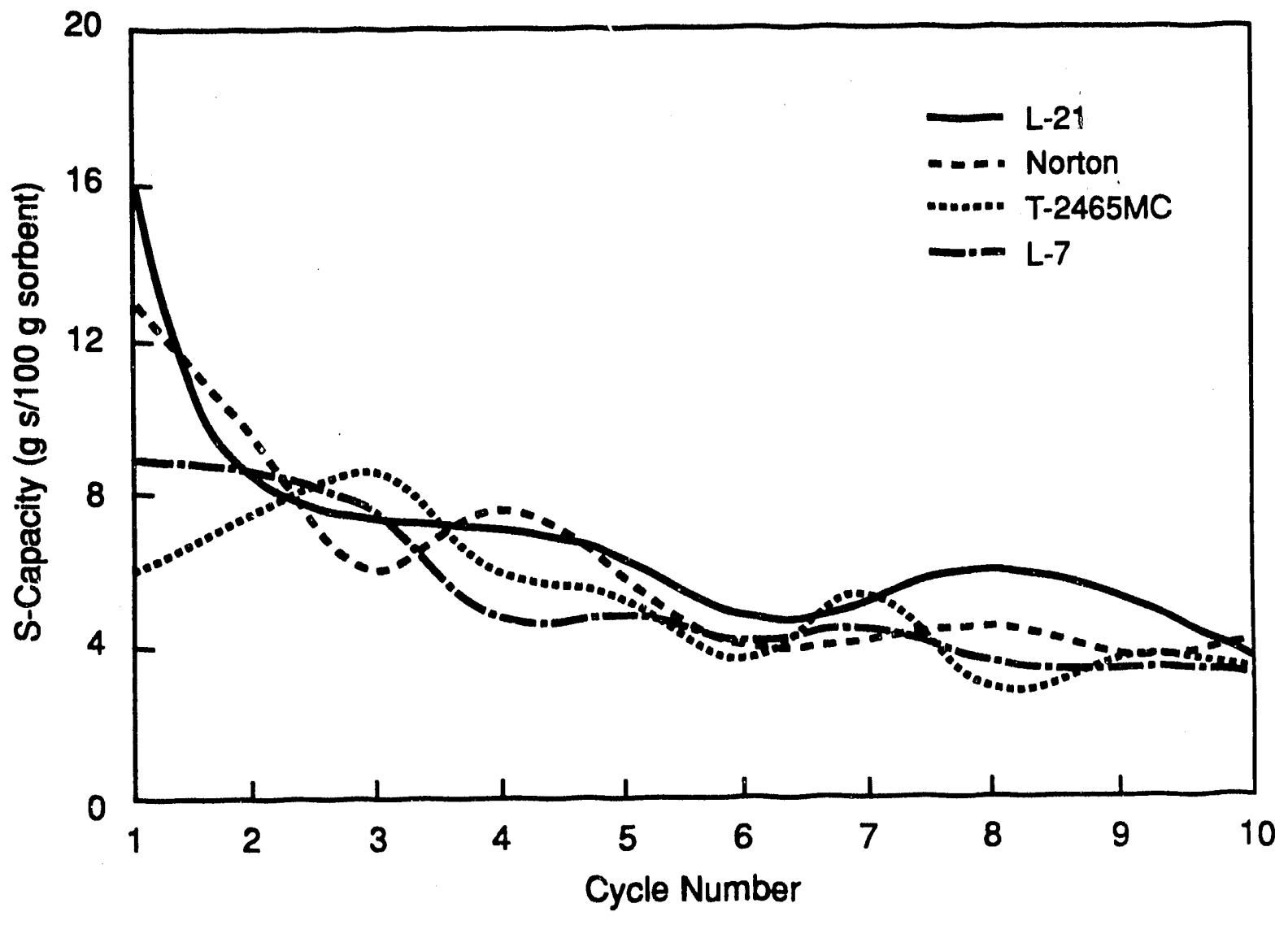

Figure 5-1. Sulfur capacities of T-2465MC, Norton, $\mathrm{L}-21$, and L-7 formulation at $550^{\circ} \mathrm{C}$. 


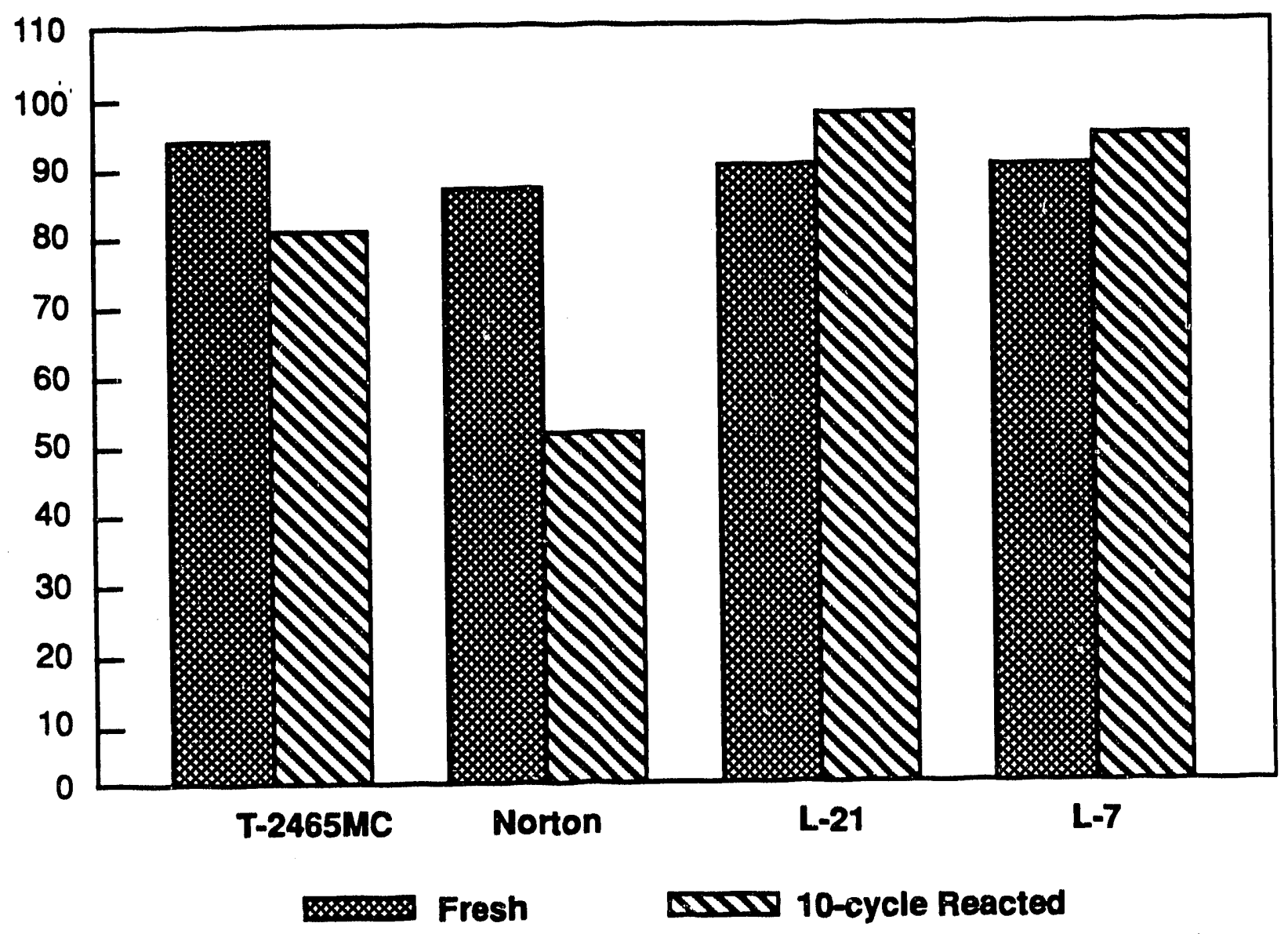

Figure 5-2. Attrition resistances of varlous zinc ferrite formulations in fresh and reacted states 


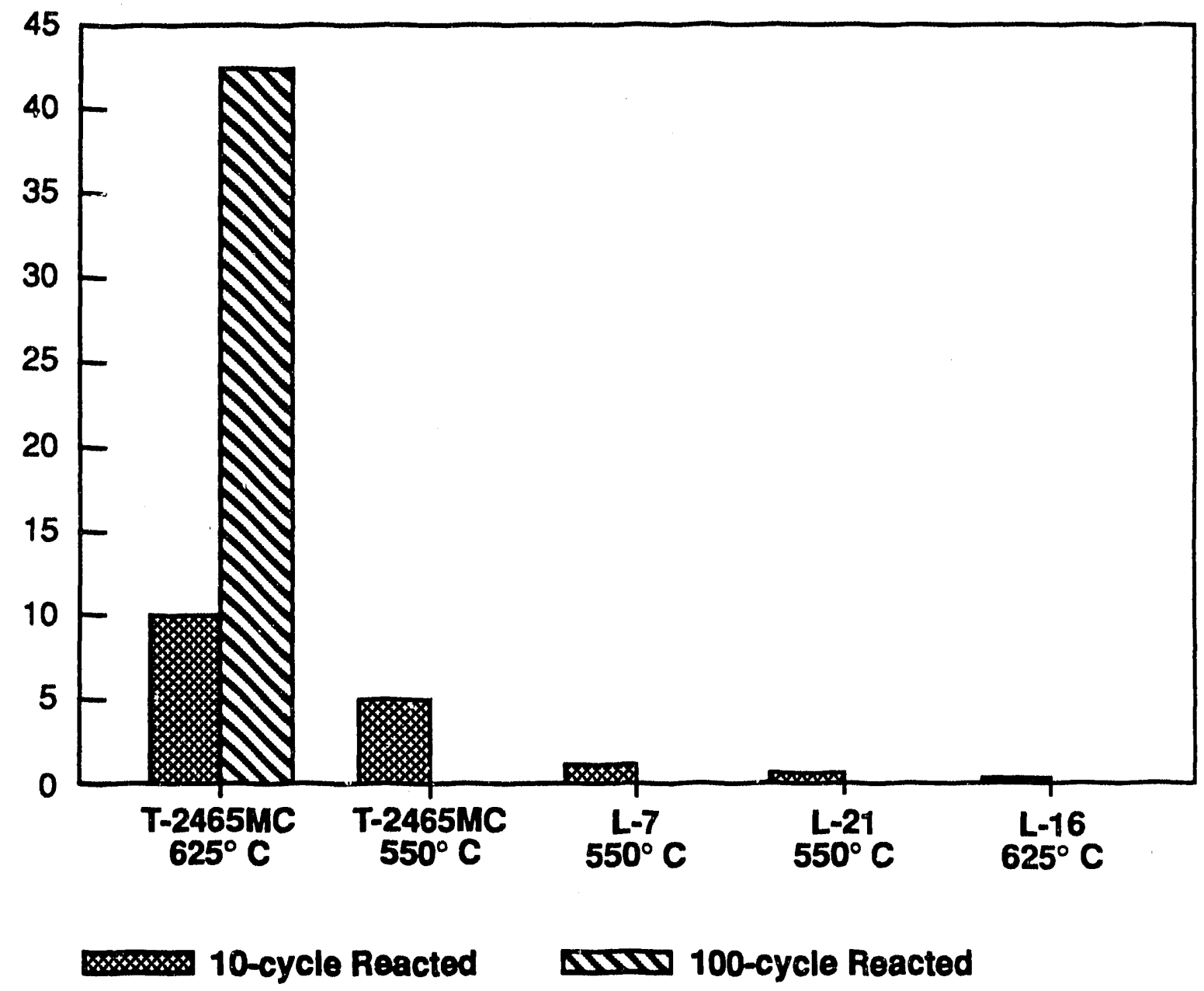

Figure 5-3. Sorbent loss in the reactor due to elutriation for various formulations. 


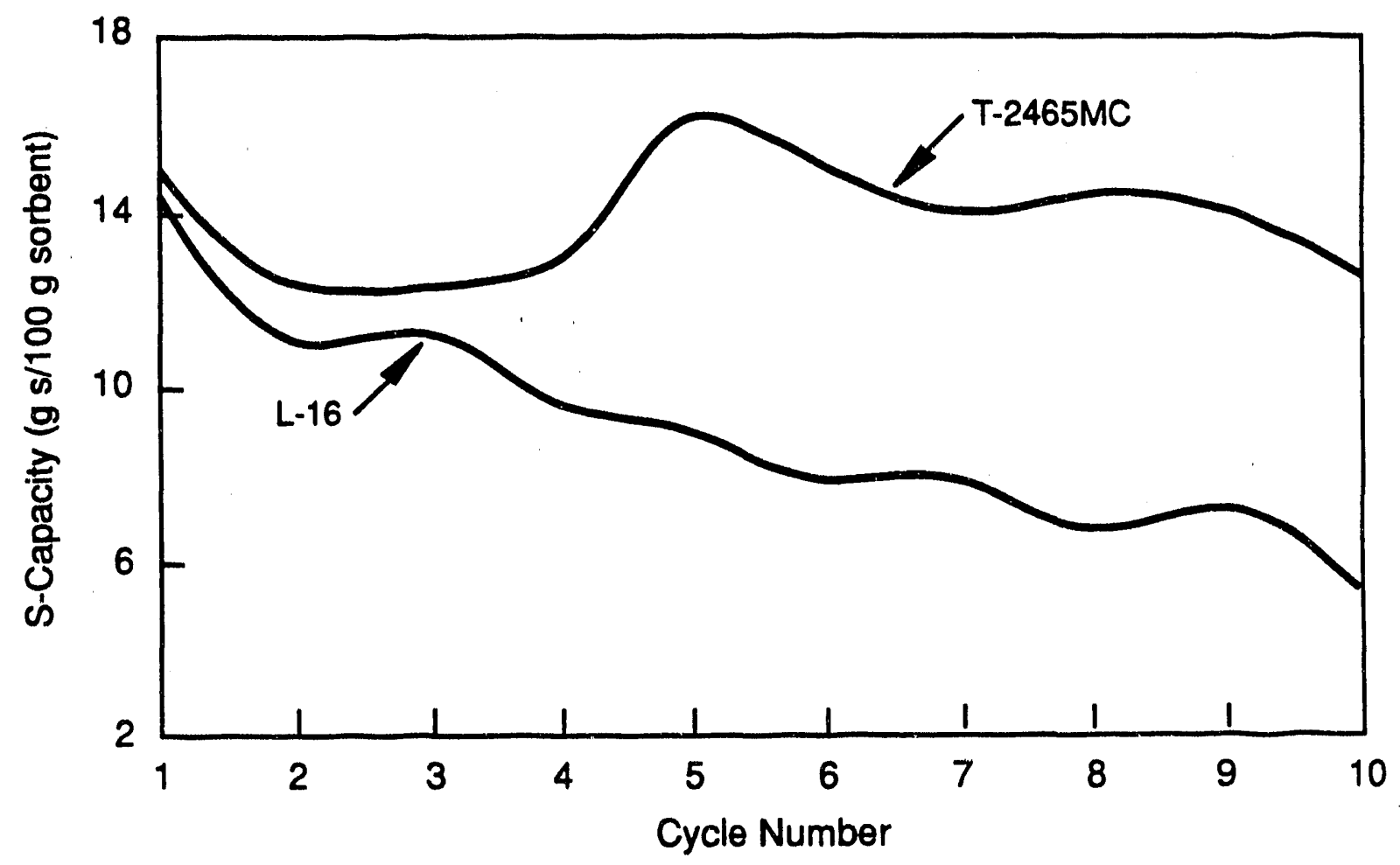

Figure 5-4. Sulfur capaclties of L-16 and T-2465MC at $625^{\circ} \mathrm{C}$. 
higher than the L-16 formulation. However, examination of attrition resistances and sorbent losses due to elutriation as depicted in Figures 5-5 and 5-3, respectively, reveals that T-2465MC undergoes severe attrition. Approximately 10 percent of the T-2465MC sorbent was lost at 625 ${ }^{\circ} \mathrm{C}$ due to attrition/carryover, while only 0.16 percent of L-16 was elutriated.

From the above analysis, it can be concluded that the formulations prepared by granulation show better overall performance than T-2465MC and Norton sorbents.

\subsection{SULFIDATION TEMPERATURE}

Figure 5-6 shows the sulfur capacities of L-7 and L-16 formulations at 550 and $625^{\circ} \mathrm{C}$, respectively. As mentioned earlier, both formulations were prepared under almost identical conditions, except for a lower granulation speed used in preparing L-16. Figure 5-6 clearly shows that the rate of the sulfidation reaction is significantly faster at $625^{\circ} \mathrm{C}$ than at $550^{\circ} \mathrm{C}$. This suggests that global kinetics is controlled, at least in part, by an intrinsic reaction rate between the sorbent and $\mathrm{H}_{2} \mathrm{~S}$.

Figure 5-7 compares the sulfur capacities of $\mathrm{T}-2465 \mathrm{MC}$ at 625 and $550^{\circ} \mathrm{C}$. This figure also shows that sulfidation kinetics is appreciably faster at $625^{\circ} \mathrm{C}$ than at $550^{\circ} \mathrm{C}$. While both of the above cases clearly demonstrate that higher temperature operation could be carried out using a smaller commercial reactor (due to increased reaction rate), the loss of mechanical strength oi the sorbent at higher temperatures is a major concern. As depicted previously in Figure 5-3, the sorbent loss due to attrition/carryover becomes unacceptable, at least for $\mathrm{T}$ $2465 \mathrm{MC}$, at $625^{\circ} \mathrm{C}$. Figure 5-5 also shows that for L-16 attrition resistance drops sharply from 8.3 to 67 percent over 10 -cycle testing at $625^{\circ} \mathrm{C}$.

The above observations suggest that although there may be some initial sorbent loss due to mechanical attrition, most of the latter loss is due to chemical transformations leading to sorbent particle weakening, breakup, and carryover. This is probably caused by a reduction of $\mathrm{Fe}_{2} \mathrm{O}_{3}$ to $\mathrm{FeO}$ or even to $\mathrm{Fe}$ and $\mathrm{ZnO}$ followed by some zinc vaporization. It is believed that reduction of hematite is predominantly responsible for disintegration of the sorbent (Woods et al., 1989).

Hence, these results show that zinc ferrite is not a suitable desulfurization sorbent candidate at $625^{\circ} \mathrm{C}$ in commercial reactors.

\subsection{BINDER CONTENT}

In addition to manufacturing technique and temperature, the effect of binder on the sorbent's desulfurization performance was studied. Most of the sorbent formulations, to date, have been prepared using bentonite as a binder, although other clays can also be used as binders. The montmorillonite structure of bentonite results in excellent binding properties. Bentonite is thermally stable up to $700^{\circ} \mathrm{C}$ (Grim, 1980).

The formulations L-21 and L-7, containing 2 and 5 percent bentonite binder, respectively, were subjected to a 10-cycle testing. The results are shown in Figure 5-1. Both of these formulations have comparable sulfur capacities and attrition resistances. However, as depicted 


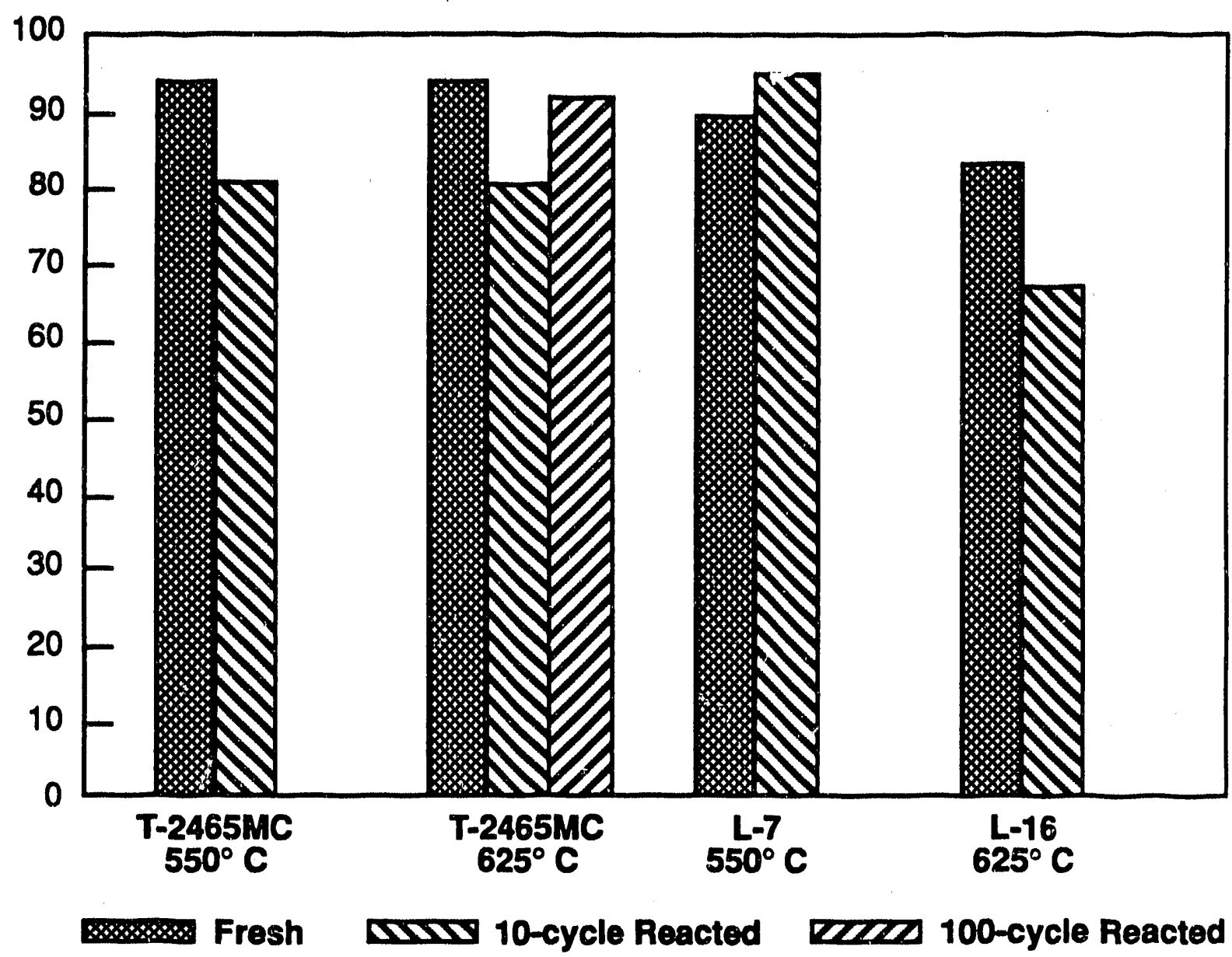

Figure 5-5. Attrition resistances of T-2465MC and other sorbents at $550^{\circ} \mathrm{C}$ and $625^{\circ} \mathrm{C}$ in fresh and reacted states. 


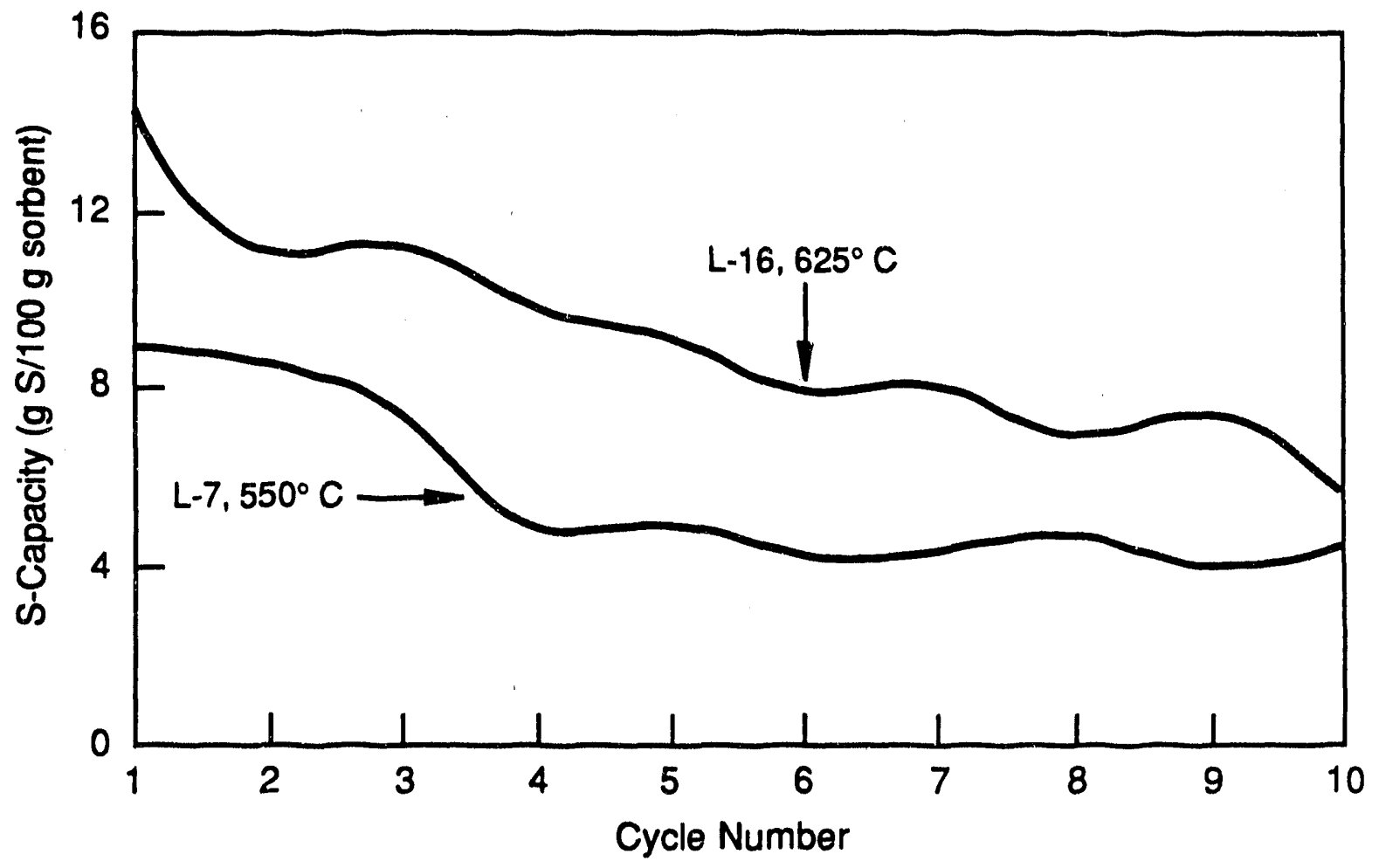

Figure 5-6. Sulfur capacities of $L-7$ and $L-16$ formulations at $550^{\circ}$ and $625^{\circ} \mathrm{C}$. 


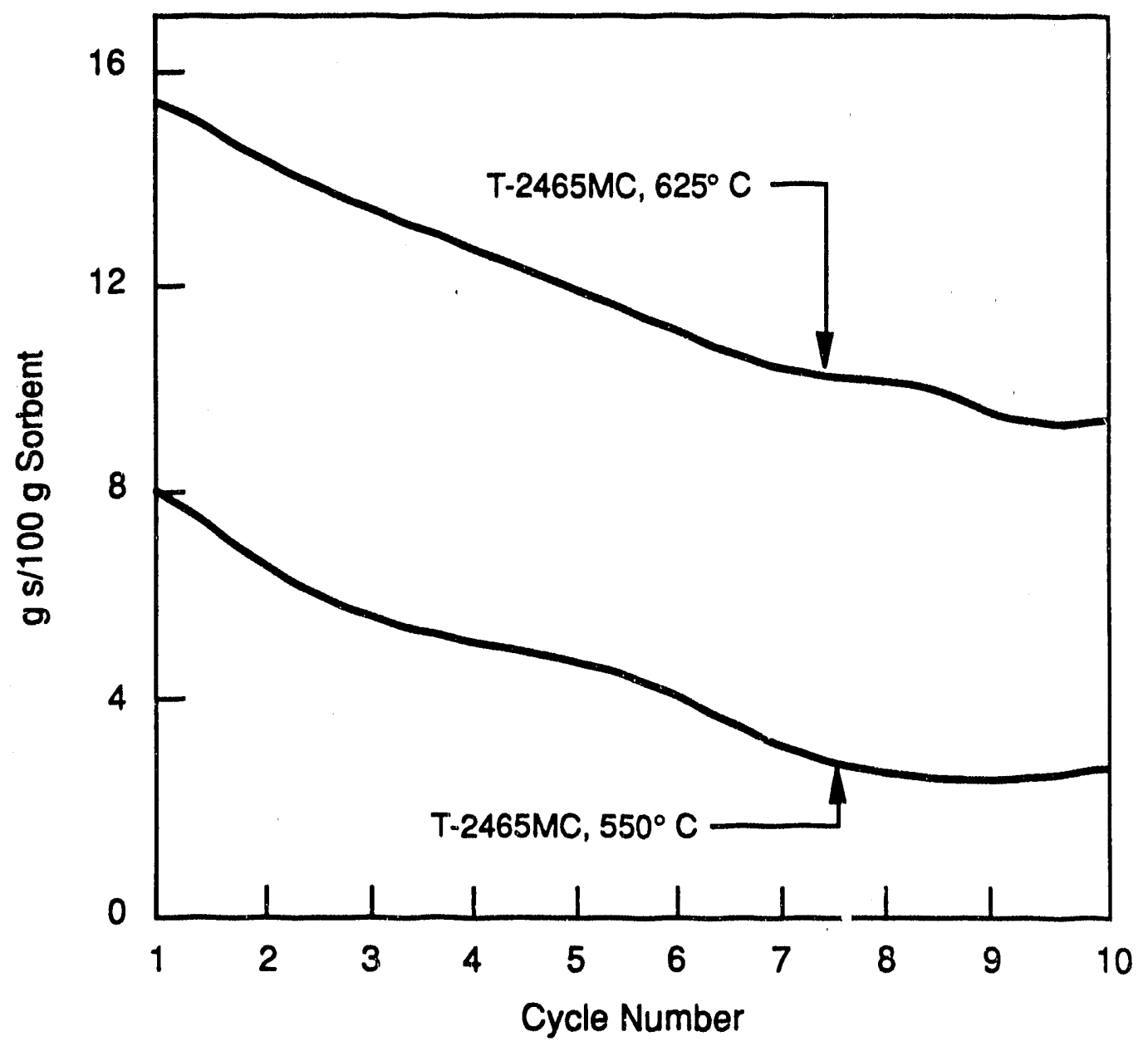

Figure 5-7. Sulfur capacities of T-2465MC at $625^{\circ}$ and $550^{\circ}$. 
in Figure 5-1, the L-7 formulation attains a stability in sulfur capacity after four cycles, while L21 shows a steady decline in capacity. Thus, 5 percent bentonite may be needed. 


\subsection{MATHEMATICAL MODELING}

\subsection{BACKGROUND}

While considerable emphasis has been given in the past to devel $v_{\mathrm{p}} \mathrm{ing} \mathrm{h}_{\text {, }}$ hly reactive and attrition-resistant sorbents for hot gas desulfurization, very little effort has been spent in understanding the kinetics of the reaction in a fluidized-bed reactor. Recently, in a study sponsored by DOE/METC, Wang et al. (1988) developed mathematical models to describe the bchavior of integral reactors, including fluid-bed reactors, used in high-temperature desulfurization process.

Initially, modeling studies of fluidized-bed reactors by Wang et al. (1988) were aimed at designing and optimizing steady-state continuous recirculation reactors that could be used in a commercial operation. However, Cockrill (1988) modified the steady-state material balances in order to describe the operation of a batch fluidized-bed reactor such as the one used in this study. This batch model, which was based on the three-phase fluidization model of Kunii and Levenspiel (1969), was fairly successful in describing the limited experimental results of Schrodt (1981). This model was used to predict the experimental results obtained in our bench-scale reactor, but with disappointing results, as outlined below.

\subsection{THE KUNII-LEVENSPIEL MODEL}

The $s: m i-b a t c h$ fluidized-bed reactor used in modeling is schematically shown in Figure 6-1. A known quantity of sorbent is initially charged to the reactor. A simulated coal gas containing $\mathrm{H}_{2}$ i" of known concentration is then fed to the reactor. Perfect mixing of the solids is assumed in the reactor so that the sulfur loading is only a function of time.

The three-phase model of Kunii and Levenspiel (1969) is assumed to describe the fluidization behavior of the sorbent in the reactor, although the model has severe limitations under high pressure conditions as will be discussed later. According to this model, the overall bed is composed of bubble, cloud, and emulsion phases as shown in Figure 6-2. The majority of the gas passes through the reactor in the bubble phase which contains very little sorbent. The cloud, which surrounds the bubble, has a high solids concentration. The emulsion phase contains little gas and the majority of the solid. The solid density in the emulsion phase is assumed to correspond to that at minimum fluidization. Interchange of gas is permitted between the bubble and cloud, and between he cloud and emulsion.

The gas is assumed to pass through the reactor in plug flow at the bubble velocity and the solids within the reactor are assumed to be perfectly mixed. Only the isothermal sulfidation cycle is considered so that no energy balance is needed.

The sulfidation reaction in the reactor is a typical gas-solid reaction of the type $A(g)+$ $b S(s) \rightarrow$ Products, where A represents $\mathrm{H}_{2} \mathrm{~S}, \mathrm{~B}$ represents zinc ferrite, and $\mathrm{b}=0.33 .3$ for zinc ferrite. 


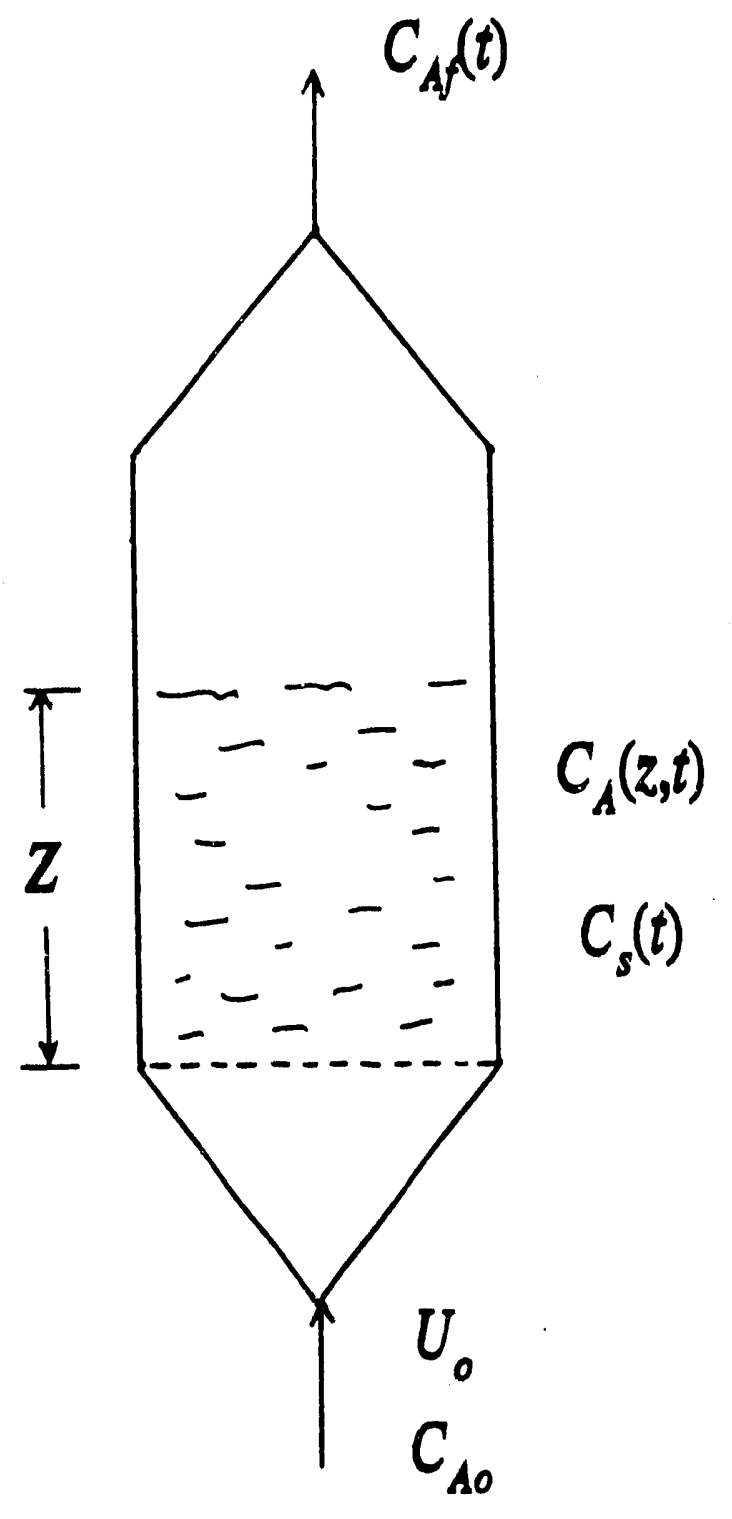

Figure 6-1. Batch fluidized-bed reactor. 


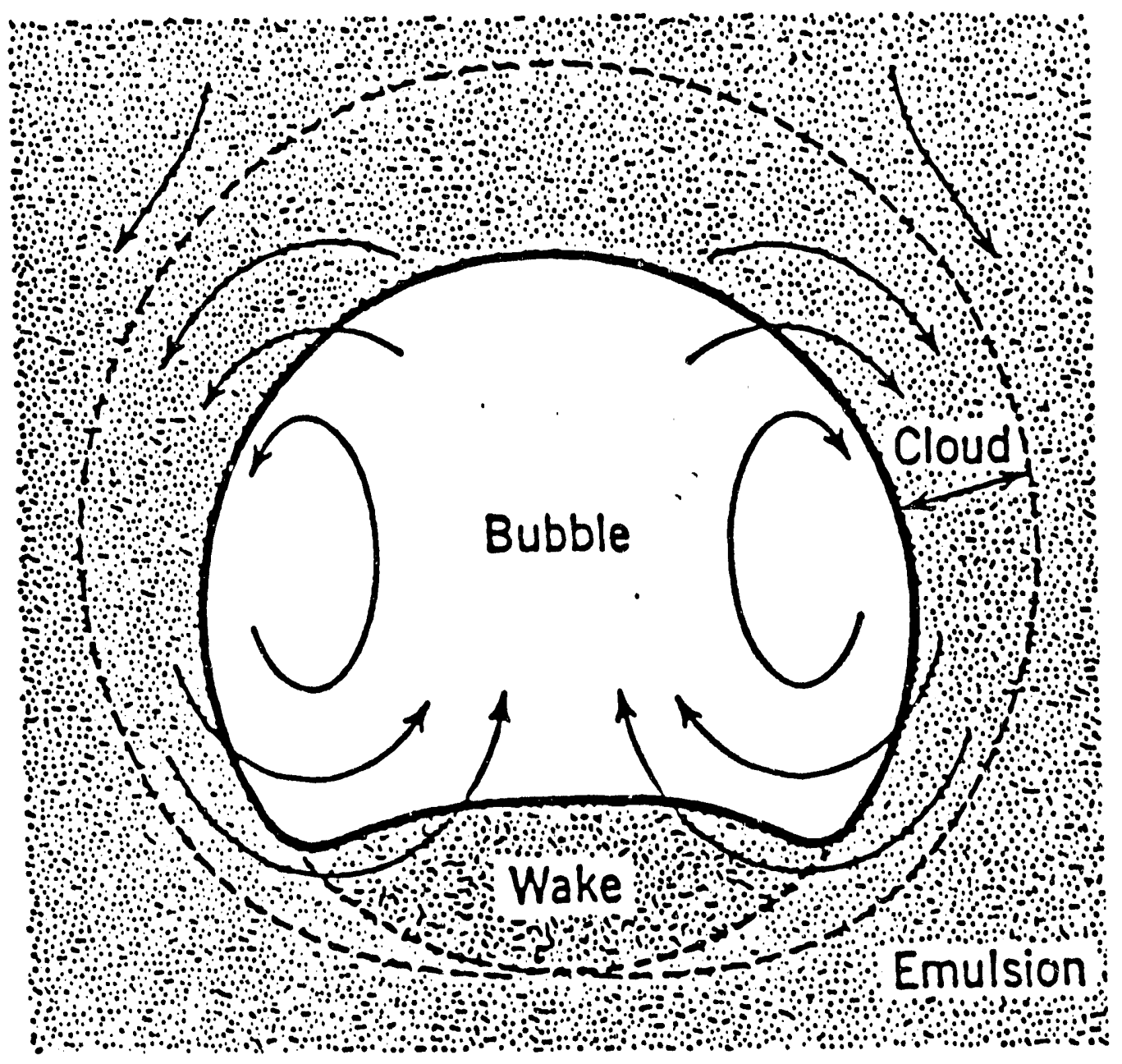

Figure 6-2. Three phase bubble model. 


\subsubsection{Homogeneous Reaction Model}

- First it is assumed that because of the small particle size of the sorbent, each particle reacts homogeneously. Since particles are porous, nothing prevents the gas from entering into sorbent pores rather than reacting only at the surface as is assumed in the shrinking core model. Then it is assumed further that the intrinsic rate per unit sorbent mass is first order in the concentration of reacting solid and gas. Thus, at any instant of time, rate can be described as

$$
r_{a m}=k C_{s}(t) C_{A}(z)
$$

where $\mathrm{C}_{3}(t)$ represents the instantaneous solid reactant concentration and $\mathrm{C}_{A}(\mathrm{z})$ represents $\mathrm{H}_{2} \mathrm{~S}$ concentration which is dependent on axial position only. Therefore at any instant, the reaction rate is pseudo first order in the gas concentration. Since reaction and phase interchange are all first order, the overall process becomes first order.

The component A material balances for the bubble, cloud, and emulsion phases, respectively, are

$$
\begin{gathered}
U_{b} \frac{d C_{A b}}{d z}+k_{b c}\left(C_{A b}-C_{A c}\right)+k C_{s}(t) C_{A b} \rho_{b}=0 \\
k_{b c}\left(C_{A b}-C_{A c}\right)=k C_{s}(t) C_{A c} \rho_{c} \frac{V_{i z}}{V_{b}}+k_{c e}\left(C_{A c}-C_{A e}\right) \\
k_{c e}\left(C_{A c}-C_{A e}\right)=k C_{s}(t) C_{A c} \rho_{e} \frac{1-f}{f} .
\end{gathered}
$$

The nomenclature for the various symbols is provided at the end of this chapter. Subscripts $b$, $c$ and $e$ in the above equations refer to bubble, cloud, and emulsion phases, respectively.

Since all the terms are first order, the individual phase equations may be combined to yield the following expression for the change in the gas concentration with respect to expanded bed height

$$
-U_{b} \frac{d C_{A b}}{d z}=K_{r}(t) C_{A b}
$$

$K_{r}(t)$ is an overall apparent rate constant which varies with time because it contains $C_{s}(t)$. 


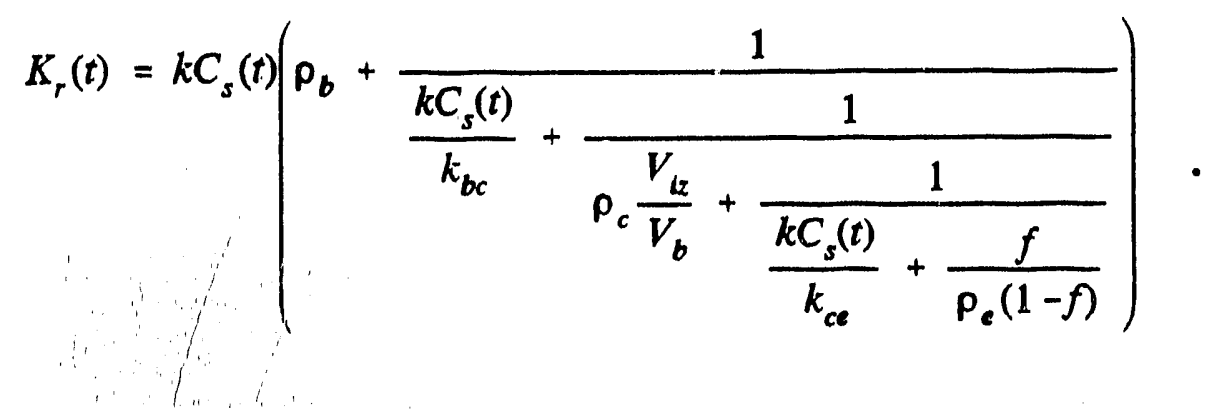

Equation (6.5) can be integrated directly to give an instantaneous gas concentration at the reactor exit

$$
\frac{C_{A f}}{C_{A O}}=\exp \left(-K_{r}(t) Z / U_{b}\right)
$$

The variation in solid concentration with time, and therefore the variation in $\mathrm{K}_{\mathrm{T}}$ with time, can be obtained by an unsteady-state material balance over the entire reactor

$$
\frac{d C_{s}}{d t}=\frac{-b U_{o}\left(C_{A o}-C_{A f}(t)\right)}{Z(1-f)\left(1-\epsilon_{m f}\right)} .
$$

Once numerical values are assigned to all the parameters, reactor performance can be determined.

\section{Parameter Evaluation}

The solution to the model equations requires that a number of parameters be evaluated. Available literature correlations were used as described below.

The correlations of Wen and Yu (1966) were used to estimate the bed voidage and the velocity at minimum fluidization.

$$
\begin{gathered}
\epsilon_{m f}=\left(14 \phi_{s}\right)^{-1 / 3} \\
U_{m f}=\frac{\mu}{d_{p} \rho_{g}}\left[\left((33.7)^{2}+0.0408 \frac{d p^{3} \rho_{g}\left(\rho_{s}-\rho_{g}\right) g}{\mu^{2}}\right)^{1 / 2}-33.7\right] .
\end{gathered}
$$

The average bubble velocity was determined using the $c$ rrelation of Davidson and Harrison (1963) as shown by Equation (6.11).

$$
U_{b}=\left(U_{o}-U_{m f}\right)+0.711 \sqrt{8 d_{b}} .
$$

The volume fractions of the bubble and cloud phases were predicted using correlations of Kunii and Levenspiel (1969) and Partridge and Rowe (1966) shown by Equations (6.12) and (6.13), respectively. 


$$
\begin{gathered}
f=\frac{U_{o}-U_{m f}}{U_{b}} \\
\frac{V_{i z}}{V_{b}}=\frac{1.17}{\frac{U_{b} \sigma_{m f}}{U_{m f}}-1} .
\end{gathered}
$$

The equations for the interphase transfer coefficients were taken from Kunii and Levenspiel (1969).

Mass transfer coefficient for bubble to cloud based on bubble volume can be given as

$$
k_{b c}=4.5\left(\frac{U_{m f}}{d_{b}}\right)+5.85\left(D_{A}^{1 / 2} g^{5 / 4} d_{b}^{5 / 4}\right)
$$

Mass transfer coefficient for cloud to bubble again based on bubble volume can be given as

$$
k_{c e}=6.79\left[\frac{\epsilon_{n f f} D U_{b}}{d_{b}^{3}}\right]^{1 / 2}
$$

\section{Comparison of Model Predictions and Experiment}

A FORTRAN program, FLUBATCH, was written to compute the breakthrough curves using the above model. A total of 18 parameters need to be supplied in order to execute the program. Numerical values to these parameters were assigned whenever possible based upon the reactor experimental data for Run No. 2-T24565MC, Cycle 1.

The parameters of intrinsic rate constant, average bubble diameter, and, to some extent, initial solids concentration were treated as adjustable parameters in an effort to match the experimental $\mathrm{H}_{2} \mathrm{~S}$ breakthrough results.

Three cases with various combinations of intrinsic rate constant and bubble diameter were considered as shown in Table 6-1.

In general, the modeling effort was unsuccessful, as can be seen in Figure 6-3. In this figure, experimental data are shown by the discrete points while model predictions for all three cases are represented by the solid lines. Each of the test cases illustrated here represents a solid density of $3.21 \mathrm{~g} / \mathrm{cm}^{3}$, which corresponds to a particle porosity of 0.4 . The predicted effect of bubble diameter is shown by comparing curves 1 and 2 , while the effect of intrinsic rate constant is shown by curves 2 and 3 . The relatively small change in expanded bed height is caused by the variation in bubble diameter and the requirement to match the total sorbent inventory of 357 g. 


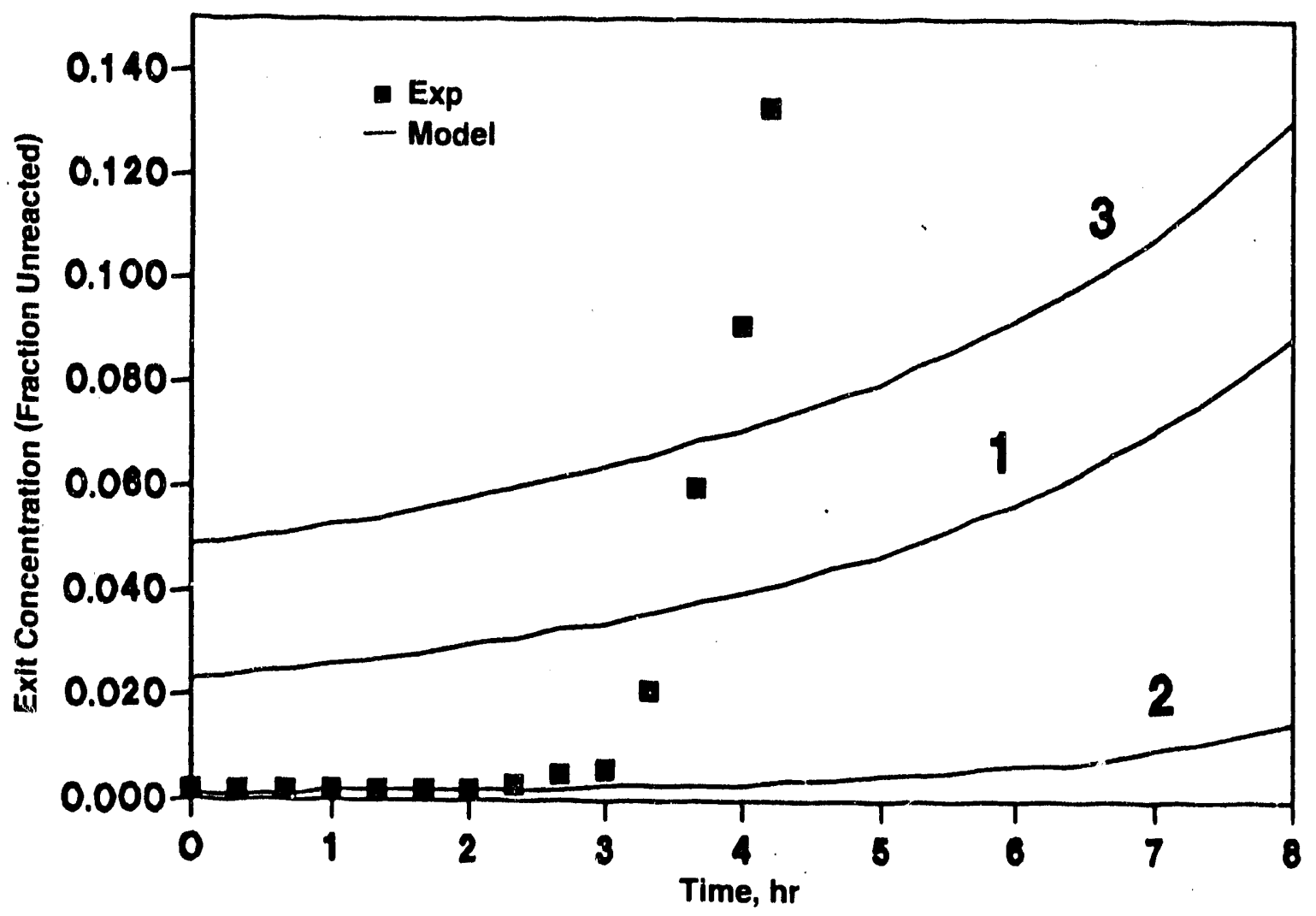

Figure 6-3. Comparison of model and experiment. 


\begin{tabular}{|c|c|c|c|}
\hline \multirow{2}{*}{ Parameter } & \multicolumn{3}{|c|}{ Case } \\
\hline & 1 & 2 & 3 \\
\hline $\begin{array}{c}\rho_{\mathrm{s}}-\text { solid density } \\
\mathrm{g} / \mathrm{cm}^{3}\end{array}$ & 3.21 & 3.21 & 3.21 \\
\hline $\begin{array}{l}\mathrm{k} \text { - rate constant, } \\
\mathrm{cm}^{6} / \mathrm{mol} \mathrm{hr} \mathrm{g}\end{array}$ & $1 \times 10^{7}$ & $1 \times 10^{7}$ & $1 \times 10^{6}$ \\
\hline $\begin{array}{c}d_{b}-\text { bubble diameter, } \\
\mathrm{cm}\end{array}$ & 0.9 & 0.6 & 0.6 \\
\hline $\begin{array}{l}\mathrm{z} \text { - expanded bed } \\
\text { height, } \mathrm{cm}\end{array}$ & 11.3 & 11.8 & 11.8 \\
\hline
\end{tabular}

While curve 2 provides a close match with experimental data during the first $2 \mathrm{hr}$, none of the curves possess the sharp breakthrough shown in the experiment beginning at $3 \mathrm{hr}$.

This general shape of the predicted breakthrough curve was comparable for all parameter combinations tested. Several combinations could be chosen that would match the low prebreakthrough results, but unfortunately all produced a much more gradual breakthrough curve.

\section{Possible Sources of Model Error}

Pressure is probably the most significant difference between the experiment (where the model is unsatisfactory) and the previous results of Schrodt (1981) (where the model provided satisfactory agreement with experiment). The effect of pressure on fluidized-bed operation is not well understood, and it is possible that certain correlations (or even the basic Kunii-Levenspiel model) are not applicable at elevated pressures.

Another possible source of error could be due to the assumption that individual particles react homogeneously. A sharper breakthrough would result if the individual particle reaction rate decreased more rapidly than predicted by the homogeneous reaction model. The unreacted core model does predict a more rapid decrease in reaction rate.

\subsubsection{Unreacted Core Model}

Because the homogeneous reaction model could not predict the experimental data, the unreacted core model for individual particles was used to model the semi-batch fluidized-bed reactor.

The modeling equations used in this analysis were essentially the same as those used in the homogeneous reaction model except for Equations (6.2) to (6.4). For the unreacted core model

$$
r_{A i}^{s}=k C_{S O} C_{A i}^{c}
$$


$\mathrm{C}_{\mathrm{Ai}}{ }^{\mathrm{C}}$ may be obtained from the well-known unreacted core model solution for a single spherical pellet.

$$
C_{A i}^{c}=\frac{C_{A i}}{1+\frac{k C_{S O}(1-x)^{2 / 3}}{k_{B}}+\frac{k C_{S O} R(1-x)^{1 / 3}\left[1-(1-x)^{1 / 3}\right]}{D_{A A}}}
$$

The units of $\mathrm{r}_{\mathrm{Ai}}^{\mathrm{s}}$ are moles of $\mathrm{A}$ per unit time per unit reaction area (core area) of a single particle. This may be converted into the proper form for use in the phase material balance equations, Equations (6.2) to (6.4) as follows:

$$
\begin{gathered}
k C_{s} C_{A b} \rho_{b}=r_{A b}^{s}=\left[\left(\frac{3}{\rho_{p} R}\right)(1-X)^{2 / 3}\right] \rho_{b} \\
k C_{s} C_{A c} \rho_{c} \frac{V i z}{V_{b}}=r_{A c}=r_{A b}^{s}\left[\left(\frac{3}{\rho_{p} R}\right)(1-X)^{2 / 3}\right] \rho_{c}\left(\frac{V_{i z}}{V_{b}}\right) \\
k C_{s} C_{A e} \rho_{e} \frac{1-f}{f}=r_{A e}=r_{A e}^{s}\left[\left(\frac{3}{\rho_{p} R}\right)(1-X)^{2 / 3}\right] \rho_{e}\left(\frac{1-f}{f}\right) .
\end{gathered}
$$

The common term in the brackets in Equations (6.18), (6.19), and (6.20) represents the ratio of the single particle core area to the single particle mass, and the final term converts the particle mass within the individual phases to unit bubble volume. Finally, substitution of Equations (6.16) and (6.17) into Equations (6.18), (6.19), and (6.20) produces the proper rate equations for use in Equations (6.2), (6.3), and (6.4). Furthermore, the solids concentration, $C_{s}(t)$ can be related to total conversion $X(t)$ via

$$
\begin{aligned}
& r_{A B}=\frac{k C_{S o}\left[\left(\frac{3}{\rho_{p} R}\right)(1-X)^{2 / 3}\right] \rho_{b} C_{A b}}{\frac{1+k C_{S o}(1-X)^{2 / 3}}{k g}+\frac{k C_{S O} R(1-X)^{1 / 3}}{D_{C A}}\left[1-(1-X)^{1 / 3}\right]} \\
& r_{A C}=\frac{k C_{S O}\left[\left(\frac{3}{\rho_{p} R}\right)(1-X)^{2 / 3}\right] \rho_{c}\left(\frac{V_{i z}}{V_{o}}\right) C_{A c}}{1+k C_{S O} \frac{(1-x)^{2 / 3}}{k g}+k C_{S O} R \frac{(1-X)^{1 / 3}}{D_{o A}}\left[1-(1-X)^{1 / 3}\right]}
\end{aligned}
$$




$$
\begin{gathered}
r_{A e}=\frac{k C_{S O}\left[\left(\frac{3}{\rho_{p} R}\right)(1-X)^{2 / 3}\right] \rho_{e}\left(\frac{1-f}{f}\right) C_{A e}}{1+\frac{k C_{S o}(1-X)^{2 / 3}}{k g}+\frac{k C_{S o} R(1-X)^{1 / 3}}{D_{e A}}\left[1-(1-X)^{1 / 3}\right]} . \\
C_{s}(t)=C_{s o}(1-X)
\end{gathered}
$$

Although Equations (6.21), (6.22), and (6.23) for the unreacted core model are considerably more complex than the analogous Equations (6.2), (6.3), and (6.4) for the homogeneous model, they are of identical form. Each pair of equations is directly proportional to the concentration of $A$ within the particular phase. Each pair contains the term $\rho_{\mathrm{h}}, \rho_{\mathrm{c}} \mathrm{V}_{\mathrm{iz}}, \mathrm{V}_{\mathrm{b}}$, or $p_{e}(1-f) / f$, as appropriate. Therefore, equations $(6.22)$ to (6.24) may all be written as:

$$
r_{A i}=k_{i} f(X) C_{A i} .
$$

The substitution of (6.22), (6.23), and (6.24) into (6.2), (6.3), and (6.4) with elimination of $\mathrm{C}_{\mathrm{Al}}$ and $\mathrm{C}_{\mathrm{Ac}}$ would lead to equations analogous to (6.6) and (6.7). The only difference is that the term $k C_{s}(t)$ in Equation (6.6) would be replaced by

$$
\frac{k C_{S o}\left[\left(\frac{3}{\rho_{p} R}\right)(1-X)^{2 / 3}\right]}{1+\frac{k C_{S o}(1-X)^{2 / 3}}{k_{g}}+\frac{k C_{S o} R(1-X)^{1 / 3}}{D_{e A}}\left[1-(1-X)^{1 / 3}\right]} .
$$

This means that Cockrill's model can still be used directly by making the above substitution, and by making a small number of additions and modifications to the input/output section of the original "FLUBATCH" program.

\section{Comparison of Model Predictions and Experiment}

Similar to the previous model, bubble diameter and effective diffusivity were used as adjustable parameters. Expanded bed height, $Z$, also was adjusted in order to maintain the proper solids inventory in the reactor.

Figure 6-4 shows a comparison of experimental data with the model predictions. At first glance, the results look reasonably good, certainly better than the comparable results obtained by assuming that individual particles react homogeneously.

Very small values of $D_{e A}$ were required if the sieep breakthrough portion of the curve (from 3 to $4 \mathrm{hr}$ ) was to be even approximately matched. In turn, this required very small values of $d_{1}$ in order to approximate the early results $(0$ to $2 \mathrm{hr}$ ). 


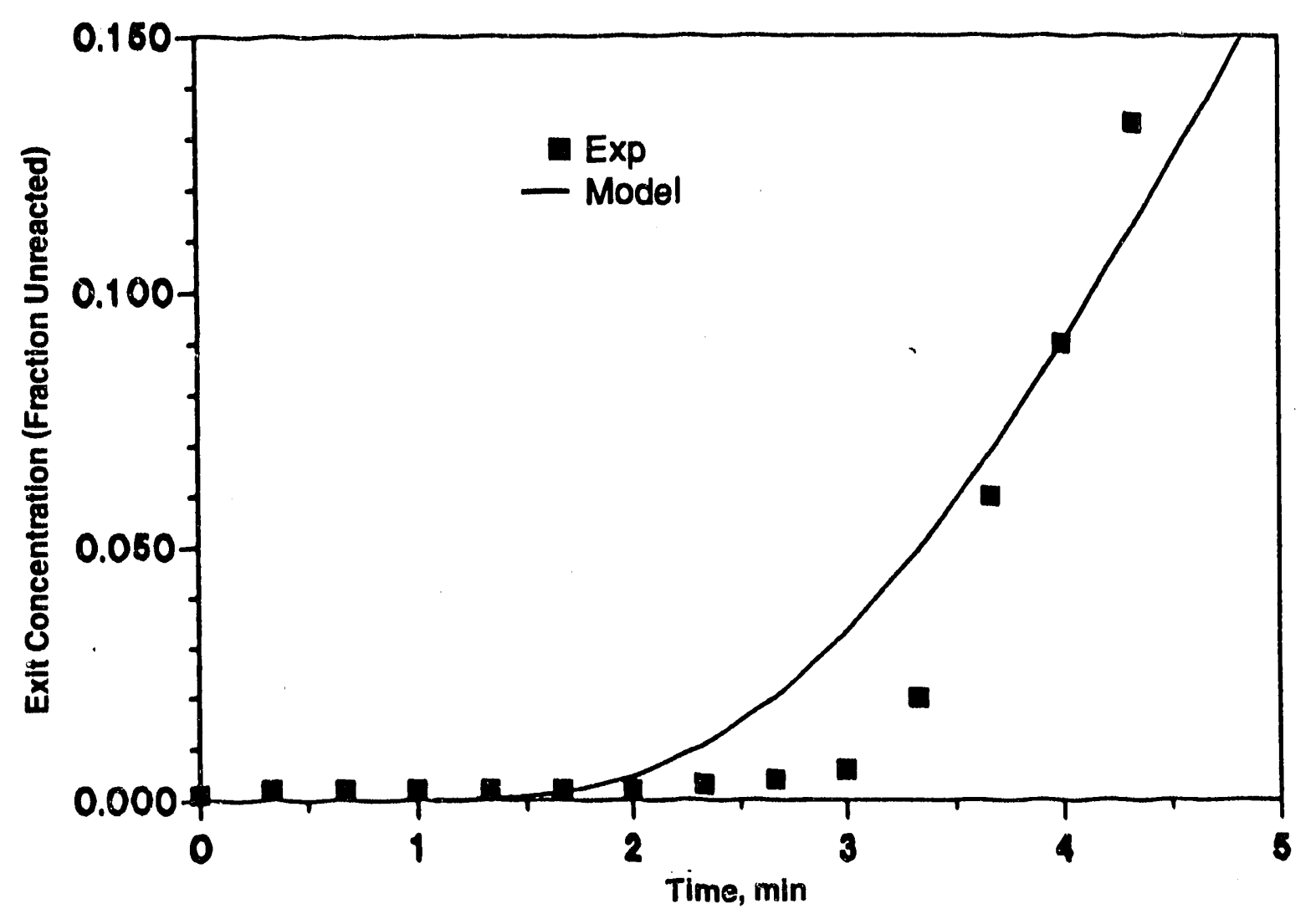

Figure 6-4. Comparison of experimental data with predictions of unreacted core model. 
The final values of bubble diameter and effective diffusivity used were:

$$
\begin{aligned}
\mathrm{d}_{\mathrm{b}} & =0.1 \mathrm{~cm} \\
D_{e A}=0.02 \mathrm{~cm}^{2} / \mathrm{hr} & =5.5 \times 10^{-6} \mathrm{~cm}^{2} / \mathrm{sec} .
\end{aligned}
$$

Both of the above values are smaller than the 'expected' values approximately by one order of magnitude in the case of $d_{h}$ and at least several orders of magnitude in the case of $D_{e A}$. Even so, the fit is not really as exact as it first appears in the figure. The slope of the breakthrough portion is not as steep as measured and the predicted exit concentrations for the first hour are truly zero compared to experimentally measured values in the range of 0.01 to 0.02 ( for $\mathrm{C}_{\mathrm{AP}} / \mathrm{C}_{\mathrm{Ao}}$ ).

Based on above analyses, it appears that the basic Kunii-Levenspiel model does not adequately fit the experimental data with either homogeneous or shrinking core kinetics.

\subsection{DETERMINATION OF RATE CONTROLLING STEP}

The key to developing a successful model capable of predicting experimentally observed breakthrough behavior is the identification of the rate controlling step in the reactor. Based on available literature on gas-solid reactions, the following three possibilities can exist:

1. External mass transfer: diffusion of reactant to sorbent surface;

2. Intrinsic rate of reaction: reaction of $\mathrm{H}_{2} \mathrm{~S}$ with sorbent particle; and

3. Internal mass transfer: diffusion of reactant into the sorbent particle.

At any time, (1), (2), or (3) or any combination may control the global sulfidation kinetics. Furthermore, it is also possible that during the course of reaction, relative contributions of these three resistances vary with time, which makes this problem extremely complex.

An attempt was made to use simple criteria available in the literature to identify the relative magnitude of these resistances. For the first order reaction, the Carberry criteria can be used to determine whether film diffusion is the prevailing rate-controlling mechanism. The criterion states that if

$$
\frac{k}{k_{g} A}<0.1
$$

then film diffusion is fast and does not control the global kinetics.

Similarly for pore diffusion, the Weisz and Prater criterion can be used; the criterion states that for a first order reaction if 


$$
\frac{R^{2} k}{D_{a A}}<1
$$

pore diffusion is fast and does not control the rate of reaction. Here $R$ is particle radius and $D_{\text {eA }}$ is the effective diffusivity inside the particle.

\section{Parameter Estinuation}

\section{Estimation of $\mathbf{k}$}

Using the low temperature TGA data (measured at 260,288 , and $315^{\circ} \mathrm{C}$ ), activation energy for the sulfidation reaction is estimated to be approximately $14 \mathrm{kcal} / \mathrm{mol}$ (Woods et al., 1989).

The values for $\mathrm{k}$, the intrinsic reaction rate constant, were estimated to be 0.33 and 34.8 $\mathrm{cm}^{3}$ gas per $\mathrm{g}$ of sorbent per sec at 260 and $550{ }^{\circ} \mathrm{C}$, respectively. The value of effective diffusivity, $D_{e A}$, is typically 0.01 to $0.001 \mathrm{~cm}^{3}$ of gas per cm of particle per sec at $550{ }^{\circ} \mathrm{C}$ and 20 atm, which yields a value of $R^{2} / D_{e A}$ of 0.24 to 2.4 . This is a borderline case and hence pore diffusion may influence the global reaction rate.

Similarly, $k / k_{g} A$ also can be estimated. The typical value of $k_{g}$ estimated from correlations is approximately $40 \mathrm{~cm}^{3}$ of gas per $\mathrm{cm}^{2}$ of external surface area per sec and $\mathrm{A}=200$ $\mathrm{cm}^{2} / \mathrm{cm}^{3}$ for a $150 \mu \mathrm{m}$ radius particle, giving $\mathrm{k} / \mathrm{k}_{\mathrm{g}} \mathrm{A}=0.001$. This indicates that film diffusion is probably too fast to influence the overall reaction rate.

Hence, based on the above simplified analysis, it can be tentatively concluded that sulfidation kinetics is controlled by intrinsic reaction and internal pore diffusion resistances.

\subsection{ALTERNATIVE MODELS}

The preliminary model calculations shown in Section 6.2.1 indicate that breakthrough time is significantly overpredicted by the homogeneous rate assumption. The unreacted core model, on the other hand, predicted the experimental data reasonably well, but the bubble diameter and diffusivity values required to fit the data were unrealistically low.

Levenspicl (1989) has described a number of advanced models to stucly gas-solid reactions. These models include the shrinking unreacted core model, the changing voidage model, and the grainy pellet model. For the shrinking, unreacted core model, the controlling mechanism is expected to follow kinetic control initially and then shift to ash layer diffusion control as the reaction progresses with time. The grainy pellet model is an extension of the shrinking unreacted core model. It assumes that each particle is composed of small spherical grains of solid and that all of the grains are the same size. If no size change occurs with reaction, the voidage in the particie does not change. Each grain reacts according to the shrinking unreacted core model either with ash diffusion or reaction control or a combination of the two. The movement of gaseous reactant between the grains into the pellet is subject to f: ther diffusional resistance. 
If the molar volume of the sorbent changes as the solid reactant converts to product, the grainy pellet model needs to be extended to the changing voidage model. In our sulfidation reaction, the voidage between the grains decrieases and the diffusional resistance increases. This phenomenon is similar to the pore closing mechanism studied by Ramachandran and Smith (1976). Further refinement in the model is possible by considering the size distribution of particles. For particles in the 100 to $300 \mu \mathrm{m}$ range, the larger particles may be better described by one of the more complicated models, whereas the smaller particles may be best described by the homogeneous reaction model.

In addition to determining the rate expression for the sulfidation reaction, other fluidization models should be investigated since the Kunii and Levenspiel (K-L) model is not adequate. It is not anticipated that operation of the reactor at high pressure will significantly alter the fluidization behavior. However, the various correlations embodied in the K-L model may not be applicable at high pressures such as in this case. Therefore, it may be desirable to use a model that does not have any adjustable parameters, such as bubble size in the K-L model.

\subsection{NOMENCLATURE}

A - external surface to volume ratio of sorbent particle

b . stoichiometric coefficient, dimensioniess

$\mathrm{C}_{\mathrm{A}} \quad-\quad$ molar concentration of reacting gas

$C_{s} \quad-\quad$ molar concentration of reacting solid

$\mathrm{C}_{\mathrm{SO}} \quad$ - initial molar concentration of solid reactant

D - - reactor diameter

$D_{A} \quad-\quad$ diffusivity

$D_{e A} \quad-\quad$ effective diffusivity

d, - - butuble diameter

$d_{n} \quad$ - particle diameter

i - volume fraction of bubble in bed

g - gravitational constant

$\mathrm{K}_{\mathrm{T}} \quad$ - overall apparent rate constant defined by Equation (6.6)

k - instinsic reaction rate constant

$k_{t x} \quad$ - mass transfer coefficient from bubble to cloud

$k_{\text {ie }} \quad$ - mass transfer coefficient from c'oud to emulsion

$\mathrm{k}_{\mathrm{g}} \quad$ - mass transfer coefficient between bulk gas and individual particles

$P \quad$ - pressure

$\mathrm{R} \quad$ - radius of particle

$r_{\text {AnI }} \quad-\quad$ intrinsic reaction rate per unit particle mass

T - temperature

t - time 
$\mathrm{U} \quad$ - gas velocity, $\mathrm{cm} / \mathrm{hr}$

$\mathrm{U}_{\mathrm{u}} \quad$ - superficial gas velocity

$\mathrm{U}_{\mathrm{mf}} \cdot \quad$ gas velocity at minimum fluidization

$V_{i z} V_{h} \quad-\quad$ volume fraction of cloud

$\mathrm{X}$ - fractional sulfidation of solid

$\mathrm{Y}_{\mathrm{A} \text { I }} \quad$ - mole fraction of reacting gas in feed

$\mathrm{Z}$ - expanded bed height, $\mathrm{cm}$

z - axial coordinate

Greek Symbols

$\varepsilon \quad$ - particle porosity

$\varepsilon_{\mathrm{mf}} \quad$ - bed porosity at minimum fluidization

$p$ - density

$\phi_{\mathrm{s}} \quad$ - particle shape factor

$\mu \quad$ - gas viscosity

Subscripts

b - bubble phase

c - cloud phase

e - emulsion phase

i - artitrary phase

p - particle

g - gas

Superscripts

S

surface 


\subsection{CONCLUSIONS AND RECOMMENDATIONS}

Desulfurization of hot coal-derived gas using zinc-ferrite sorbent was studied in a benchscale high-pressure fluidized-bed reactor to develop durable sorbents in the 100 to $300 \mu \mathrm{m}$ range. This was the first study of its kind in a fluid-bed reactor, previous investigations having been conducted in fixed- and moving-bed reactors.

The following major conclusions can be drawn based on this study:

- A number of techniques including spray drying, impregnation, crushing/screening of pellets, and granulation were investigated to prepare mechanically durable sorbents. The spray drying technique proved to be unsuccessful for manufacturing fluidizable sorbent particles.

- Sorbent formulations prepared by impregnating up to 20 weight percent zinc ferrite on alumina had very low sulfur capacity and appeared to be commercially unattractive.

- A fluidizable sorbent prepared by crushing durable sorbent pellets (prepared by UCI for GE's moving-bed reactor) and screening had acceptable levels of chemical reactivity, but on multicycle testing it underwent excessive sorbent loss due to attrition/carryover amounting to approximately 40 percent of the reactor inventory.

- The most significant accomplishment of this program was the identification of a granulation technique to manufacture chemically reactive and attrition-resistant sorbent formulations. A number of sorbent formulations prepared using this technique showed good attrition resistance and acceptable sulfur capacity during multicycle testing. Highe: reactivities may be needed at $550{ }^{\circ} \mathrm{C}$ for successful operation.

- Commercial applicability of the granulation technique was demonstrated. Approximately $80 \mathrm{~kg}$ of the best sorbent were prepared and delivered to METC.

- There is evidence that attrition of the sorbent in the reactor is primarily due to chemical transformations rather than mechanical forces. The possible chemicai transformations responsible for "chemical" attrition were excessive reduction of zinc ferrite, specifically reduction of $\mathrm{Fe}_{2} \mathrm{O}_{3}$ into $\mathrm{FeO}$ or even to $\mathrm{Fe}$ and zinc oxide followed by some evaporation of metallic zinc.

- The applicability of zinc ferrite as a hot gas desulfurization sorbent was found to be limited to about $550^{\circ} \mathrm{C}$. Excessive sorbent weakening was observed due to chemical attrition at $625^{\circ} \mathrm{C}$. The sorbent reactivity at $625^{\circ} \mathrm{C}$ was, however, significantly higher. 
- It was demonstrated that sulfided sorbent can be completely regenerated using a mixture of 2 to 3 percent $\mathrm{O}_{2}$ in $\mathrm{N}_{2}$. Sulfate formation during regeneration can be pre nted by operating the reactor at about $760^{\circ} \mathrm{C}$ at $1-5 \mathrm{MPa}$. More research is needed to determine the effect of higher pressures or higher oxygen concentrations in the regeneration gas on sulfate formation.

- The sulfidation reaction was found to be controlled by intrinsic reaction and pore diffusion steps. The external mass transfer resistance was found to be negligible. Both homogeneous reaction and unreacted shrinking core kinetics in conjunction with the Kunii-Levenspiel bubbling-bed model over-predicted the breakthrough time.

The following major recommendations are made based on the results of this study:

- Since zinc ferrite is limited to $550^{\circ} \mathrm{C}$, methods should be investigated to prepare more reactive zinc ferrite for use up to $650^{\circ} \mathrm{C}$.

- The possible use of other sorbents, especially zinc titanate, should be investigated for higher desulfurization temperatures and/or with highly reducing gases such as Texaco oxygen-blown gasifier gas. This will be studied under an option to this contract.

- In addition to bentonite, use of other clays such as forsterite, vermiculite, kaolinite, etc., as potential binders should be investigated.

- After having developed a durable sorbent, to aid in design and optimization of a scaled-up version of the bench-scale unit, advanced mathematical models should be developed to predict the system behavior. Developing such models will require some fundamental studies on fluidization and kinetics of sulfidation and regeneration of that specific sorbent.

- The effect of other contaminants on the performance of zinc ferrite present in coal gas such as alkali, $\mathrm{HCl}$ and $\mathrm{NH}_{3}$ should be studied.

- A continuous sulfider-regenerator system with sorbent circulation between them should be designed, built, and tested. Such a system would serve as a bench-scale prototype of a commercial fluidized-bed hot gas desulfurization system. 


\subsection{REFERENCES}

Anderson, R.R., and K.C. Pratt. 1985. Introduction to Characterization and Testing of Catalysts. Academic Press, Orlando, pp. 190-196.

ASTM D-4058. 1981. Attrition and Abrasion of Catalysts and Catalyst Carriers. American Society for Testing Materials.

Ayala, R.E., E. Gal, S.K. Gangwal, and S.C. Jain. 1990. "Enhanced Durability of HighTemperature Desulphurization Sorbents for Moving-Bed Applications." Proc. Division of Fuel Chemistry, 199th American Chemical Society Meetinf, pp. 120-127.

Bemrose, C.R., and J. Bridgwater. 1987. "A Review of Attrition and Attrition Test Methods." Powder Technology, 49:97-126.

Bruenaner, S., P. Emmett, and E. Teller. 1938. J. American Chem. Society. 60:309.

Cockrill, D.E. 1988. "Modeling Fluidized-Bed and Moving-Bed Coal Gas Desulfurization Reactors," M.S. Thesis, Department of Chemical Engineering, Louisiana State University.

Cockrill, D.E., F.R. Groves, and D.P. Harrison. 1988. "Modeling of a High-Temperature Fluidized-Bed Desulfurization Reactor." Presented at 1988 AIChE Spring National Meeting, Paper 9b, New Orleans, LA, March 6-10.

Cook, C.S., B. Parekh, E. Gal, and A.H. Furman. 1989. "Integrated Operation of a Pressurized Fixed-Bed Gasifier and Hot Gas Desulfurization Systems." In Proceedings of the Ninth Annual Gasification and Gas Stream Cleanup Systems Contractors Review Meeting, DOE/METC-89/6107, Vol. I, NTIS/DE89011706, June, pp. 37-46.

Curran, G.P., et al. 1973. "Production of Clean Fuel Gas from Bituminous Coals." EPA650/2-73-049, PB232-695/AS.

Davidson, J., and D. Harrison. 1963. "Fluidized Particles." Cambridge University Press, Cambridge.

Energy Statistics. 1988. Institute of Gas Technology publication, Vol. 11, No. 4.

Forsythe, W.L., and WR. Hertwig. 1949. "Attrition Characteristics of Fluid Cracking Catalysts." Ind. Eng. Chem., 41:1200-1206.

Gal, E.M., S.C. Cook, A.H. Furman, and D.P. Smith. 1987. "Design Studies for Hot Gas Cleanup System in a Load Following Mode." Proc. VIIth Annual Gasification Gas Stream Cleanup Systems Contractors Review Meeting, DOEMETC-87/6079, Vol. 2 (DE87006496), pp. 668-677. 
Gangwal, S.K., et al. 1988. "Bench-Scale Testing of Novel High-Temperature Desulfurization Sorbents." Final Report to DOE/METC, DOEMC/23126-2662.

Grim, R.E. 1980. Clay Mineralogy. McGraw Hill, New York.

Grindley, T, and H. Goldsmith. 1987. "Development of Zinc Ferrite Desulfurization Sorbents for Large Scale Testing." Presented at the AIChE Annual Meeting, Session $114 \mathrm{~d}$, New York, November 15-20.

Grindley, T., and G. Steinfeld. 1981. "Development and Testing of Regenerable Hot CoalGas Desulfurization Sorbents." DOE/MC/16545-1125.

Haldipur, G.B., et al. 1987. "KRW Process Development Coal Gasification/Hot-Gas Cleanup." In Proceedings of the Seventh Annual Gasification and Gas Stream Clearup Systems Contractors Review Meeting, DOE/METC-87/6079, Vol. 2 NTIS/DE87006496, pp. 668-677.

Haldipur, G.B., D.K. Schmidt, and K.J. Smith. 1989. "A 50-Month Gasifier Mechanistic Study and Downstream Unit Process Development Program for the Pressurized AshAgglomerating Fluidised-Bed Gasification System." Final Report, DOE/MC/21063-2740 (2 Volumes), NTIS/DE89011704 and NTIS/DE87006496, pp. 668-677.

Hashimoto, K., et al. 1989. "The Mathematical Simulator for IHI Hot Gas Desulfurization Process." In Proceedings of International Conference on Coal Science, October.

Jalan, V. 1985. "High-Temperature Desulfurization of Coal-Gases." Acid and Sour Gas Treating Processes. Gulf Publishing Co., Houston, pp. 466-491.

Jha, M.C., et al. 1988. "Enhanced Durability and Reactivity for Zinc Ferrite Desulfurization Sorbent." In Proceedings of the Eighth Annual Gasification and Gas Stream Cleanup Systems Contractors Review Meeting, DOE/METC-88/6092, Vol. I, NTIS/DE88010253, pp. 83-92.

Kunii, D., and O. Levenspiel. 1969. Fluidization Engineering. Wiley, New York.

Levenspiel, O. 1989. The Chemical Reactor Omnibook. OSU Book Stores, Corvallis, Oregon.

Partridge, B.A., and P.N. Rowe. 1966. Trans, Inst. Chem. Engrs., 45:335.

Ramachandran, P.A., and J.M. Smith. 1976. "A Single-Pore Model for Gas-Solid Non-catalytic Reactions." AIChE Journal, 23, 353. 
Satterfield, C.N. 1980. Heterogeneous Catalysis in Practice. McGraw-Hill Book Company, New York.

Schrodt, J.T. 1981. "Hot Gas Desulfurization: Use of Gasifier Ash in a Fluidized-Bed Process. DOE/ET/10463, Vol. 2.

Sugitani, T., et al. 1987. "Fundamental Studies and Present Status of IHI Hot Gas Desulfuri zation Process." Intl. Conf. Coal Sci., J.A. Moulgyn, et al. (eds), Elsevier Science Publishers B.V., Amsterdam, pp. 915-919.

Wang, J., et al. 1988. "Dynamic Simulation Models for High-Temperature Desulfurization Processes." Final Report to DOE/METC. DOE/MC/23089-2601.

Wen, C.Y., and Y.H. Yu. 1966. AIChE J, 12:610.

Westmoreland, et al. 1977. Environmental Science \& Technology, 11:488.

Williams, M.C., and R.C. Bedick. 1988. "Gas Stream Cleanup." Technology Status Report, DOE/METC-89/0263.

Woods, M.C., et al. 1989. "Reaction Kinetics and Simulation Models for Novel High Temperature Desulfurization Sorbents." Final Report to DOE/METC, DOE/MC/241602671 .

Wu, J.C., A.M. Robin, and J.S. Kassman. 1989. "Integration and Testing of Hot Gas Desulfurization and Entrained Flow Gasification for Power Generation Systems." In Proceedings of the Ninth Annual Gasification and Gas Stream Cleanup Systems Contractors Review Meeting, Volume 1, DOE/METC-89/6107, Vol. I, (DE89011706), June.

Zenz, F.A., and D.F. Othmer. 1960. "Fluidization and Fluid-Particle Systems." Reinhold Publishing Corporation, New York. 

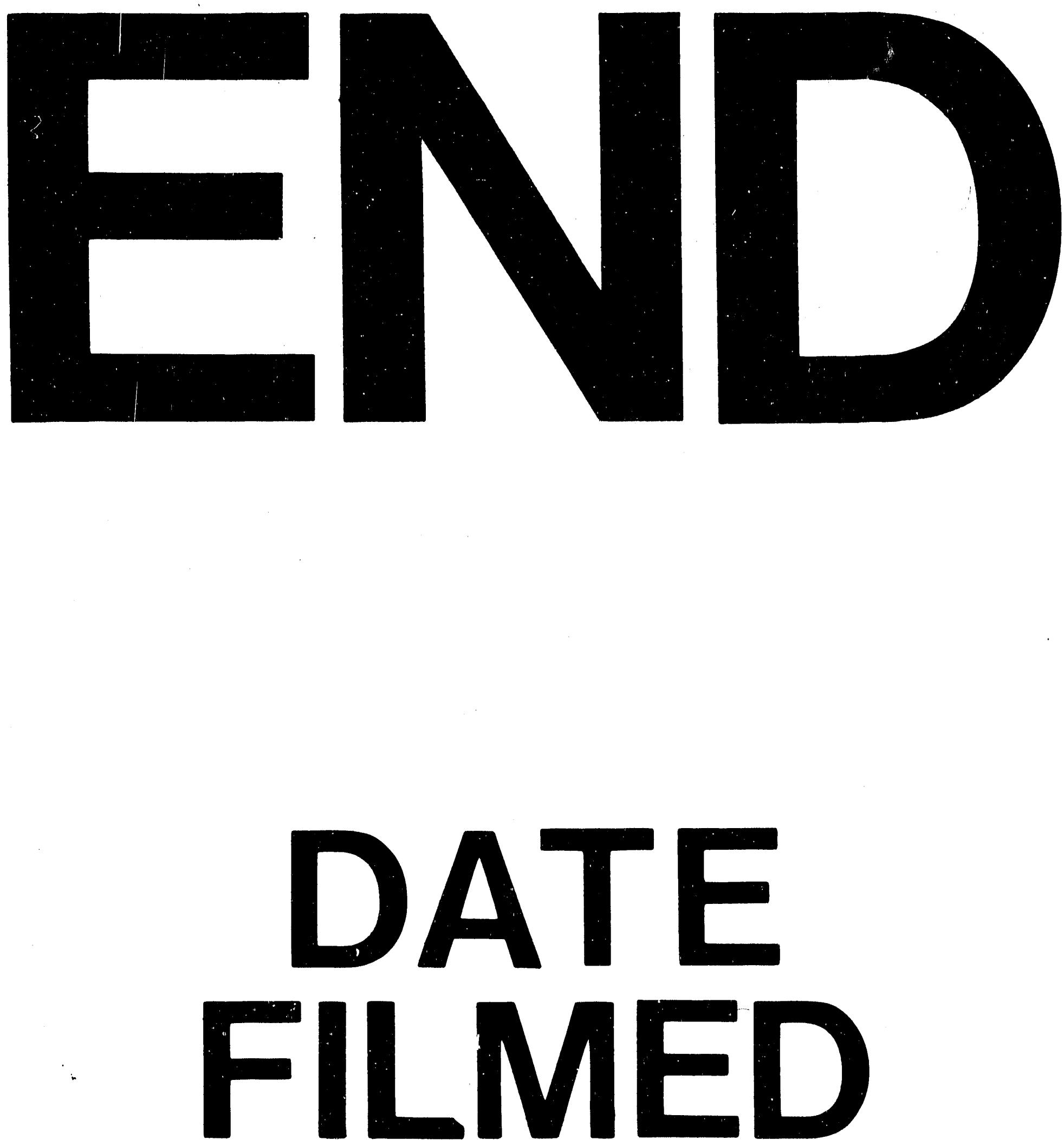

1
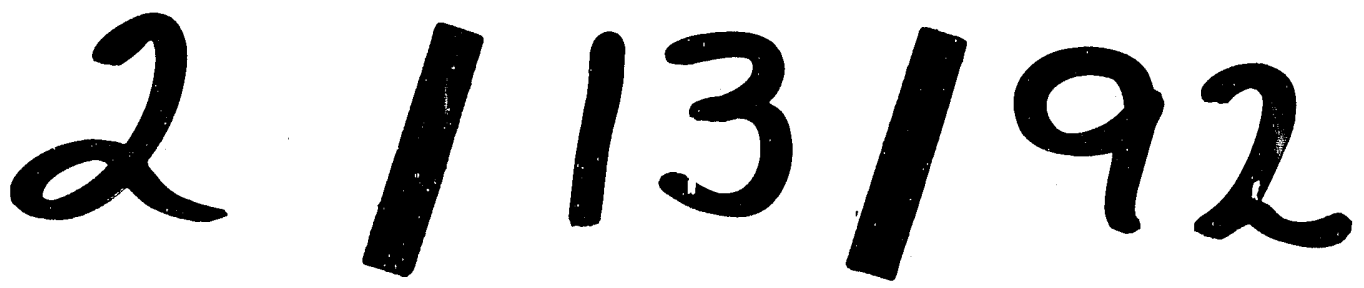
